\title{
THE EFFECT OF SILICON ON FABRICATION AND REPROCESSING OF ALUMINUM ALLOY REACTOR FUELS
}

By

\author{
Bernice E. Paige \\ George W. Gibson \\ Kenneth L. Rohde
}

\section{LEGAL NOTICE}

This report was prepared as an account of Government sponsored work. Neither the United States, nor the Commission, nor any person acting on behalf of the Commisston:

A. Makes any warranty or representation, expressed or implied, with respect to the accuA. Makes any warranty or representation, expressed or implied, sith respect to the accu-
raction racy, completeness, or usefulness of the information contained in this report, or that the use
of any information, apparatus, method, or process disclosed in this report may not infringe privately owned rights; or

B. Assumes any liabilities with respect to the use of, or for damages resulting from the se of any information, apparatus, method, or process disclosed in this report.

As used in the above. "person actung on behalf of the Commission" includes any employee or contractor of the Commission, or employee of such contractor, to the extent that such employee or contractor of the Commission, or employee of such contractor prepares, disseminates, or provides access to, any information pursuant to his employment or contract with the Commission, or his employment with such contractor.

\section{IDAHO NUCLEAR CORPORATION}

\section{A JOINTLY OWNED SUBSIDIARY OF AEROJET AWNED SLLIED \\ GENERAL}

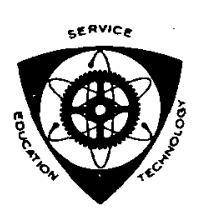

U. S. Atomic Energy Commission Research and Development Report

Issued Under Contract A T(10-1)-1230

Idaho Operations Office 


\section{DISCLAIMER}

This report was prepared as an account of work sponsored by an agency of the United States Government. Neither the United States Government nor any agency Thereof, nor any of their employees, makes any warranty, express or implied, or assumes any legal liability or responsibility for the accuracy, completeness, or usefulness of any information, apparatus, product, or process disclosed, or represents that its use would not infringe privately owned rights. Reference herein to any specific commercial product, process, or service by trade name, trademark, manufacturer, or otherwise does not necessarily constitute or imply its endorsement, recommendation, or favoring by the United States Government or any agency thereof. The views and opinions of authors expressed herein do not necessarily state or reflect those of the United States Government or any agency thereof. 


\section{DISCLAIMER}

Portions of this document may be illegible in electronic image products. Images are produced from the best available original document. 


\section{ACKNOWLEDGEMENTS}

The authors are indebted to the following people for assistance with this project:

A. G. Angilella - Tensile Testing

B. G. Carlson - Metallography

E. S. Dickerson - X-ray Diffraction Analysis

T. L. Evans - Dissolution Studies

M. Hatch - Tensile Testing

R. J. Pollard - Sample Preparation

S. Wildman - Spectrographic Silicon Analysis

W. F. Zelezny - Microprobe Analysis 


\section{ABSTRACT}

Some fabricators of nuclear reactor fuels add substantial quantities of silicon to aluminum-uranium fuel core alloys to stabilize the $\mathrm{UAl}_{3}$ phase and improve the fabrication characteristics of the alloy. The effect of silicon upon both the fabrication and reprocessing of aluminumuranium fuel has been studied. Rolled castings of alloys used in these studies contained 0,22 , and 31 percent uranium, a range of silicon contents from 0 to 11 percent, and the remainder aluminum. Alloys were typical of those found in fuel element plates according to radiographic and metallographic examination.

The silicon present in the alloys in excess of one atom of silicon per atom of uranium was segregated as elemental silicon in the aluminum matrix according to both $\mathrm{X}$-ray diffraction and electron beam microprobe analyses. Maximum softness, as indicated by minimum tensile strength, was obtained in alloys with silicon-to-uranium atom ratios near one, while there was a hardening of the alloy above a ratio of one.

The alloys were dissolved at the boiling point using nitric acid and mercuric nitrate catalyst for reprocessing studies. The dissolution rates and the preferential dissolution of aluminum compared to uranium were related to the metallurgical composition of the alloy which, in turn, is related to the silicon content. Both emulsion stabilization during liquid-liquid extraction of uranium and the quantity and nature of the solids produced during dissolution were related to the metallurgical composition of the alloys and to the atom ratio of silicon to uranium in the alloys. Residues were examined by centrifugation techniques, light scattering, and $\mathrm{X}$-ray spectrographic analysis. 
ACKNOWLEDGEMENTS. . . . . . . . . . . . . . . . . . . i i

ABSTRACT. . . . . . . . . . . . . . . . . . . . . . iii

SUMMARY . . . . . . . . . . . . . . . . . . . . . . vi

I. INTRODUCTION. . . . . . . . . . . . . . . . . . . . . I

II. PREPARATION OF THE ALLOYS . . . . . . . . . . . . . . . . . 3

III. ALLOY COMPOSITION . . . . . . . . . . . . . . . . . 5

1. CHEMICAL ANALYSIS . . . . . . . . . . . . . 5

2. RADIOGRAPHIC AND METALIOGRAPHIC EXAMINATION . . . . . 5

3. X-RAY DIFFRACTION ANALYSIS. . . . . . . . . . 6

4. ELECTRON-BEAM MICROPROBE ANALYSIS . • . . . • . . . . 7

IV. RESULTS AND DISCUSSION OF SILICON IN FUEL FABRICATION . . . . 9

l. RESULTS OF MECHANICAL TESTING . . . . . . . . . . . . . . 9

2. EFFECT OF SILICON-TO-URANIUM ATOM RATIO . . . . . . . . . 9

3. HIGH TEMPERATURE PROPERTIES . . . . . . . . . . . . 13

V. RESULTS AND DISCUSSIONS OF SILICON IN FUEL REPROCESSING . . . 14

1. DISSOLUTION STUDIES . . . . . . . . . . . . 14

1.I Relationship Between Dissolution Rates and

Metallurgy . . . . . . . . . . . . . 15

1.2 Difference in Dissolution of Aluminum and Uranium. . 16

1.3 Effect of Acidity. . . . . . . . . . . . . 16

1.4 Uranium Concentration in Solution. . . . . . . . . 17

1.5 Dissolution of Silicon . . . . . . . . . . . . 17

1.6 Comparison of Rolled and Cast Aluminum . . . . . . 18

1.7 Effect of Trace Alloy Metals . . . . . . . . . 18

2. EXTRACTION STUDIES. . . . . . . . . . . . . . . 18

2.I Relationship of Emulsion Stabilization to Dissolution of Silicon . . . . . . . . . . . . . . . . 19

2.2 Nature of Emulsion Stabilizer. . . . . . . . . 20

2.3 Treatments to Prevent Emulsion Stabilization... . 21

3. RESIDUES. . . . . . . . . . . . . . . . . 23

3.1 Residues of Elemental Silicon........... . 24

3.2 Residues of Silica............... 24

3.3 Small Suspended Residues . . . . . . . . . 25

VI. CONCLUSIONS . . . . . . . . . . . . . . . 26

VII. REFERENCES. . . . . . . . . . . . . . . . . . . 28

APPENDIX A--DETAILS OF THE COMPOSITION OF URANIUM-ALUMINUM-SILICON AND ALUMINUM-SILICON ALLOYS . . . . . . . . . . . . . . . . . . . . . . 33 APPENDIX B--MECHANICAL PROPERTIES OF URANIUM-ALUMINUM-SILICON ALLOYS 59 APPENDIX C--EFFECT OF SILICON IN URANIUM-ALUMINUM FUEL ON CHEMICAL

REPROCESSING. . . . . . . . . . . . . . . . . . . . . 63 
1. Two-dimensional microprobe scans of uranium-aluminum alloys with silicon added. Sample taken from Heat 3 with Si-to-U atom ratio of 1.85. . . . . . . . . . . . . . . . 8

2. Effect of silicon additions on the mechanical properties of aluminum alloys with $32 \mathrm{wt} \%$ uranium at three temperatures. . . 10

3. Effect of silicon additions on the mechanical properties of aluminum alloys with 22 wt\% uranium at three temperatures. . . 11

4. Relative strength loss of aluminum-uranium-silicon alloys as a function of the silicon-to-uranium atom ratio . . . . . . . . 12

5. Relative dissolution of aluminum and uranium from alloy containing $22 \%$ uranium - $5 \%$ silicon $-73 \%$ aluminum in boiling $\left(103^{\circ} \mathrm{C}\right)$ nitric acid. . . . . . . . . . . . . . . . . .

6. Residues of particles separated by centrifugation to include diameters $<2 \mu$ and $>35 \mathrm{~m} \mu$ containing globules of polymerized silica

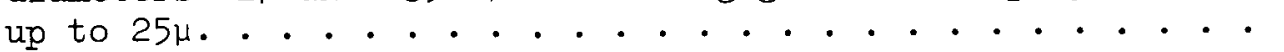

TABLES

I. Nominal Chemical Composition of Test Alloys . . . . . . . . 4

II. Sample Rolling Schedule for Heat 9. . . . . . . . . . . 4

III. Effect of Silicon Content on Aluminum Alloy Composition . . 6

IV. Results of Electron Beam Microprobe Analysis. . . . . . . 7

V. Instantaneous Dissolution Rates of Aluminum-Uranium-Silicon Alloys in Boiling $\left(103^{\circ} \mathrm{C}\right)$ Nitric Acid . . . . . . . . 15

VI. Effect of Dissolved Silicon on Emulsion Stabilization . . . 20

VII. Effect of Boiling on Emulsion Stabilization . . . . . . . . 21

VIII. Effect of Acidity and Time of Boiling on Emulsion Stabilization . . . . . . . . . . . . . . 22

IX. Residues From Incomplete Dissolution of Alloys. . . . . . 23 


\section{SUMMARY}

During the fabrication of some reactor fuel elements from aluminumuranium alloys, substantial quantities of silicon have been added to stabilize the $\mathrm{UAl}_{3}$ phase of the alloy and prevent the formation of $\mathrm{UAI}_{4}$. This improves the fabrication of fuel plates for nuclear reactors. The current study was undertaken to determine the effect of increasing the silicon concentration, both on the fabrication and on the reprocessing of the fuel. This investigation was confined to aluminum-silicon casting alloys and to alloys which may be used in fuel-plate cores for the Engineering Test Reactor (ETR). These fuel-plate cores range from 22 to $32 \mathrm{wt} \%$ uranium. Test alloys ranged from 0 to $10.5 \mathrm{wt} \%$ silicon. Using procedures similar to those employed by fuel plate fabricators, castings of the alloys were prepared, rolled to 0.1 -inch thickness, and cut into coupons for dissolution and extraction studies and for X-ray diffraction and electron beam examination. Radiographic and metallographic examination showed that the alloys prepared were typical of those found in the cores of aluminum-clad fuel plates used in nuclear reactors.

The silicon present in uranium-aluminum alloys in excess of one atom of silicon per atom of uranium was found to be segregated as elemental silicon in the aluminum matrix according to both $X$-ray diffraction and electron beam microprobe analysis. Maximum softness, as indicated by minimum tensile strength, occurs between a silicon-to-uranium atom ratio of 0.8 and 1.0. Above these ratios, there is a hardening of the alloy which is detrimental in fabrication. Previously, alloys had not been examined above an atom ratio of 0.6 which was adequate to stabilize the $\mathrm{UAl}_{3}$ phase.

Highly irradiated fuel elements of uranium-aluminum alloy containing small amounts of silicon have been successfully reprocessed for many years at the Idaho Chemical Processing Plant; however, at times, silicon produces undesirable dissolution behavior, excessive solids in plant streams, and stable emulsions resulting in poor phase separation in the liquidliquid extraction of uranium with tributyl phosphate. Dissolution rates measured in the present work were adequate for reprocessing of fuel; however, differences in rates measured were related to the metallurgical composition of the alloy. The slow dissolution rates encountered for some fuels with different types of cladding are not due to the silicon alone but are due to the combination of silicon with other minor impurities in the alloy. The silicon present in the alloy when the siliconto-uranium atom ratio is less than unity is present as the intermetallic phase $\mathrm{U}(\mathrm{Al}, \mathrm{Si})_{3}$. This silicon dissolves and is responsible for the emulsion stabilization which has been a serious problem in fuel reprocessing; the emulsion stabilization was found to be primarily due to polysilicic acid. If an emulsion stabilizer is produced by the dissolution of aluminum-uranium alloys, the concentration of the silicon in the alloy does not appear to be important because even a small amount of silicon 
may produce solutions which require treatment to improve coalescence behavior. The effects of acidity, gelatin treatment, and other treatments to avoid emulsion stabilization are discussed. If sufficient polymerization and agglomeration of the dissolved silica occurs, as is usually the case during dissolution, emulsion stabilization is not a problem during extraction, but an increase in the quantity of colloidal silica will result. Solids in process streams are primarily due to the insoluble elemental silicon present in the alloys having an atom ratio $>1$. In any case, an increase in silicon content in the alloy will result in an increased solids content in the process stream.

According to this work, some silicon is needed to stabilize the $\mathrm{UAl}_{3}$ phase in uranium-aluminum alloys. Up to an atom ratio of about 1 , increasing the silicon content decreases the tensile strength of the alloy for easier fabrication, while increasing the silicon in the alloy does not greatly increase the problems in reprocessing beyond those encountered upon adding even a small amount of silicon. The addition of silicon at $>$ I atom per atom of uranium, however, does not improve the properties of the alloy; therefore, the addition should be kept below this amount as this excess silicon adds to the bulk of the solids to be processed. Likewise, silicon in the cladding of the alloys should be kept to a minimum to reduce the bulk of solids in process streams.

This work establishes the relationship between the metallurgy of the fuel and the reprocessing of the fuel, thus introducing a new approach to reprocessing studies. 
THE EFFECT OF SILICON ON FABRICATION AND REPROCESSING

OF ALUMINUM ALLOY REACTOR FUELS

\section{INTRODUCTION}

A joint program was initiated by the Metallurgical Development Section of the Reactor Engineering Branch and the Chemistry Section of the Chemical Technology Branch to investigate the advantages and disadvantages of the use of silicon in test reactor fuel elements. The investigation included several phases of the fuel cycle. The effects on the operation of the Idaho Chemical Processing Plant (ICPP) were determined by laboratory scale tests, and in addition, metallurgical studies were undertaken to determine the effect of increasing the concentration of silicon in the fuel core on the mechanical properties of the alloys of the fuel elements.

For a number of years, the fabricators of some of the test reactor fuel elements have requested that substantial quantities of silicon be allowed in the core alloy of the fuel plates. These requests were based on work performed by $W$. C. Thurber and R. J. Beaver of ORNL (1) during development of procedures for the fabrication of fuel plates containing $48 \mathrm{wt} \%$ uranium-aluminum alloy cores in uranium-aluminum plate-type fuel elements. According to this work, the effect of silicon is to stabilize the $\mathrm{UAl}_{3}$ phase of the alloy and prevent the formation of UAl4. This decreases the amount of thickening at the end of the core ("dog boning") during composite fuel plate rolling because of the decrease in the volume of hard, brittle, intermetaliic particles present. The metallurgical effects of varying amounts of silicon in alloys containing lower concentrations of uranium have not been studied previously.

Silicon is a common ingredient in most aluminum welding rods and casting alloys. If the fuel specifications permitted the presence of appreciable quantities of silicon in the side plates of the fuel elements, these components could be made by welding or casting. Some of the manufacturers believe that such procedures could be more economical than the roll swaging or pinning currently used. Therefore, aluminumsilicon alloys were examined to determine the effect of silicon in casting alloys.

Highly irradiated uranium-aluminum fuel elements containing silicon have been successfully reprocessed at the Idaho Chemical Processing Plant (ICPP) for many years; however, at times silicon produces undesirable dissolution behavior, excessive solids in plant streams, and poor phase separation during liquid-liquid extraction of the uranium with tributyl phosphate. The greatest amount of difficulty has been encountered in the last area. During solvent extraction of uranium in either pulse columns or mixer-settlers, formation of stable emulsions can reduce 
throughput, cause the carryover of contaminants, or make the contacting unit inoperable. In the case of dissolution of fuels, excessively large amounts of mercury catalyst have sometimes been required to obtain adequate dissolution rates for alloys with new or different types of cladding.

In earlier work $(2,3,4,5)$, the effect of silicon upon emulsion stabilization has been studied using synthetic solutions prepared from silicon or silica, but neither the causes of the problems nor the effect of the silicon concentration has been clear from these studies. The present work makes it evident that solutions derived from alloy specimens should be used for studies of the problems associated with silicon because the effect of the silicon is related to the metallurgical composition of the alloy and, particularly, to the atom ratio of silicon to uranium. Previous work has considered only the weight percent of silicon in the alloy. 


\section{PREPARATION OF THE ALLOYS}

The fuel elements of three thermal test reactors located at the National Reactor Testing Station, the Materials Testing Reactor (MTR), the Engineering Test Reactor (ETR), and the Advanced Test Reactor (ATR), have fuel-plate cores which contain uranium in the range from 18 wt in the MTR to 35 wt\% in the ATR. This range of uranium content is lower than the concentration investigated by Thurber and Beaver(1). The uranium-aluminum alloy cores used in the MTR fuel plates have seldom presented fabrication problems even without silicon additions; the cores of the ATR fuel plates are prepared by powder-metallurgy techniques. Consequently, the MTR and ATR fuels were excluded from this study, and the investigation was confined to alloys which may be used in ETR fuelplate cores which contain from 22 to $32 \mathrm{wt} \%$ uranium. Uranium contents represent those required in ETR fuel elements containing 400 and 500 grams of U-235.

The alloys prepared for this study are shown in Table I. Silicon was added to the aluminum (Heats 11-14) as elemental silicon and to the uranium-aluminum alloys (Heats $1-7$ and 9 ) as silicon-aluminum hardener. Both methods were used to make the silicon additions to alloys containing $32 \mathrm{wt} \%$ uranium and $3 \mathrm{wt} \%$ silicon (Heats 8 and 9). In order to simplify the investigation, no boron additions were made to the alloys.

The starting materials used to prepare the melts were $99.99 \mathrm{wt} \%$ pure aluminum ingot, electrolytic silicon, and depleted uranium metal bar. Batches of 650 grams were made of each of the alloys. The alloys were melted in air using induction heating. Graphite crucibles coated with magnesium zirconate were used for melting, and the alloys were cast into graphite slab molds. The following steps were used for melting and casting the alloys:

(1) Melt the aluminum metal and silicon-aluminum hardener.

(2) Increase the temperature to $800^{\circ} \mathrm{C}$, add the elemental silicon, if required, and stir with a graphite rod until the silicon is dissolved.

(3) Increase the temperature to $1000^{\circ} \mathrm{C}$, add uranium metal, and stir with a graphite rod until uranium is dissolved.

(4) Allow the molten alloy to freeze in order to remove dissolved gases.

(5) Heat to $1175^{\circ} \mathrm{C}$, stir well with a graphite rod, and skim dross from the bath.

(6) Pour into graphite molds which have been preheated to $325^{\circ} \mathrm{C}$. 


\section{TABLE I}

\section{NOMINAL CHEMICAL COMPOSITION OF TEST ALLOYS}

\begin{tabular}{|c|c|c|c|c|}
\hline Heat & $\begin{array}{c}U \\
(w t \%) \\
\end{array}$ & $\begin{array}{c}\mathrm{Si} \\
(\mathrm{w} t \%) \\
\end{array}$ & $\begin{array}{c}A l \\
\text { (wt\%) }\end{array}$ & Remarks \\
\hline 1 & 22 & 0 & 78 & \\
\hline 2 & 22 & 3 & 75 & Si added as Si-Al hardener \\
\hline 3 & 22 & 4.5 & 73.5 & Si added as Si-Al hardener \\
\hline 4 & 32 & 0 & 68 & \\
\hline 5 & 32 & 0.1 & 67.9 & Silicon picked up as an impurity \\
\hline 6 & 32 & 0.6 & 67.4 & Si added as Si-AI hardener \\
\hline 7 & 32 & 1.3 & 66.7 & Si added as Si-Al hardener \\
\hline & 32 & 3 & 65 & Si added as elemental $\mathrm{Si}$ \\
\hline $9[a]$ & 32 & 3 & 65 & Si added as Si-Al hardener \\
\hline 10 & 32 & 4.5 & 63.5 & Si added as Si-Al hardener \\
\hline 11 & 0 & 0.6 & 99.4 & Si added as elemental $\mathrm{Si}$ \\
\hline 12 & 0 & 1.3 & 98.7 & $\mathrm{Si}$ added as elemental $\mathrm{Si}$ \\
\hline 13 & 0 & 4.5 & 95.5 & Si added as elemental Si \\
\hline 14 & 0 & 10.5 & 89.5 & Si added as elemental $\mathrm{Si}$ \\
\hline
\end{tabular}

[a] 5 batches were made of this heat.

The one-inch thick castings were removed from the mold and preheated for one hour at $500^{\circ} \mathrm{C}$. They were then hot rolled at this temperature to a final thickness of $0.10 \pm 0.01$ inch. The rolling schedule used was: 10\% reduction in thickness on the first and second passes, $20 \%$ reduction on the third pass, and then 25\% reduction on subsequent passes. Heat 9 was divided into five batches and rolled according to five different schedules; sample $9 e$ had the same rolling schedule as the other alloy heats. The schedules in these five batches for Heat 9 are shown in Table II. All slabs were cross-rolled on the second pass. The plates were radiographed to insure homogeneity and sampled for metallurgical and chemical examination.

\section{TABLE II}

\section{SAMPLE ROLLING SCHEDULE FOR HEAT 9}

Sample Number

\section{$9 \mathrm{a}$}

$9 \mathrm{~b}$

$9 c$

$9 d$

$9 e$

\section{Rolling Schedule}

$15 \%$ reduction on 1 st pass and $25 \%$ reduction per pass on balance. $20 \%$ reduction per pass on all passes

$10 \%$ reduction per pass for lst two passes and then $15 \%$ reduction per pass.

$5 \%$ reduction on lst pass and then $10 \%$ reduction per pass. 10\% reduction per pass on lst and 2nd passes, $20 \%$ reduction on $3 r$ pass, and then $25 \%$ per pass. 


\section{ALLOY COMPOSITION}

\section{CHEMICAL ANALYSIS}

All metal alloys were homogeneous after rolling, according to chemical analyses of samples selected from the top, middle, and bottom of the rolled sheet of each alloy. The difference between the maximum and minimum analysis for three samples from any one alloy was $<8 \%$ of the absolute value of the silicon content, $<3 \%$ of the absolute value of the aluminum content, and $<6 \%$ of the absolute value of the uranium content. The average chemical analysis of the three samples of each alloy is presented in Table A-I in Appendix A. The values used throughout the text to describe the alloys are the nominal values and are within $\pm 1 \%$ of the analyzed aluminum and uranium concentration and within $\pm 0.3 \%$ of the analyzed silicon concentration.

Impurities in the alloys were determined by emission spectroscopy and are given in Table A-II of Appendix A. The aluminum-silicon alloys each contained less than $0.05 \mathrm{wt} \%$ total impurities composed of iron, nickel, magnesium, and copper. The alloys containing $32 \mathrm{wt} \%$ uranium each contained less than 0.08 wt\% impurities composed of the same elements plus a trace amount of manganese.

\section{RADIOGRAPHIC AND METALLOGRAPHIC EXAMINATION}

The radiographs of each heat of all alloys were carefully inspected and compared. The radiographs not only indicate how well the uranium is distributed, but also show the apparent grain size and extent of edge cracking. Positive prints of the radiographs taken through the center section of the as-rolled slabs of the uranium-aluminum alloys are shown in Figures A-l through A-5 in Appendix A. A discussion of the effect of different levels of silicon on grain size and edge cracking is also given in Appendix A. Metallographic specimens were also prepared from representative areas of the slabs in order to investigate the cause of the grainy appearance of the radiographs. These samples were polished so as to reveal the structure of the alloys in the plan view. The photomosaics and micrographs in Figures A-6 through A-19 (Appendix A) show that the acicular structure is actually a cluster of intermetallic particles. According to these data, the alloy specimens used in this study were typical of those found in the cores of aluminum clad fuel plates used in nuclear reactors 


\section{X-RAY DIFFRACTION ANALYSIS}

The surfaces of the alloy sheets were examined by X-ray diffraction to determine the metallurgical composition of each alloy. The results obtained by examination of three samples selected from the top, middle, and bottom of each as-rolled sheet are presented in Table III. In the alloys which do not contain uranium, the aluminum and silicon are present only in the elemental form, and no intermetallic phases are found. In all of the uranium alloys, a uranium-aluminum intermetallic phase is present in an aluminum matrix. Uranium alloys which do not contain silicon contain $\mathrm{UAl}_{4}$ as would be predicted from the work by Thurber and Beaver(I) with alloys containing $48 \mathrm{wt} \%$ uranium. Alloys which contain silicon contain $\mathrm{UAl}_{3}$.

According to Thurber and Beaver $(1)$, the addition of silicon to UAI 3 causes a shift in the lattice parameter corresponding to the percent of silicon added. The intermetallic phase designated as $\mathrm{U}(\mathrm{Al}, \mathrm{Si})_{3}$ was identified in a number of our uranium alloys. The relationship of the shift in lattice parameter to the atom ratio of silicon to uranium is given in Figure A-20 of Appendix A together with a discussion of the intermetallic phase.

\section{TABLE III}

EFFECT OF SILICON CONTENT ON ALUMINUM ALLOY COMPOSITION

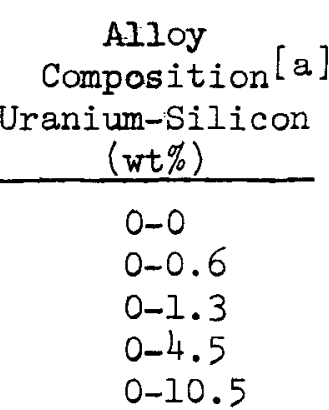

22-0

$22-3$

$22-4.5$

32-0

$32-0.6$

$32-1.3$

$32-3$

$32-4.5$
Atom

Ratio

$\underline{(\mathrm{Si} / \mathrm{U})}$

No $\mathrm{U}$ or $\mathrm{Si}$

No $U$

No $\mathrm{U}$

No U

No U

No $\mathrm{Si}$

1.1

1.9

No $\mathrm{Si}$

0.2

0.4

0.8

1.2
Alloy

Composition

By X-ray

Diffraction

Al

AI, $S i$

$\mathrm{Al}, \mathrm{Si}$

Al, Si

$\mathrm{Al}, \mathrm{Si}$

$\mathrm{UAl}_{4}, \mathrm{AI}$

$\mathrm{U}(\mathrm{Al}, \mathrm{Si})_{3}, \mathrm{Al}, \mathrm{Si}$

$\mathrm{U}(\mathrm{Al}, \mathrm{Si})_{3}, \mathrm{Al}, \mathrm{Si}$

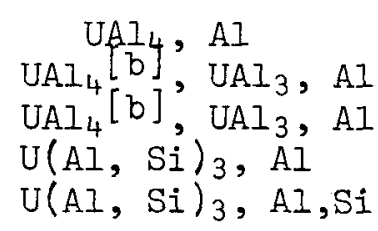

[a] Remainder of alloy is pure aluminum.

[b]

A slight shift in lattice parameter is possibly due to silicon. 


\section{ELECTRON-BEAM MICROPROBE ANALYSIS}

As shown in Table III, the X-ray diffraction studies indicate that some free silicon was detected with increasing silicon content in the uranium-aluminum alloys. In order to determine the location of this free silicon in the microstructure of the alloys, metallographic samples were prepared for electron-beam microprobe examinations. The samples were selected from both the 22 and 32 wt $\%$ uranium alloys with a range of silicon-to-uranium atom ratios from 0 to 1.85 . The results of these examinations are shown in Table IV.

These data show that the silicon is associated primarily with the uranium-aluminum intermetallic particles. When the silicon-to-uranium atom ratio exceeds approximately one, however, the intermetallic particles are saturated with silicon, and the excess silicon appears as segregations of silicon, free from uranium, throughout the matrix of the alloy. An illustration of this is shown in Figure 1. Two-dimensional electron-beam microprobe scans are shown for both uranium and silicon for two uranium-aluminum alloys. The scans of the same alloy were made from the same area of a metallographic specimen. The top two figures show scans for the alloy with a silicon-to-uranium atom ratio of 0.85 (Heat $9 \mathrm{e}$ ). All of the silicon is associated with the uranium bearing intermetallic particles at this atom ratio. The bottom two figures are scans from the alloy with a silicon-to-uranium atom ratio of 1.85 . In this alloy, silicon is also found in areas that are free of uranium.

\section{TABLE IV}

RESULTS OF ELECTRON BEAM MICROPROBE ANALYSIS

\begin{tabular}{|c|c|c|c|}
\hline Heat & $\begin{array}{c}\mathrm{U} \\
(\mathrm{wt} \%) \\
\end{array}$ & $\begin{array}{l}\mathrm{Si} \\
(\mathrm{wt} \%) \\
\end{array}$ & $\begin{array}{l}\text { Atom Ratio } \\
(\mathrm{Si} / \mathrm{U})\end{array}$ \\
\hline 4 & 32 & 0 & 0 \\
\hline 7 & 32 & 1.3 & 0.4 \\
\hline $9 e$ & 32 & 3 & 0.8 \\
\hline 2 & 22 & 3 & 1.1 \\
\hline 3 & 22 & 4.5 & 1.9 \\
\hline
\end{tabular}

Results

Silicon not detected, either in fuel or matrix.

Silicon associated only with fuel particles. No silicon detected in matrix.

Silicon associated only with fuel particles. No silicon detected in matrix.

Silicon associated with all fuel particles; only a slight tendency to be found independent of fuel particles.

Silicon associated with all fuel particles; also numerous segregations of silicon (free from uranium) present throughout matrix. 
Heat $9 e$ - silicon-to-uranium atom ratio 0.85

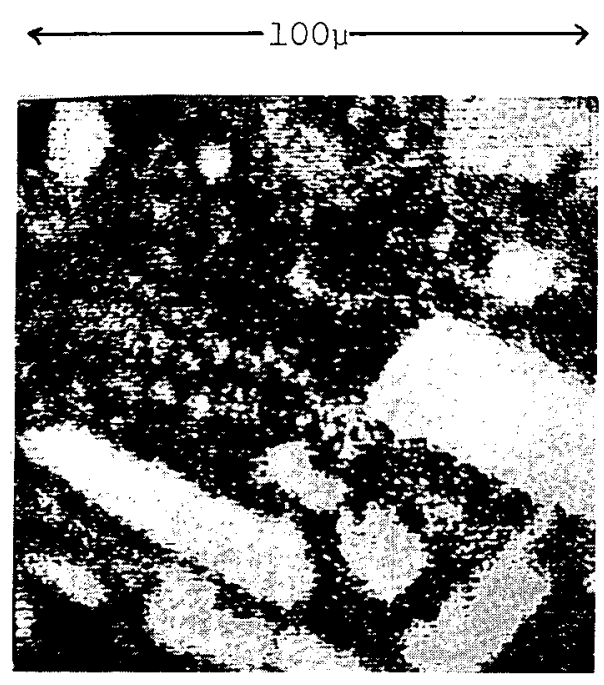

Uranium $M B I$

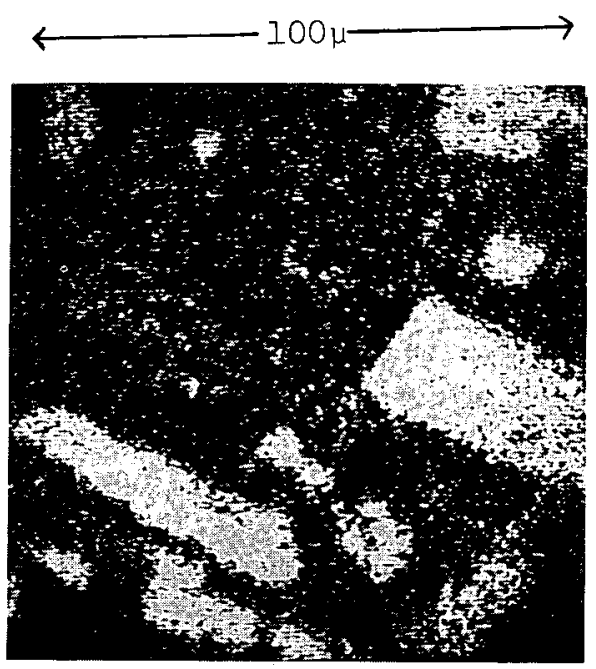

Silicon $K_{\alpha}$

Heat 3 - silicon-to-uranium atom ratio 1.85

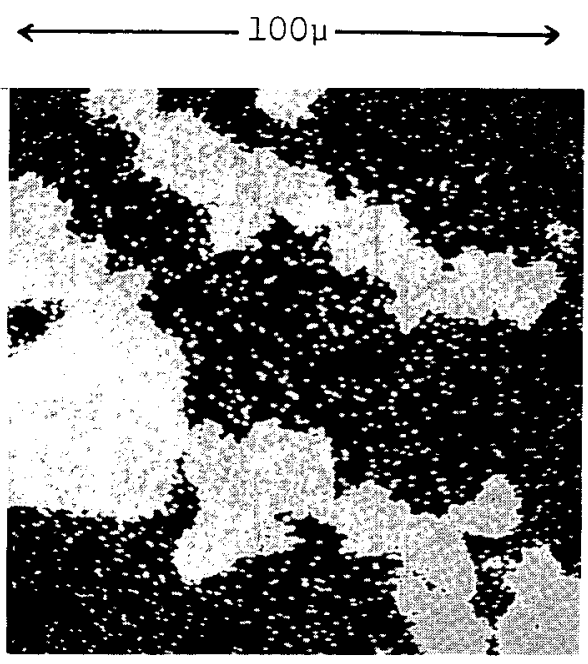

Uranium $M_{\beta} 1$

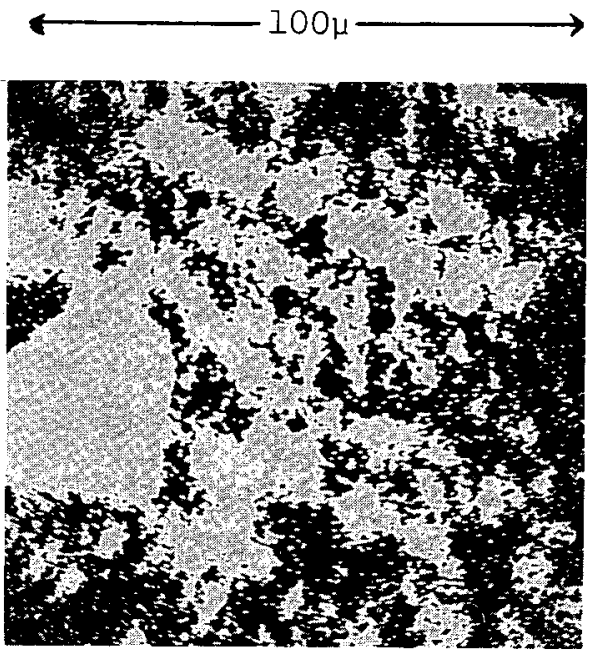

Silicon $K_{\alpha}$

Figure 1 Two-dimensional microprobe scans of uranium-aluminum alloys with silicon added. 


\section{RESULTS AND DISCUSSION OF SILICON IN FUEL FABRICATION}

In order to study the effect of silicon addition on the mechanical properties of uranium-aluminum alloys, one-inch gage-length tensile specimens prepared from the rolled alloy sheets were heated in air for one hour at $500^{\circ} \mathrm{C}$ and air cooled. Tensile testing was performed on the Instron-type Tr'-D testing machine at room temperature, at $150^{\circ} \mathrm{C}$ (the estimated operating temperature of test reactor fuel plates), and at $550^{\circ} \mathrm{C}$ (the fuel plate hot rolling temperature). Since the effect of silicon on the properties of aluminum alloys is well known $(6)$, these alloys were not tested.

\section{RESULTS OF MECHANICAL TESTING}

The results of mechanical testing of uranium-containing alloys are plotted in Figures 2 and 3. The data used in preparing these graphs are compiled in Table B-l in Appendix B. Examination of the plots reveals that, as expected, the initial addition of silicon lowers the tensile strength of both the alloy containing 22 wt $\%$ uranium and the alloy containing 32 wt\% uranium at all three test temperatures. The minimum strength, corresponding to maximum ductility, was achieved with 3 wt $\%$ silicon in both alloys. The work at ORNL (I) indicated that 3 wt silicon was the desirable amount for a 48 wt $\%$ uranium-aluminum alloy; higher silicon contents were not studied. Inasmuch as the effect of the silicon is to stabilize the $\mathrm{UAl}_{3}$ phase in the alloy, it would be expected that the optimum amount of silicon required to soften the alloy should be directly related to the uranium content and not to the silicon content alone.

\section{EFFECT OF SILICON-TO-URANIUM ATOM RATIO}

In order to investigate the relationship of the silicon-to-uranium atom ratio in the alloy to the amount of softening produced in the alloy, the data in Figure 4 were developed. The silicon-to-uranium atom ratios in the alloys are plotted against the following ratios:

$$
\frac{u t s_{0}-u t s_{S i}}{u t s_{0}} \text { and } \frac{\text { tys }_{0}-t^{t y s_{S i}}}{\text { tys }_{0}}
$$

where

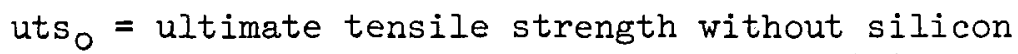

uts $\mathrm{Si}=$ ultimate tensile strength with silicon

tyso $=$ tensile yield strength without silicon

tys $_{\mathrm{Si}}=$ tensile yield strength with silicon. 


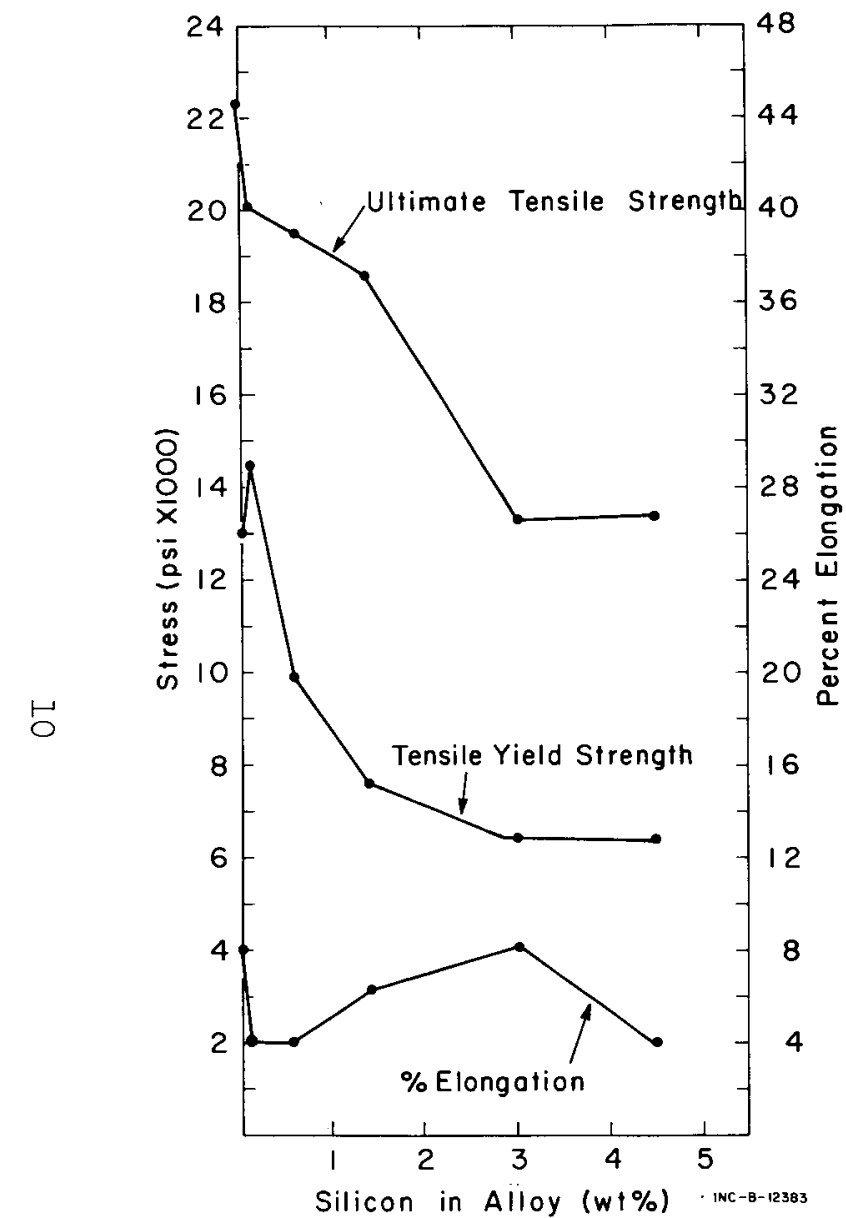

Room Temperature

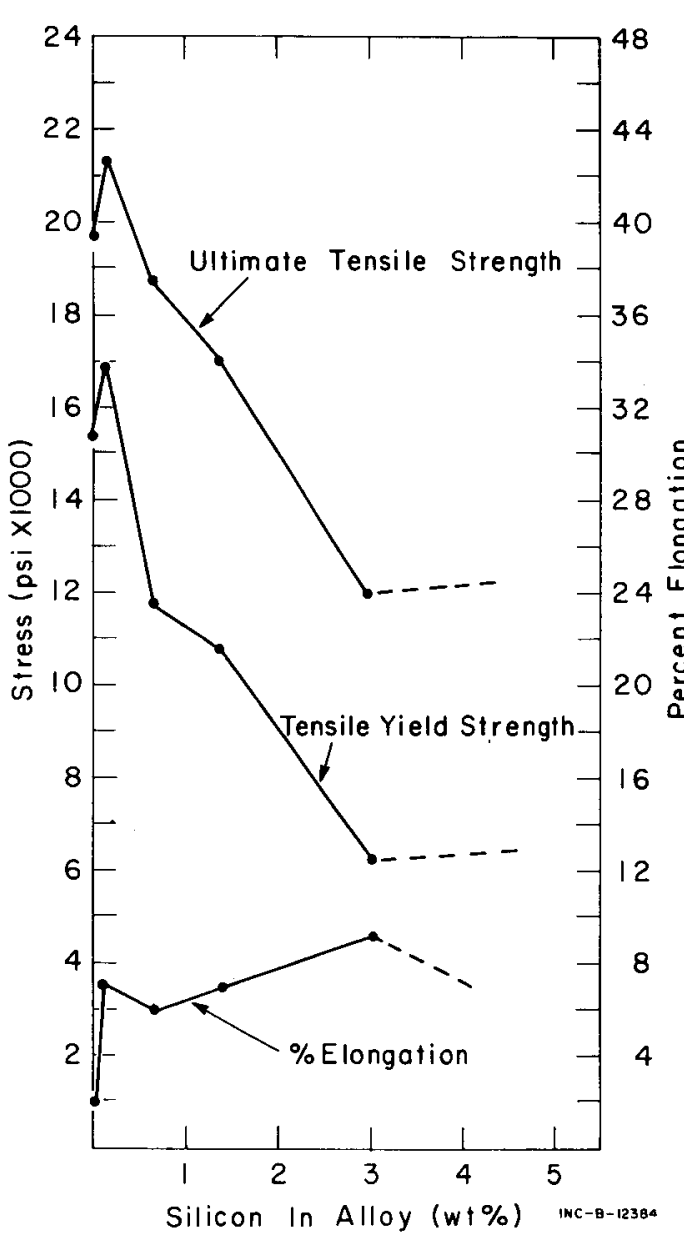

$150^{\circ} \mathrm{C}$

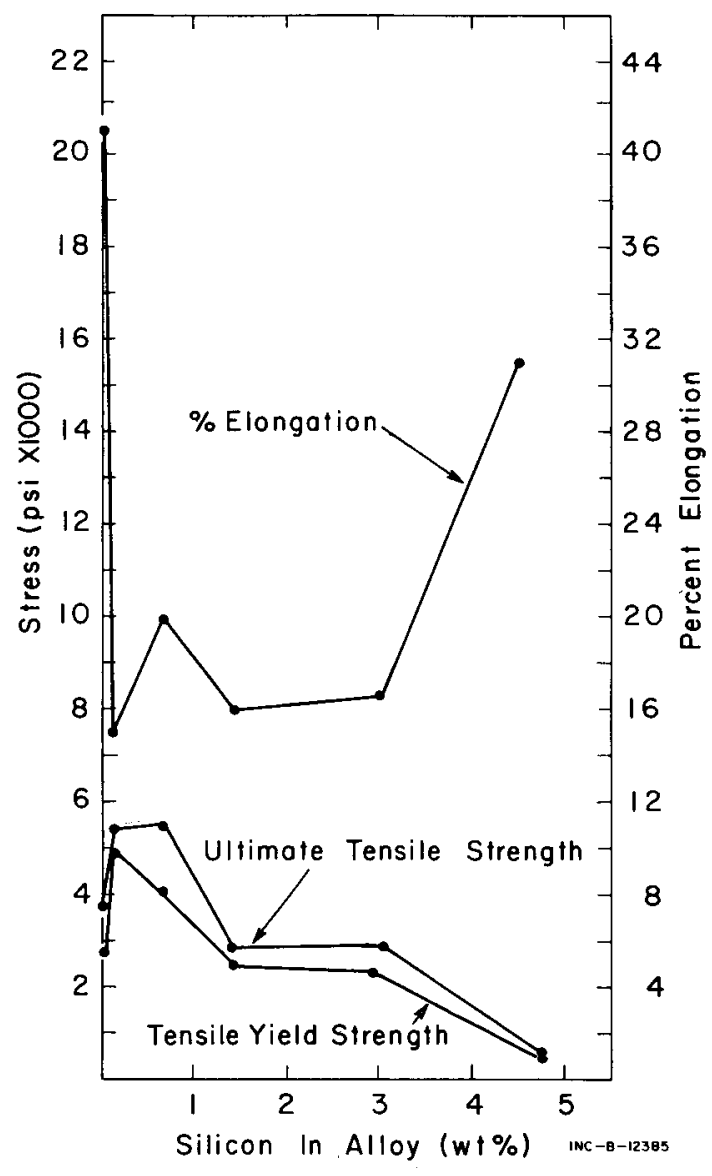

$550^{\circ} \mathrm{C}$

Figure 2

Effect of silicon additions on the mechanical properties of aluminum alloys with 32 wt $\%$ uranium at three temperatures. 


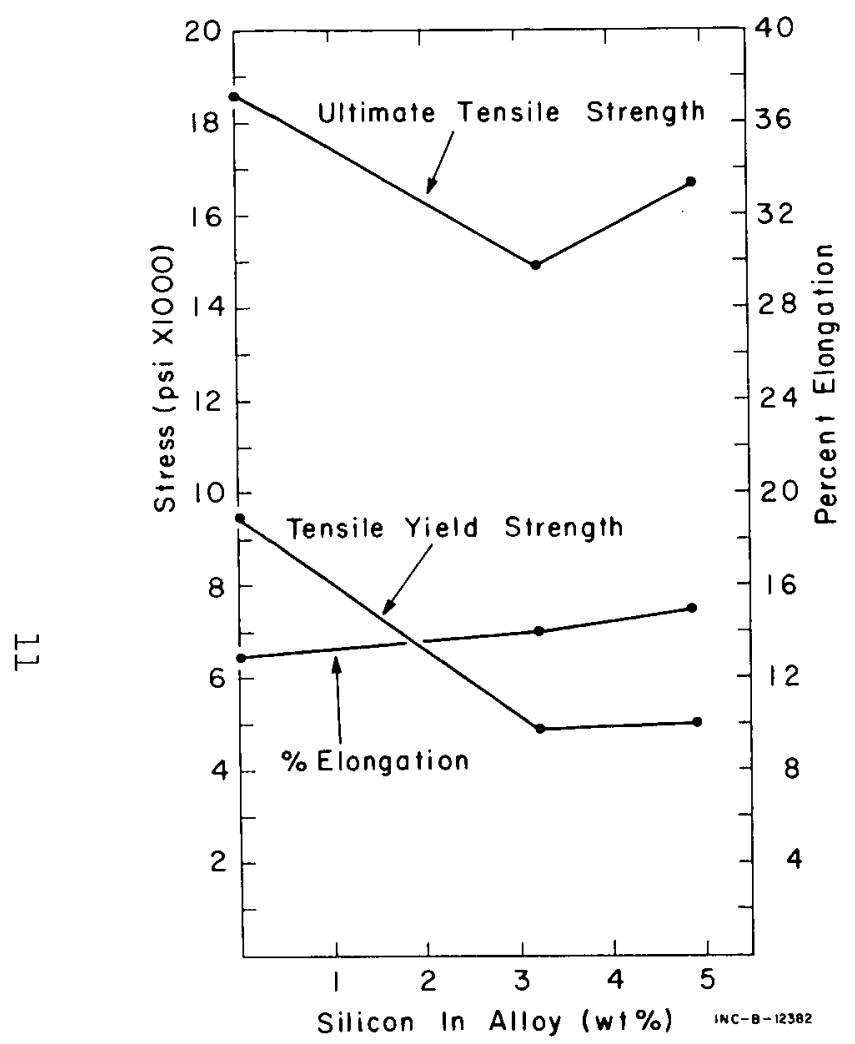

Room Temperature
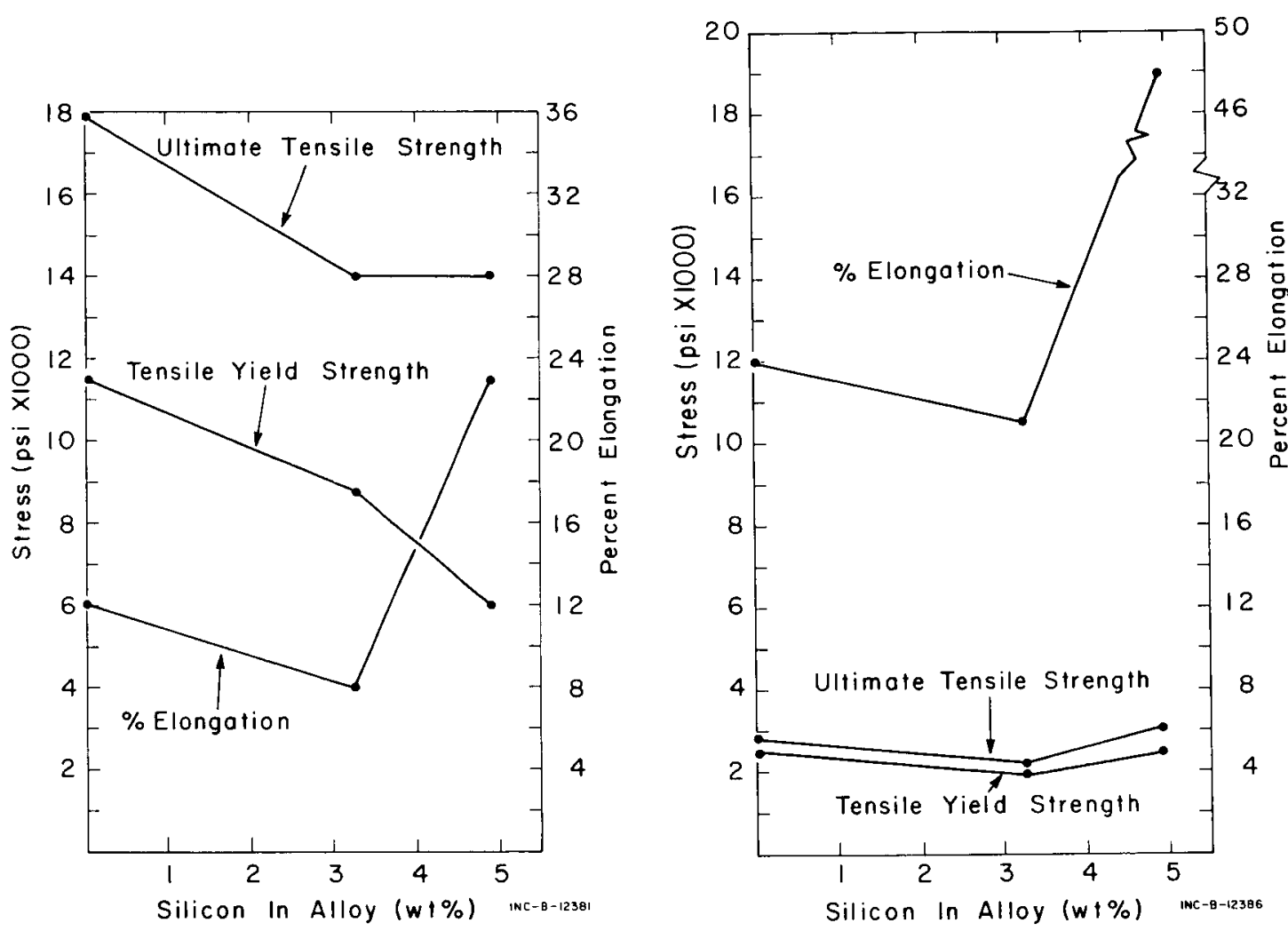

$550^{\circ} \mathrm{C}$

Figure 3

Effect of silicon additions on the mechanical properties of aluminum alloys with 22 wt $\%$ uranium at three temperatures. 


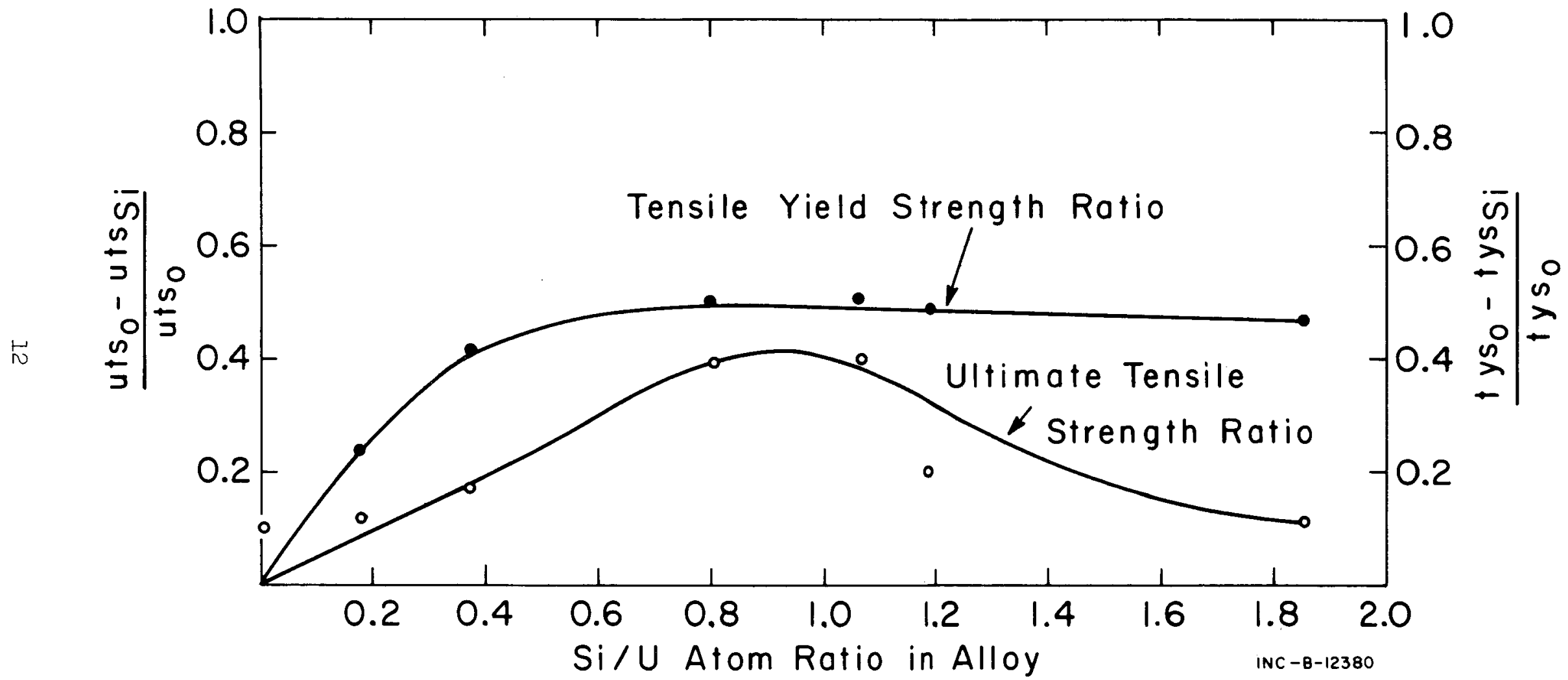

Figure 4 Relative strength loss of aluminum-uranium-silicon alloys as a function of the silicon-to-uranium atom ratio. 
As seen in Figure 4, the maximum decrease in strength is produced when the silicon-to-uranium atom ratio is in the range of 0.8 to 1.1 . Excess silicon causes hardening of the alloy which is detrimental in the fabrication of aluminum-uranium alloys. This would be the expected result according to the chemical dissolution studies, X-ray diffraction patterns, and electron microprobe scans. These studies, which are capable of producing much more definitive results than tensile testing, all indicate that the uranium aluminide particles become saturated with silicon when the silicon-to-uranium atom ratio is between 0.8 and 1.1 . Up to the point of saturation of the intermetallic particles, increasing the amount of silicon decreases the strength of the uranium-aluminum alloy since this results in a smaller volume percent of intermetallic particles. However, once the fuel particles are saturated with silicon, the free elemental silicon appears in the matrix of the alloy and tends to increase the strength. This effect was not seen by Thurber and Beaver in the uraniumaluminum alloys containing $48 \mathrm{wt} \%$ uranium because the maximum atom ratio of silicon to uranium for which mechanical properties were studied was only 0.6. However, the same effect would be expected in the materials with the higher uranium content.

\section{HIGH TEMPERATURE PROPERTIES}

The high atom ratios of silicon to uranium (1.85 and 1.16) used in Heats 3 and 10 appreciably improved the ductility, as measured by percent elongation, of the alloys at $550^{\circ} \mathrm{C}$. As shown in Table B-I (Appendix B) this improved ductility was not completely reflected in the results obtained in hot rolling the alloy slab from Heat 3 (atom ratio of 1.85), probably because the hot rolling was performed at lower temperature than the tensile testing. The pre-heating temperature for rolling was $50^{\circ} \mathrm{C}$ lower than the tensile testing temperature; in addition, a temperature drop occurred between the time the alloy slab left the furnace and entered the roll. 


\section{RESULTS AND DISCUSSIONS OF SILICON IN FUEL REPROCESSING}

\section{DISSOLUTION STUDIES}

In the first phase of the chemical reprocessing studies, instantaneous dissolution rates were determined in duplicate for the entire set of alloys. The dissolutions were initiated at the boiling point $\left(103-104^{\circ} \mathrm{C}\right)$ in $6.6 \mathrm{M}$ nitric acid using $0.007 \mathrm{M}$ mercuric nitrate as catalyst, 4.8 moles of acid per mole of aluminum, and a uniform ratio of surface area to solution volume. At various time intervals, the solutions were sampled and analyzed for aluminum, hydrogen ion, and uranium. The solutions contained approximately 1.5 moles of aluminum per liter, -11 and 19 grams of uranium per liter, and were 0.5 to $2.0 \mathrm{M}$ in hydrogen ion when the dissolutions were completed.

Most aluminum alloy fuels are dissolved continuously at ICPP. In these studies, batch dissolutions were made rather than continuous dissolutions in order to limit the quantity of alloy used and still control final product compositions. Batch dissolutions resemble continuous dissolutions adequately in the following ways: (a) the contact time of the alloy with the solution is related to the dissolution rate of the alloy and is equal for alloys with equal dissolution rates; (b) similarly, the digestion time for the solution at the elevated temperature of the dissolution is related to the dissolution rate of the alloy; (c) the degree of dissolution of the coupon at various intervals of sampling is not important since the alloy is homogeneous. On the other hand, the greatest difference between the two methods of dissolution is the acidity of the solutions during the dissolution. The acidity in the continuous dissolver is fairly uniform and low, whereas the acidity in the batch dissolution is quite high at the beginning of the dissolution but drops rapidly to acidities comparable to those in the continuous dissolver.

The instantaneous dissolution rates for the alloys were calculated as milligrams of aluminum dissolved per square centimeter of surface area per minute of dissolution time $\left(\mathrm{mg} / \mathrm{cm}^{2}-\mathrm{min}\right)$ at concentrations of 10 and $30 \mathrm{~g} /$ liter of aluminum in the dissolver solution. Since the early portions of the dissolution obey a parabolic rate law fairly closely, the dissolution rates were determined from the slope of a graphical presentation of the square of the aluminum concentration versus the dissolution time. These graphs of the dissolution data are shown in Figures C-1 through C-13 in Appendix C. The method of calculation is also discussed in detail in Appendix $C$.

Six dissolutions were performed for alloys containing $32 \mathrm{wt} \%$ uranium and $3 \mathrm{wt} \%$ silicon and having five different rolling schedules and two different methods of adding silicon. The rates for the six 
dissolutions were within $\pm 10 \%$ of their average,indicating that the rolling schedules and method of silicon addition did not have an effect.

\subsection{Relationship Between Dissolution Rates and Metallurgy}

All of the dissolution rates measured are satisfactory for the reprocessing of reactor fuels at ICPP. The dissolution rates, however, differ significantly among the uranium-aluminum alloys studied and are related to the metallurgical composition of the alloy. The average dissolution rates for duplicate dissolutions are presented in Table $V$ for concentration levels of 10 and $30 \mathrm{~g} /$ liter of aluminum in the dissolver solution. The duplicate dissolution rates are reported in Table C-I of Appendix C.

\section{TABLE V}

INSTANTANEOUS DISSOLUTION RATES OF ALUMINUM-URANIUM-SILICON ALLOYS IN BOILING $\left(103^{\circ} \mathrm{C}\right)$ NITRIC ACID

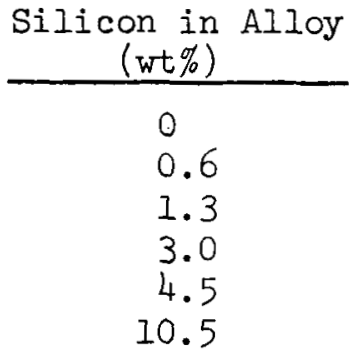

Silicon in Alloy

$($ wt $\%)$
0
0.6
1.3
3.0
4.5
10.5

Rates (mg/ $\left.\mathrm{cm}^{2}-\mathrm{min}\right)$ in Solutions Containing $30 \mathrm{~g} /$ liter of Aluminum

\begin{tabular}{|c|c|c|}
\hline $\begin{array}{c}\text { No U } \\
\text { in Alloy }\end{array}$ & $\begin{array}{l}22 \text { wt } \% \\
\text { in } \mathrm{All} \text { - }\end{array}$ & $\begin{array}{l}32 \text { wt } \% \\
\text { in Alloy }\end{array}$ \\
\hline 26 & 9 & 4 \\
\hline 23 & - & 8 \\
\hline 25 & -- & 10 \\
\hline- & 26 & 12 \\
\hline 28 & 16 & II \\
\hline 8 & -- & -- \\
\hline
\end{tabular}

Rates $\left(\mathrm{mg} / \mathrm{cm}^{2}-\mathrm{min}\right)$ in Solutions Containing $10 \mathrm{~g} /$ liter of Aluminum

\begin{tabular}{|c|c|c|}
\hline $\begin{array}{l}\text { No } U \\
\text { in AIloy } \\
\end{array}$ & $\begin{array}{l}22 \text { wt } \mathrm{U} \\
\text { in Alloy }\end{array}$ & $\begin{array}{l}32 \text { wt } \% \\
\text { in Alloy }\end{array}$ \\
\hline 67 & 23 & 18 \\
\hline 58 & -- & 26 \\
\hline 63 & -- & 28 \\
\hline-- & 65 & 44 \\
\hline 70 & 43 & 56 \\
\hline 38 & -- & - \\
\hline
\end{tabular}

Based on our results, instantaneous dissolution rates of the components of the alloy appear to decrease in the order: $\mathrm{Al}^{>} \mathrm{UAl}_{3}>$ $\mathrm{U}(\mathrm{Al}, \mathrm{Si})_{3}>\mathrm{UAl}_{4}>\mathrm{Si}$. The dissolution rate for $\mathrm{U}(\mathrm{Al}, \mathrm{Si})_{3}$ apparently decreases with increasing silicon content in the phase. The alloys that contain little or no silicon have the lowest rates because they contain $\mathrm{UAl}_{4}$; the rates increase with increasing silicon content until there is no UAl 4 present in the alloy. Elemental aluminum has the highest dissolution rate; therefore, the alloys containing the higher aluminum concentrations and correspondingly lower uranium concentrations 
have the higher dissolution rates. Elemental silicon, present in some of the alloys, did not affect the rates in most cases; extremely large excesses, however, may cause lower dissolution rates as in the case of the aluminum containing 11 wt silicon and in the alloy containing 22 wt\% uranium and 5 wt $\%$ silicon.

A statistical analysis of the dissolution rates verified that the three variables examined (two levels of uranium content in the alloy, four levels of silicon content in the alloy, and two levels of aluminum concentration in the dissolver solution) are all significant at the $99 \%$ confidence level. An increase in the concentration of the aluminum in solution is expected to be highly significant because it corresponds to a decrease in acid level. in the solution. The high dissolution rate for metallic aluminum is responsible for the difference reflected in the effect of the uranium concentration in the alloy because each level of uranium has a corresponding aluminum level. According to the statistical analysis the silicon content of the alloy has a significant effect, but the change in rate is not systematic with the change in silicon concentration. Our data indicate that the effect is due to changes in metallurgical composition which result from the addition of silicon to the alloy, and accordingly the uranium-silicon interaction is significant at the $99 \%$ confidence level.

\subsection{Difference in Dissolution of Aluminum and Uranium}

During dissolution studies with alloys of uranium-aluminum-silicon, aluminum appeared in the dissolver solution more rapidly than uranium. Figure 5 shows the two separate curves obtained from a single dissolution of the alloy containing $22 \mathrm{wt} \%$ uranium and $5 \mathrm{wt} \%$ silicon. The difference in rate of appearance occurs because the uranium-aluminum intermetallics dissolve more slowly than the aluminum metal matrix and is a further verification of the relationship to metallurgical composition. The difference in rate occurs in alloys with and without silicon added; however, the three alloys containing an atom ratio of silicon to uranium of greater than one exhibit the largest lag in dissolution of uranium with only $72 \%$ of the uranium being dissolved when $80 \%$ of the aluminum is dissolved. Differences in rate of dissolution of aluminum and uranium in the uranium alloys are presented in Tables C-III and C-IV in Appendix C.

Residues of the intermetallic $\mathrm{U}(\mathrm{Al}, \mathrm{Si})_{3}$ are found when dissolutions of the alloys are $80 \%$ complete, showing that the uranium-aluminum-silicon intermetallic is especially slow to dissolve. If enriched uranium fuel is being processed, the possibility of a concentration of uranium in the residues must be considered from a criticality standpoint whenever the dissolution is incomplete. These uranium-bearing solids dissolve slowly at room temperature, but at the boiling point they are completely dissolved soon after the dissolution of the aluminum matrix is complete.

\subsection{Effect of Acidity}

The decrease in acidity of the dissolver solution during the dissolution is shown in Figures $\mathrm{C}-1$ through $\mathrm{C}-13$ in Appendix C. The acidity of the dissolver solution at $30 \mathrm{~g} /$ liter of aluminum in solution varied 


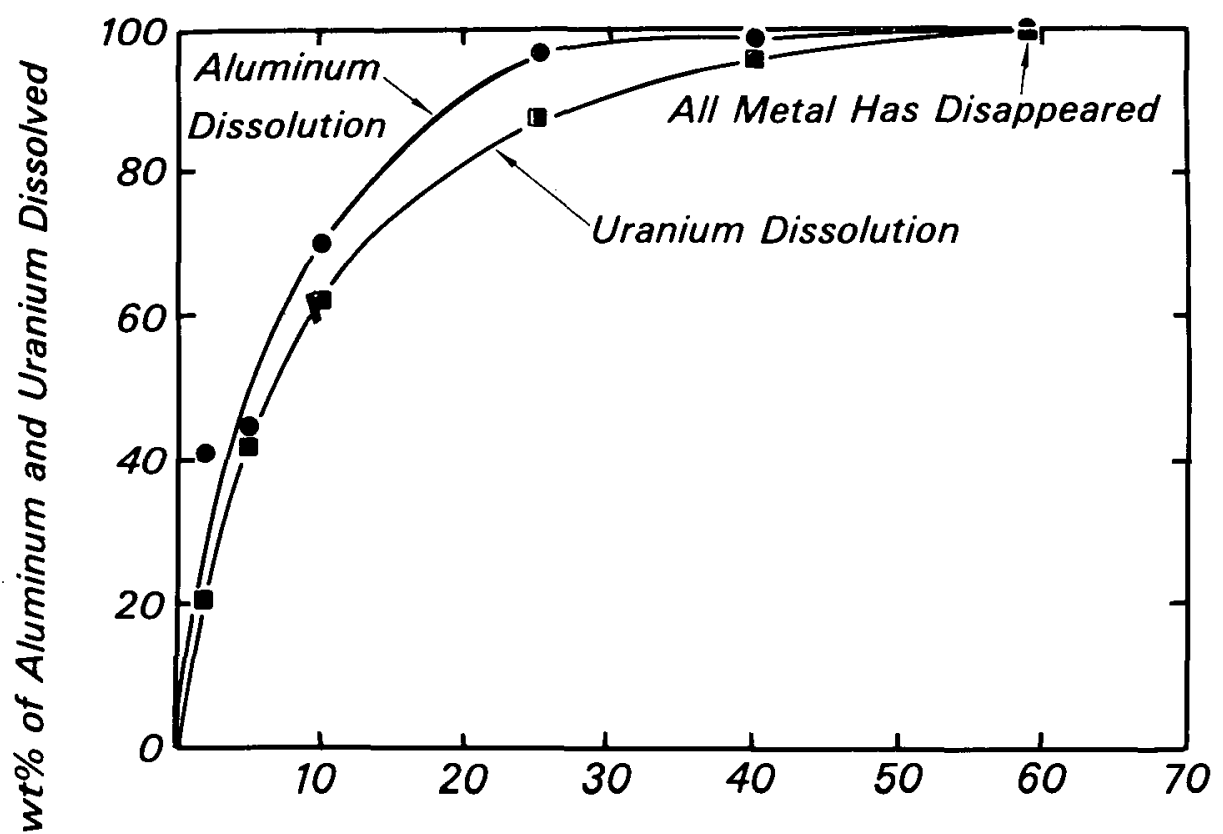

Time From Start of Dissolution (min)

Figure 5 Relative dissolution of aluminum and uranium from alloy containing $22 \%$ uranium - $5 \%$ silicon - $73 \%$ aluminum in boiling $\left(103^{\circ} \mathrm{C}\right)$ nitric acid containing $0.007 \mathrm{M}$ mercuric nitrate.

from about 1.5 to $3.2 \mathrm{M}$ in the dissolutions performed. At this aluminum concentration, no correlation was evident between the acidity of the solution and the dissolution rate.

\subsection{Uranium Concentration in Solution}

The concentration of uranium was determined in the dissolver solution during the dissolution in order to compare the rates for aluminum and uranium. The dissolution rate of the alloy based upon the uranium dissolution was not calculated. The uranium concentrations which can be used for this purpose are given in Table C-II of Appendix C. The final uranium concentrations were about $11 \mathrm{~g} / \mathrm{liter}$ for the $22 \mathrm{wt} \%$ uranium alloy and $19 \mathrm{~g} /$ liter for the $32 \mathrm{wt} \%$ uranium alloy.

\subsection{Dissolution of Silicon}

Silicon analyses were obtained upon filtered dissolver solutions by emission spectroscopy during the first set of dissolutions of the alloys. The analyses are arranged according to the approximate time from the start of the dissolution in Tables C-V, C-VI, and C-VII in Appendix C. In the alloys that did not contain uranium, the silicon essentially did not dissolve. The dissolved silicon increases with increasing silicon content in the uranium alloys; after a maximum concentration is reached, 
however, the silicon apparently polymerizes and is removed from the solution by the filtration. As the multiplicate dissolutions show in Table C-VII, this phenomenon occurs repeatedly in alloys with the same composition. These data were the basis for using the solutions from incomplete dissolutions to obtain reproducible emulsion stabilization for extraction studies discussed in Section $\mathrm{V}-2$.

\subsection{Comparison of Rolled and Cast Aluminum}

No difference was found in the dissolution rates for rolled and cast aluminum coupons. The dissolution rate of $26 \mathrm{mg} / \mathrm{cm}^{2}-\mathrm{min}$ reported in Table $V$ for pure aluminum in a solution containing $30 \mathrm{~g} / \mathrm{liter}$ of aluminum is for coupons rolled to 0.1 -inch thickness. Coupons of the same size were machined from a cast ingot of the same pure aluminum and dissolved at identical conditions. Dissolution rates for duplicate dissolutions were 29 and $30 \mathrm{mg} / \mathrm{cm}^{2}-\mathrm{min}$ which is in reasonable agreement with the rate for the rolled aluminum. These rates for pure aluminum are comparable to the rates measured previously $(8)$ when the differences in mercury catalyst level and temperature are taken into consideration.

\subsection{Effect of Trace Alloy Metals}

The effect of trace alloy metals was not examined in this study. The alloys were prepared from $99.99 \%$ pure aluminum in order to clearly reveal the effect of silicon. This type of alloy prepared from pure aluminum is important as fuel element core alloy. However, the importance of trace elements can not be ignored, especially with regard to the aluminum-silicon alloys used for side plates and usually prepared from commercial alloys of aluminum. Studies performed earlier by Fletcher, Jacobson, and Beard $(8)$ at this laboratory showed that copper and nickel in aluminum alloys have a pronounced passivating effect upon the rate of dissolution. It was also believed that silicon had a similar effect, but current work indicates that the effect ascribed to silicon in the earlier work was related to its association with the other trace elements and not to the silicon alone.

\section{EXTRACTION STUDIES}

In the second phase of the chemical reprocessing studies, the formation of emulsions by solutions of the alloys and the tributyl phosphate diluted with kerosene was studied for six different types of alloys. The selection of the alloys was based on the atom ratio of uranium to silicon. The solutions resulting from the dissolution studies had only a slight tendency to stabilize emulsions and would probably not create phase-separation difficulties in the extraction cycle during the reprocessing of aluminum fuels. Similarly, dissolver product solutions at ICPP do not normally cause phase-separation difficulties. Data for the solutions from the dissolver studies are given in Table C-VIII of Appendix C.

During plant operation, stable emulsions which prevent good phase separation are, however, encountered on occasion. In order to study 
the problem of emulsion stabilization, solutions which would reproducibly form stable emulsions were prepared for the study by stopping the dissolution when it was about $80 \%$ complete. Lower acid-to-aluminum ratios and lower acid concentrations were used in order to obtain solution concentrations similar to dissolver product solutions. Other dissolution conditions were the same as for the dissolution rate studies. The solutions prepared for the extraction studies contained approximately $1.2 \mathrm{M}$ aluminum and 10 or 13 grams per liter of uranium and were from 0.2 to $0.8 \mathrm{M}$ in hydrogen ion. The effect of the final acidity of the dissolver product on emulsion stabilization is shown in Table C-IX in Appendix C.

Immediately following the dissolution, the dissolver solutions were separated into three different fractions according to particle size of the suspended solids by a combination of settling and centrifugation techniques described in Appendix C, Section 3.1. The supernate fractions contained particles with maximum diameters of approximately 2000, 250, and $35 \mathrm{m \mu}$, respectively. The supernates were immediately examined with a Brice Phoenix Light Scattering Photometer to determine the solias content and with a dispersion-coalescence tester to determine the degree of emulsion stabilization during extraction. At the same time, total silicon content of the supernate was determined by emission spectroscopy. The suspended solids and residues are described in Section V-3.

\subsection{Relationship of Emulsion Stabilization to Dissolution of Silicon}

The emulsion characteristics determined for the supernates from the various alloys are given in Table VI. In the test used $(7)$, coalescence of the aqueous phase after dispersion with tributyl phosphate and kerosene should be complete in less than 180 seconds to assure satisfactory phase separation in the ICPP columns. Correlation of the dispersion-coalescence test with plant operation has shown that the persistence of either the emulsion or a web of aqueous phase in the organic phase is an indication of difficulties in the process extraction columns.

The coalescence behaviors of the dissolver solutions are related to the total silicon content of the centrifuged solutions; solutions containing the highest concentration of dissolved silicon exhibit the greatest amount of emulsion stabilization. However, even a small amount of silicon in the alloys can produce sufficient emulsion stabilization to be unsatisfactory from a process standpoint and require treatment (9) therefore, an increase in silicon content in uranium-aluminum fuel is not of importance in this regard. Since the silicon responsible for the surfactancy dissolves only as the intermetallic phase, only solutions of the alloys which contain $U(A I, S i)_{3}$ form stable emulsions. Silicon present in the alloy as elemental silicon does not dissolve and, therefore, does not cause stable emulsions.

In order to verify this, the amount of $\mathrm{U}(\mathrm{Al}, \mathrm{Si})_{3}$ present in each of the six alloys was estimated using the alloy composition, and then the concentration of silicon in the dissolver solution was calculated assuming complete dissolution of the intermetallic phase. As shown in Table VI, the calculated amount of silicon dissolved as U(AI, Si) 3 was nearly the same as the analysis of silicon in solution after dissolution of 
TABLE VI

EFFECT OF DISSOLVED SILICON ON EMULSION STABILIZATION

\begin{tabular}{|c|c|c|c|c|}
\hline $\begin{array}{c}\text { Alloy } \\
\text { Composition }[a] \\
\text { (wt } \%) \\
\text { Uranium-Silicon } \\
\end{array}$ & $\begin{array}{l}\text { Atom } \\
\text { Ratio } \\
(\mathrm{Si} / \mathrm{U})\end{array}$ & $\begin{array}{c}\text { Silicon } \\
(<250 \mathrm{~m} \mu) \\
\text { Determined } \\
(\mu \mathrm{g} / \mathrm{ml}) \\
\end{array}$ & $\begin{array}{l}\text { Estimated } \\
\text { Silicon as } \\
\mathrm{U}(\mathrm{Al}, \mathrm{Si})_{3} \\
(\mu \mathrm{g} / \mathrm{ml}) \\
\end{array}$ & $\begin{array}{l}\text { Coalescence } \\
\text { Time and } \\
\text { Behavior in } \\
\text { Extraction } \\
\end{array}$ \\
\hline $32-0$ & No $\mathrm{Si}$ & 10 & 0 & $90 \mathrm{Sec}$. \\
\hline $0-4.5$ & No U & 14 & 0 & $110 \mathrm{Sec}$. \\
\hline $32-0.6$ & 0.2 & 290 & 260 & Stable Web \\
\hline $22-3$ & 1.1 & 1200 & 1100 & Stable Web \\
\hline $32-3$ & 0.8 & 1550 & 1510 & Stable Emulsion \\
\hline $32-4.5$ & 1.2 & 1700 & 1710 & Stable Emulsion \\
\hline
\end{tabular}

[a] Remainder of alloy is pure aluminum.

each alloy. Since three of the alloys contained excess silicon not present in the intermetallic phase, this calculation clearly demonstrates that silicon dissolves only when it is associated with uranium in the intermetallic phase.

Residues from the alloys with a silicon-to-uranium atom ratio $>1$ contained elemental silicon which had not dissolved. Alloys with an atom ratio <l had little or no residue, indicating that essentially all of the silicon is associated with uranium in the alloy and is dissolved. Residues are discussed in detail in Section V-3.

The electron-beam microprobe data discussed in Section III-4 agree with these dissolution results. According to the microprobe scans, the silicon in the uranium alloys is present primarily in the fuel particles. In the alloys with a silicon-to-uranium atom ratio $>1$, numerous segregations of silicon, not associatea with the fuel particles, are found throughout the aluminum matrix. There are essentially no segregations of silicon in the uranium matrix for the alloys with an atom ratio $<1$.

\subsection{Nature of Emulsion Stabilizer}

A primary objective of this study was to be able to predict poor phase separation in plant operation and, thereby, to avoid it or, if required, treat it. Therefore, considerable effort was devoted to determining the nature of the silicon responsible for the stabilization of emulsions. The turbidity measurements of the solutions showed that the three alloys with atom ratios of silicon to uranium of greater than unity contained the largest quantity of suspended solids with less than $2000 \mathrm{~m} \mu$ diameter. Successive removal of suspended particles down to $35 \mathrm{~m} \mu$ diameter by centrifugation decreased neither the emulsion stabilization nor the amount of dissolved silicon, showing that the surfactancy is not related to the quantity or size of the suspended solids. These 
data are given in Table C-X in Appendix C. Selective determination of the monomer and dimer of silicic acid, presented in Table C-XI, showed that these species do not stabilize the emulsions. According to Iler, (10) the following picture exists after the silicon is dissolved in an acid solution from the intermetallic phase:

\begin{tabular}{|c|c|c|c|c|c|c|}
\hline Mono- \& Di- & Polymeri- & Polysilicic & Polymeri- & Colloidal & Aggre- & Silica \\
\hline Silicic Acid & zation & Acid & zation & Silica & gation & Particles \\
\hline
\end{tabular}

According to our work, the species stabilizing the emulsion is probably polysilicic acid or possibly colloidal silica with less than $35 \mathrm{~m} \mu$ diameter.

Continued polymerization or aggregation will decrease the emulsion stabilization. Although the occurrence of emulsion stabilization during the reprocessing of fuels is not fully understood, this work shows that it is related to the kinetics of polymerization of the dissolved silica. Dissolver solutions which remain at room temperature have essentially the same degree of emulsion stabilization after 2 weeks of standing. Dissolver solutions which form stable emulsions when the dissolution is only partially complete do not form stable emulsions when the dissolution is complete (after about 1 hour of boiling) indicating that continuing the dissolution at the boiling point promotes polymerization and removes the emulsion stabilizer. On the other hand, a dissolver solution containing $1.2 \mathrm{M}$ aluminum, $14.6 \mathrm{~g} /$ liter of uranium, and $1.0 \mathrm{M}$ acid was boiled for 22 hours and tested to determine the change in coalescence behavior. As shown in Table VII, the coalescence behavior became worse after 1 to 4 hours of boiling. The coalescence did improve after 22 hours of boiling, but it still formed a stable web showing that mere boiling did not readily remove the emulsion stabilizer.

TABLE VII

\section{EFFECT OF BOILING ON EMULSION STABILIZATION}

Time at Boiling (Hours)

$\begin{array}{cc}0 & \text { Stable Emulsion } \\ 1 & \text { Became Worse } \\ 4 & \text { Remained Same } \\ 22 & \text { Stable Web }\end{array}$

$\begin{array}{ccc}\text { Coalescence Behavior of a Dissolver Solution During Extraction } \\ \text { No } & 100 \mathrm{ppm} & \text { Solids } \\ \text { Treatment } & \text { Fluoride } & >100 \mathrm{m \mu} \\ \text { Added } & \text { Removed }\end{array}$

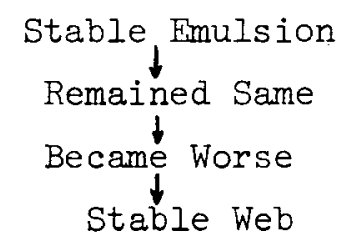

\subsection{Treatments to Prevent Emulsion Stabilization}

Several treatments of the solution were tried to prevent formation of stable emulsions. In one, solids larger than $100 \mathrm{~m} \mu$ diameter were removed by centrifugation to minimize the possibility of dissolving additional silicon during boiling, In another, fluoride ion was added to catalyze the polymerization $(10)$ of polysilicic acid. As shown in 
Table VII, neither of these treatments decreased emulsion stabilization, even with boiling. Iler stated that the rate of polymerization of polysilicic acid is slow at $\mathrm{pH} 2$ to 3 but increases with increased acidity. Data for the three solutions shown in Table VIII were obtained from the same solution after adding $\mathrm{HNO}_{3}$ or $\mathrm{NaOH}$ to adjust the acidity. The solution containing $1.8 \mathrm{M}$ acid was the least objectionable, but it did not improve with time as expected. On the other hand, the solution with a $\mathrm{pH}$ of about 2 and containing no free acid did not form a stable emulsion after 22 hours of boiling, indicating that the greatest amount of polymerization had occurred at this acidity.

\section{TABLE VIII}

EFFECT OF ACIDITY AND TIME OF BOILING ON EMULSION STABILIZATION

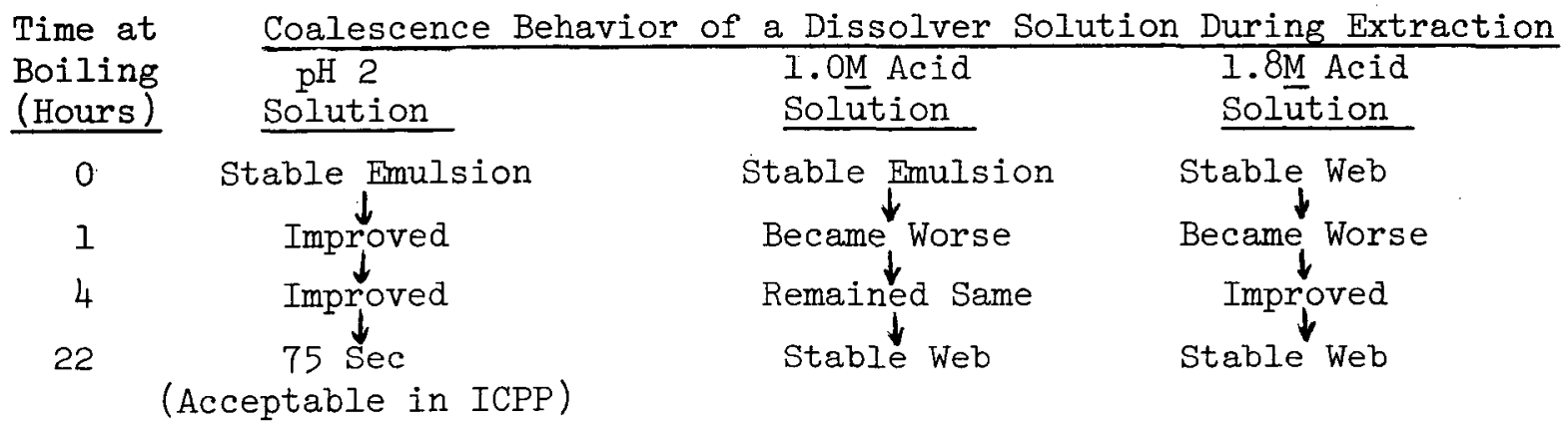

In any case, neither acidifying within limits of plant flowsheets nor simple boiling solves the problem if an emulsion stabilizer is produced during dissolution. In order to understand the process clearly, a better understanding of the kinetics of the polymerization of silicic acid is needed; however, the kinetics are extremely complicated in systems which contain high concentrations of acid and salts. The best way to avoid emulsion stabilization in solutions of alloys containing uranium and silicon, according to current information, is to be certain that the dissolution goes to completion and the temperature is maintained at the boiling point.

Dissolver solutions at ICPP which form stable emulsions are treated at the boiling point a minimum of 15 minutes with $100 \mathrm{\mu g}$ of $\mathrm{Kngx}$ food gelatin per liter, in accordance with a process developed here (9). This successfully prevents the formation of stable emulsions and permits proper operation of the extraction columns. The effect of gelatin upon solutions of the alloys used in this study was examined using a solution which formed a stable web. The addition of $100 \mathrm{\mu g}$ of gelatin per liter greatly improved the coalescence, but $200 \mu \mathrm{g}$ per liter were required to produce coalescence behavior adequate for good plant operation. Earlier work indicated that the quantity of gelatin required is proportional to the degree of emulsion stabilization. This is expected since the degree of emulsion stabilization is related to the dissolved silicon content of the solution according to our current work. 
A number of commerciai additives for coagulating solids in solutions have been studied. Two experimental gelatins which were soluble at $40^{\circ} \mathrm{C}$ were obtained from General Foods Corporation. In the solution tested, no difference in preventing emulsion stabilization was observed between these gelatins and the Knox food gelatin, either at $40^{\circ} \mathrm{C}$ or at the boiling point. Additives tested and found not to be effective include polyethylene chips and Polyhall 19, a coagulant for acid solutions produced by Stein, Hall and Co., Inc.

\section{RESIDUES}

Solids produced during the dissolution of uranium-aluminum-silicon alloys can be divided into three different groups: large particles of elemental silicon, small particles which remain suspended after centrifugation, and the hydrated silica which forms from the polymerization or agglomeration of the dissolved silica. Information about the solids was obtained from three sources. (1) Solutions from the dissolution rate studies were centrifuged and examined visually for solids content. (2) The weight of solids produced during dissolution was determined by separate dissolutions for alloys containing $32 \mathrm{wt} \%$ uranium and 1.5 and $5 \mathrm{wt} \%$ silicon. A limited number of these dissolutions were performed because the solution was extremely difficult to filter. (3) The solids produced in the dissolutions for extraction studies and described in Section V-2 were examined for identification and characterization. The solutions from these incomplete dissolutions were centrifuged at prescribed rates and times immediately following the dissolution, thus separating the solids into fractions of known size. The method of separation and a discussion of the effect of particle composition and density upon size are given in Appendix C.

The X-ray analyses for solids from the extraction dissolutions are presented in Table IX for the composite residue removed by centrifugation

TABLE IX

\section{RESIDUES[a] FROM INCOMPLETE DISSOLUTION OF ALLOYS}

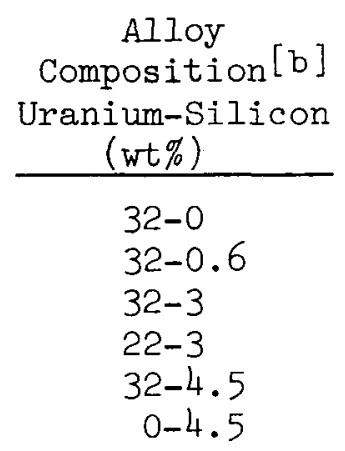

\begin{tabular}{l}
$\begin{array}{l}\text { Atom } \\
\text { Ratio } \\
(\mathrm{Si} / \mathrm{U})\end{array}$ \\
\hline No Si \\
0.2 \\
0.8 \\
1.2 \\
1.2 \\
No U
\end{tabular}

Residue Composition by X-Ray Diffraction

No precipitate No precipitate $\mathrm{U}(\mathrm{AI}, \mathrm{Si})_{3}$ $\mathrm{Si}, \mathrm{U}(\mathrm{Al}, \mathrm{Si})_{3}$ $\mathrm{Si}, \mathrm{U}(\mathrm{Al}, \mathrm{Si})_{3}$ $\mathrm{Si}$

[a] Residues represent composite of particles separated by the 3 centrifugations, (ie, >2000 $\mathrm{m \mu},>250 \mathrm{m \mu}$, and $>35 \mathrm{m \mu}$ in diameter), immediately following the dissolution of the alloy.

[b] Remainder of alloy is pure aluminum. 
for four hours at 30,000 times the force of gravity. This centrifugation removes all particles with a diameter of greater than $35 \mathrm{m \mu}$ and a particle density of two. These data show that residues from alloys having a silicon-to-uranium atom ratio $>I$ will all contain elemental silicon. In alloys having atom ratios $<I$, the silicon is entirely dissolved and no elemental silicon was found. In some cases, undissolved particles of the uranium-aluminum intermetallic were found because the dissolutions were incomplete.

\subsection{Residues of Elemental Silicon}

The elemental silicon residues are produced from the silicon which exceeds one atom per atom of uranium and, according to this work, which is segregated in the aluminum matrix. More than $95 \%$ of the elemental silicon has a diameter $>2000 \mathrm{m \mu}$ and is readily centrifuged from the solution with 1000 times the force of gravity in two minutes. After centrifugation, the solids were one to two volume percent of the solutions from aluminum alloys containing 5 and $11 \%$ silicon and no uranium; the corresponding uranium-aluminum alloys had considerably less volume of the dense elemental silicon residue because some of the silicon had dissolved. In dissolver solutions of uranium alloys, the elemental silicon residue is partially flocculated by colloidal silica after standing at room temperature for two months. The quantity of the dense silicon precipitate can be estimated in uranium-aluminum-silicon alloys by calculating the quantity of silicon present in the alloy in excess of one atom of silicon per atom of uranium. In alloys which do not contain uranium, essentially all of the silicon will remain as this type of residue.

\subsection{Residues of Silica}

The second group of solids which are of interest to the process is produced by polymerization or agglomeration of the dissolved silica. These solids originate from the silicon associated with the uranium in the fuel particles and dissolved as described in Section V-2. The quantity of these solids is related to the amount of soluble silicon in the alloy, that is, the quantity of silicon associated with uranium in the fuel particles. When the solutions are first prepared, this silica will not centrifuge easily from the solution. Figure 6 is a photo of particles which have been centrifuged to include diameters of $<2 \mu$ and $>35 \mathrm{~m} \mu$ in size, reslurried in water, and collected on a $0.3 \mu$ membrane filter. The large globules of hydrated silica visible on the membrane filter, however, measured $25 \mu$ in size, showing that either the globules had not centrifuged from the solution or they had agglomerated into larger particles after the centrifugation. The solutions are difficult to filter prior to agglomeration, and filters plug with a gel-like coating even though the solutions are centrifuged to remove solids far smaller than the pore size of the filter. The dry filtered precipitate weighs three times the weight of silicon in the original alloy for the alloy containing 32 wt \% uranium and 5 wt \% silicon. The silica may polymerize and agglomerate during the dissolution or with the passing of time, and the gelatinous precipitate formed will centrifuge from the solution. After centrifugation, this gelatinous precipitate may be as high as 20 volume 
percent of the solution. Interestingly, the volume percent of gelatinous silica appeared to be the same for uranium alloys having different silicon contents. This gelatinous silica contained up to $15 \%$ of the uranium and, therefore, the centrifugation of solutions containing dissolved silica may lead to high uranium losses unless the solution is given additional treatment. Gelatin treatment has been an accepted method to insure agglomeration of this type of solid both to improve filtration $(4)$ and to prevent emulsion stabilization $(9)$. However, neither the quantity and type of solid nor the uranium retention has been studied for centrifugation of the gelatin-treated solution.

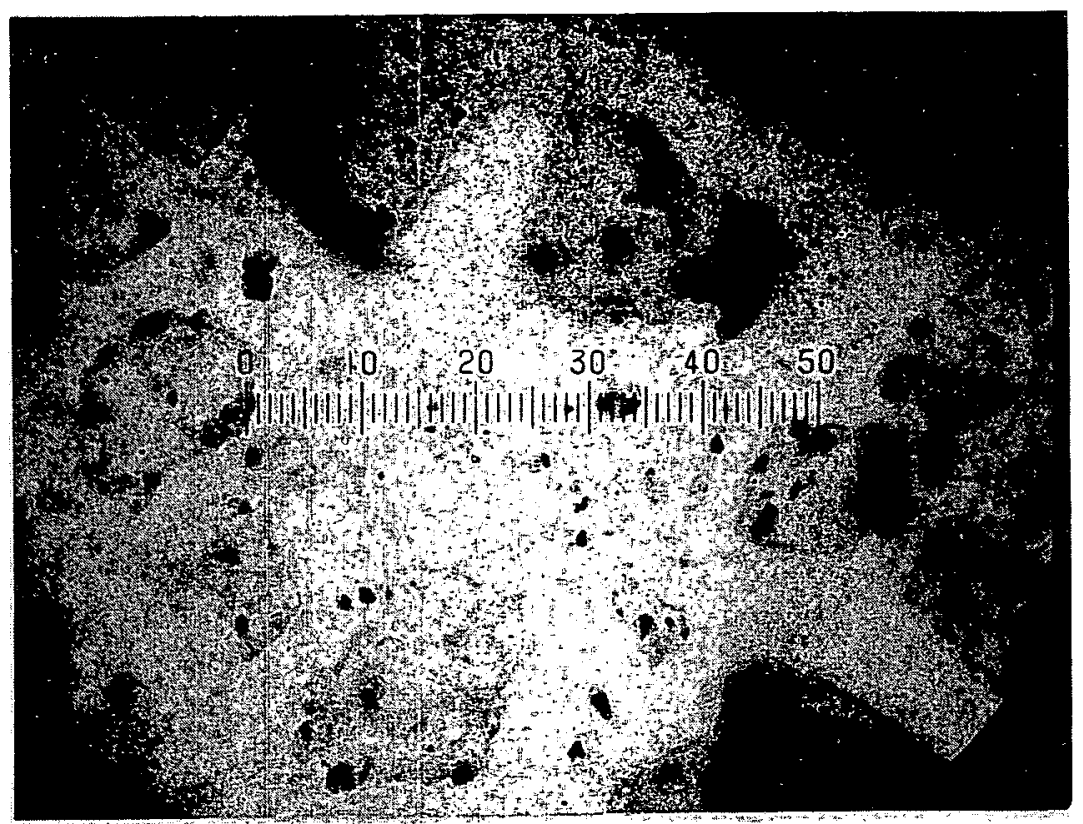

Figure 6 Residues of particles separated by centrifugation to include diameters $<2 \mu$ and $>35 \mathrm{~m} \mu$; globules of polymerized silica up to $25 \mu$ are seen.

\subsection{Small Suspended Residues}

The third group of solids remains suspended after centrifugation. As shown in Appendix C, Section 2.3, these solids do not affect emulsion stabilization during extraction. The solutions from alloys containing a silicon-to-uranium atom ratio $>1$ contain the largest quantity of particles. The particles in these solutions are mostly elemental silicon with diameters between $2000 \mathrm{m \mu}$ and $250 \mathrm{m \mu}$. All solutions produced by incomplete dissolutions contain suspended particles of undissolved alloy which are particularly rich in uranium. As pointed out in the discussion of the dissolution of the alloys (Section $\mathrm{V}-1.3$ ), the undissolved alloy particles can create a criticality hazard if the dissolution is not completed. The examination of the suspended solids by light scattering photometry is discussed in Appendix $C$. 


\section{CONCLUSIONS}

The silicon present in uranium-aluminum alloys in excess of one atom of silicon per atom of uranium is segregated as elemental silicon in the aluminum matrix according to both $X$-ray diffraction and electron-beam microprobe analysis. This excess silicon increases the strength of the alloy. Silicon present in atom ratios $<1$ combines with the intermetallic phase, reducing the strength with increasing silicon content until a silicon-to-uranium atom ratio near unity is reached.

This work has shown that silicon content has the following effects on the reprocessing of uranium-aluminum fuel:

(1) Dissolution rates are related to the metallurgical compositions of the alloys, which, to some degree, are related to the silicon content of the fuel; however, all dissolution rates are adequate for the reprocessing of the alloys studied.

(2) The silicon present at an atom ratio of silicon to uranium $<1$ is present in the alloy as the intermetallic phase $\mathrm{U}(\mathrm{Al}, \mathrm{Si})_{3}$; this silicon dissolves and is responsible for the emulsion stabilization which causes poor phase separation during the extraction of uranium. The emulsion stabilization was found to be due to either polysilicic acid or colloidal silica particles with $<35 \mathrm{~m} \mu$ diameter formed from the dissolved silicon. Even a small amount of this emulsion-stabilizing species of silicon can produce solutions which require gelatin treatment to improve coalescence behavior; therefore, an increase in silicon concentration in the alloy does not appear to cause increased difficulty from this standpoint. When sufficient polymerization occurs to produce larger particles in the dissolver solution, as is often the case in completed dissolutions, emulsion stabilization is not a problem.

(3) Silicon present at an atom ratio of silicon to uranium. $>1$, or present in aluminum alloys containing no uranium, does not dissolve and, therefore, does not cause emulsion stabilization. Residues of elemental silicon resulting from dissolution of alloys with atom ratios of silicon to uranium $>1$ are dense and are readily removed by centrifugation Gelatin treatment would probably be required to remove particles of silica formed from the polymerization of dissolved silica; the removal of these solids has not been necessary in the operation at ICPP, but fuels containing higher concentrations of soluble silica will produce larger quantities of this type of solid.

This work has shown the relationship between the metallurgy of the fuel and its behavior during reprocessing. Accordingly, synthetic solutions merely containing the proper ratio of chemical elements are not adequate for the study of the effect of silicon in reprocessing; solutions comparable to process solutions must be produced by dissolving 
uranium-aluminum-silicon alloys. When information is available on the metallurgy of fuels with high burn-up, the behavior of irradiated uranium-aluminum fuels in reprocessing can be predicted more accurately. On the other hand, understanding of the metallurgy of both irradiated and non-irradiated fuels can be greatly assisted by chemical techniques such as are introduced in this work.

In summary, some silicon is needed to stabilize the UAl3 phase in uranium-aluminum alloys. Up to a silicon-to-uranium atom ratio of about one, increasing the silicon content decreases the tensile strength of the alloy and makes fabrication easier without greatly increasing the problems in reprocessing. The addition of silicon at $>l$ atom per atom of uranium, however, does not improve properties of the alloy for fabrication; therefore, the addition should be kept below this amount as this excess silicon adds to the bulk of the solids to be processed. Likewise, silicon in the cladding and side plates of the elements should be kept to a minimum to reduce the bulk of solids in process streams. 
VII. REFEREITES

1. W. C. Thurber and R. J. Beaver, Development of Silicon-Modified 48 wt $\%$ U-AI Alloys for Aluminum Plate-Type Fuel Elements, ORNL-2602 (March 1959).

2. O. W. Parrett and K. L. Rohde, The Effect of Silicon in the Reprocessing of Uranium-Aluminum AIloy, IDO-14441 (November 1958).

3. H. J. Groh, Removal of Silica from Solutions of Nuclear Fuel, DP-293 (June 1958).

4. B. J. Newby and B. E. Paige, A Gelatin-Filtration Headend for Fuel Reprocessing Solutions from Silicon-Containing Aluminum Alloys, IDO-14468 (JuIy 1959).

5. R. D. Cannon, Characterization of Surfactants in Aluminum-Uranium Fuel Reprocessing Solutions, IDO-14489 (October 1959).

6. K. R. Van Horn, Editor, Aluminum, Vol. I, Properties, Physical Metallurgy and Phase Diagrams, Am. Soc - for Metals, p. 199-200 $(1967)$.

7. 0. W. Parrett, The Determination of Excessive Emulsification by Coalescence Behavior Measurements, IDO-14486 (November 1959).

8. R. D. Fletcher, M. E. Jacobson, and H. R. Beard, Effect of Alloying Constituents on Aluminum Dissolution Rates, IDO-14606 (April 1963).

9. B. E. Paige, K. I. Rohde, and B. J. Newby, Liquid-Suspension Extraction Process, U. S. Patent \#3,154,376 (1964).

10. R. K. Iler, The Colloid Chemistry of Silica and Silicates, p. 44 , Cornell University Press, Ithica, New York (1955). 
APPENDICES CONTENTS

APPENDIX A--DETAILS OF THE COMPOSITION OF URANIUM-ALUMINUM-SILICON

AND ALUMINUM-SILICON ALLOYS. . . . . . . . . . . . . . . 33

1. CHEMICAL ANALYSIS. . . . . . . . . . . . . . 35

2. RADIOGRAPHIC AND METALLOGRAPHIC EXAMINATION. • . . . . 36

2.1 Radiographic Results. . . . . . . . . . . . . . . 36

2.2 Metallographic Results. . . . . . . . . . . 42

3. METALLURGICAL DESCRIPTION OF FUEL PARTICLES. . . . . . 57

APPENDIX B--MECHANICAL PROPERTIES OF URANIUM-ALUMINUM-SILICON

ALLOYS . . . . . . . . . . . . . . . . . . 59

APPENDIX C--EFFECT OF SILICON IN URANIUM-ALUMINUM FUEL ON CHEMICAL

REPROCESSING . . . . . . . . . . . . . . 63

1. DISSOLUTION RATES. . . . . . . . . . . . . . . 65

1.I Dissolution Data and Calculations of Instantaneous

Rates . . . . . . . . . . . . . . . . 65

1.2 Difference in Dissolution Rate of Aluminum and

Uranium . . . . . . . . . . . . . . . 65

1.3 Behavior of Dissolved Silicon During Dissolution. . . 82

2. EXTRACTION STUDIES . . . . . . . . . . . . . 83

2.I Emulsion Stabilization in Dissolver Product Solutions 83

2.2 Acidity of Dissolver Solution and Surfactancy . . . . 84

2.3 Nature of Silicon Species Causing Stable Emulsion . . 84

3. RESIDUES .................... . . 86

3.1 Separation of Solids According to Particle Size . . 86

3.2 Examination of Suspended Solids by Light Scattering

Photometery ............... 87 


\section{APPENDICES FIGURES}

APPENDIX A

A-l Positive prints of radiographs of 0.1 -inch thick hot-rolled slabs of aluminum alloy containing 22 wt $\%$ uranium and differing amounts of silicon. . . . . . . . . . . . . . . 37

A-2 Comparison of positive prints of radiographs of aluminum alloy containing 22 and $32 \mathrm{wt} \%$ uranium made without silicon additions 38

A-3. Comparison of positive prints of radiographs of aluminum alloy containing 22 and 32 wt $\%$ uranium and 3 wt \% silicon. . . . . . 39

A-4 Positive prints of radiographs of center sections of aluminum alloy containing $32 \mathrm{wt} \%$ uranium showing effect of silicon addition. ...................... . . 40

A-5 Comparison of positive prints of radiographs of aluminum alloy containing $32 \mathrm{wt} \%$ uranium and $3 \mathrm{wt} \%$ silicon in which silicon was added by two different methods. . . . . . . . . . . 4 I

A-6 Structure of as-rolled slab of aluminum alloy containing $22 \mathrm{wt} \%$ uranium with no silicon (Heat 1). . . . . . . . . . . 43

A-7 Structure of as-rolled slab of aluminum alloy containing 22 w.t uranium and 3 wt \% silicon (Heat 2). . . . . . . . . . . . 44

A-8 Structure of as-rolled slab of aluminum alloy containing 22 wt\% uranium and 4.5 wt\% silicon (Heat 3)............ . 45

A-9 Structure of as-rolled slab of aluminum alloy containing. 32 wt\% uranium with no silicon addition (Heat 4) . . . . . . . 46

A-10 Structure of as-rolled slab of aluminum alloy containing 32 wt uranium and $0.1 \mathrm{wt} \%$ silicon (Heat 5). ......... . 47

A-ll Structure of as-rolled aluminum alloy containing 32 wt $\%$ uranium and 0.6 wt $\%$ silicon (Heat 6). . . . . . . . . . . 48

A-12 Structure of as-rolled aluminum alloy containing. 32 wt $\%$ uranium and 1.3 wt\% silicon (Heat 7). . . . . . . . . . . . 49

A-13 Structure of as-rolled aluminum alloy containing 32 wt $\%$ uranium and 3 wt\% silicon (Heat 8 ). . . . . . . . . . . . 50

A-I.4 Structure of as-rolled ailuminum aliloy containing 32 wto uranium and 3: wt\% silicon (Heat 9a) . . . . . . . . . . . . . . 51

A-15 Structure of as-rolled aluminum alloy containing, 32 wt $\%$ uranium and 3 wt $\%$ silicon (Heat $9 \mathrm{~b}$ ) . . . . . . . . . . . . . 52

A-16 Structure of as-rolled aluminum alloy containing $32 \mathrm{wt} \%$ uranium and 3 wt $\%$ silicon (Heat 9c) . . . . . . . . . . . . 53

A-17 Structure of as-rolled aluminum alloy containing $32 \mathrm{wt} \%$ uranium and 3 wt\% silicon (Heat 9d) . . . . . . . . . . . . 54

A-18 Structure of as-rolled aluminum alloy containing 32 wt\% uranium and 3 wt $\%$ silicon (Heat 9e) . . . . . . . . . . . 55 


\section{APPENDICES FIGURES (cont.)}

A-19 Structure of as-rolled aluminum alloy containing 32 wt $\%$ uranium and $4.5 \mathrm{wt} \%$ silicon (Heat 10). . . . . . . . . . . 56

A-20 Relationship of silicon-to-uranium atom ratio to lattice parameter of $\mathrm{UAl}_{3}$ phase. . . . . . . . . . . . . . . 58

APPENDIX C

C-1 Aluminum and nitric acid concentration during dissolution of aluminum ................... 66

C-2 Aluminum and nitric acid concentration during dissolution of aluminum alloy containing 0.6 wt $\%$ silicon. . . . . . . . . 67

C-3 Aluminum and nitric acid concentration during dissolution of aluminum alloy containing 1.3 wt $\%$ silicon. . . . . . . . 68

C-4 Aluminum and nitric acid concentration during dissolution of aluminum alloy containing 4.5 wt\% silicon. . . . . . . . 69

C-5 Aluminum and nitric acid concentration during dissolution of aluminum alloy containing 10.5 wt \% silicon . . . . . . . 70

C-6 Aluminum and nitric acid concentration during dissolution of aluminum alloy containing $22 \mathrm{wt} \%$ uranium and 0 wt $\%$ silicon . . 71

C-7 Aluminum and nitric acid concentration during dissolution of aluminum alloy containing 22 wt $\%$ uranium and 3 wt $\%$ silicon . .72

C-8 Aluminum and nitric acid concentration during dissolution of aluminum alloy containing 22 wt $\%$ uranium and 4.5 wt $\%$ silicon . 73

C-9 Aluminum and nitric acid concentration during dissolution of aluminum alloy containing 32 wt\% uranium and 0 wt\% silicon. . 74

C-10 Aluminum and nitric acid concentration during dissolution of aluminum alloy containing $32 \mathrm{wt} \%$ uranium and $0.6 \mathrm{wt} \%$ silicon .75

C-ll Aluminum and nitric acid concentration during dissolution of aluminum alloy containing 32 wt $\%$ uranium and 1.3 wt $\%$ silicon . 76

C-12 Aluminum and nitric acid concentration during dissolution of aluminum alloy containing 32 wt \% uranium and 3 wt \% silicon . . 77

C-13 Aluminum and nitric acid concentration during dissolution of aluminum alloy containing $32 \mathrm{wt} \%$ uranium and $4.5 \mathrm{wt} \%$ silicon . 78 


\section{APPENDICES TABLES}

APPENDIX A

A-I Average Chemical Analysis for Three Coupons From Top, Middle, and Bottom of Rolled Alloy Slabs. . . . . . . . . 35

A-II Weight Percent Impurity in Alloy by Emission Spectroscopy . 36 APPENDIX B

B-I Mechanical Properties of Uranium-Aluminum Alloys Containing 22 and 32 wt\% Uranium With and Without Silicon Additions. . 62

APPENDIX C

C-I Multiplicate Dissolution Rate Data for Alloy Coupons in Boiling $\left(103^{\circ} \mathrm{C}\right)$ Nitric Acid . . . . . . . . . . 79

C-II Uranium Concentration in Solution During Dissolution of Aluminum-Uranium-Silicon Alloys . . . . . . . . . . 80

C-III Relative Percent of Aluminum and Uranium Dissolved During Dissolution of 22 wt\% Uranium Alloy. . . . . . . . . . 81

C-IV Relative Percent of Aluminum and Uranium Dissolved During Dissolution of 32 wt\% Uranium Alloy . . . . . . . . 81

$\mathrm{C}-\mathrm{V}$ Silicon Concentration in Solution During Dissolution of Aluminum Alloys Containing No Uranium . . . . . . . . . . 82

C-VI Silicon Concentration in Solution During Dissolution of Aluminum Alloys Containing $32 \%$ U. . . . . . . . . 82

C-VII Silicon Concentration in Solution During Dissolution of Aluminum Alloy Containing 32\% Uranium and 3\% Silicon. . . . 83

C-VIII Coalescence Time for Dissolver Solutions Stored One to Two Months at Room Temperature. . . . . . . . . 84

C-IX Effect of Acidity on Emulsion Stabilization . . . . . . 85

C-X Effect of Centrifugation on Emulsion Stabilization and Silicon Content in Solutions of Dissolved Alloy . . . . . . . . 85

C-XI Effect of Mono- and Di-Silicic Acid on Emulsion Stabilization ................. . 86

C-XII Light Scattering Data for Suspended Solids. . . . . . 88 
APPENDIX A

DETAILS OF THE COMPOSITION OF URANIUM-ALUMINUM-SILICON AND ALUMINUM-SILICON ALLOYS 
DETAILS OF THE COMPOSITION OF URANIUM-ALUMINUM-SILICON AND ALUMINUM-SILICON ALLOYS

\section{CHEMICAL ANALYSIS}

Samples selected from the top, middle, and bottom of the rolled sheet of each alloy were dissolved and analyzed for aluminum, uranium and silicon by wet chemical methods. The average values for the analyses for the three samples of each alloy are given in Table A-I together with. the nominal values used to identify the alloys in the body of the report. These nominal values are the average values for all alloys with the same level of the particular component. Table A-II contains the average value for the spectrographic analyses of the impurities in the same three samples of each alloy.

\section{TABLE A-I}

AVERAGE CHEMICAL ANALYSES FOR THREE COUPONS FROM TOP, MIDDLE, AND BOTTOM OF ROLLED ALLOY SLABS

\begin{tabular}{|c|c|c|c|c|c|c|}
\hline \multirow[t]{2}{*}{ Heat } & \multirow{2}{*}{$\begin{array}{l}\text { Aluminum } \\
\text { Content } \\
\text { (wt \%) } \\
\end{array}$} & \multicolumn{2}{|c|}{$\begin{array}{l}\text { Uranium Content } \\
(\mathrm{wt} \%) \\
\end{array}$} & \multicolumn{2}{|c|}{$\begin{array}{l}\text { Silicon Content } \\
(\mathrm{wt} \%) \\
\end{array}$} & \multirow{2}{*}{$\begin{array}{l}\text { Atom } \\
\text { Ratio } \\
\text { (Si/U) }\end{array}$} \\
\hline & & Nominal & Actual & Nominal & Actual & \\
\hline 1 & 78.9 & 22 & 22.4 & 0 & 0.08 & -- \\
\hline 2 & 74.3 & 22 & 22.6 & 3 & 3.02 & 1.19 \\
\hline 3 & 72.6 & 22 & 22.8 & 4.5 & 4.89 & 1.85 \\
\hline 4 & 69.4 & 32 & 31.3 & 0 & $<0.08$ & -- \\
\hline 5 & 69.3 & 32 & 31.1 & 0.1 & 0.10 & 0.03 \\
\hline 6 & 68.3 & 32 & 31.2 & 0.6 & 0.64 & 0.18 \\
\hline 7 & 66.5 & 32 & 31.5 & 1.3 & 1.38 & 0.37 \\
\hline 8 & 66.2 & 32 & 31.5 & 3 & 2.98 & 0.81 \\
\hline $9 a$ & 64.4 & 32 & 33.0 & 3 & 2.85 & 0.73 \\
\hline $9 b$ & 65.2 & 32 & 32.5 & 3 & 2.96 & 0.77 \\
\hline $9 c$ & 65.3 & 32 & 32.4 & 3 & 3.03 & 0.80 \\
\hline $9 d$ & 65.3 & 32 & 32.2 & 3 & 3.03 & 0.80 \\
\hline $9 e$ & 67.0 & 32 & 31.0 & 3 & 2.84 & 0.85 \\
\hline 10 & 63.0 & 32 & 32.7 & 4.5 & 4.48 & 1.16 \\
\hline II & 99.4 & 0 & 0 & 0.6 & 0.49 & -- \\
\hline 12 & 99.5 & 0 & 0 & 1.3 & 1.20 & -- \\
\hline 13 & 96.4 & 0 & 0 & 4.5 & 4.33 & -- \\
\hline 14 & 89.5 & 0 & 0 & 10.5 & 10.53 & -- \\
\hline
\end{tabular}


TABLE A-II

WEIGHT PERCENT IMPURITIES IN ALLOY

BY EMISSION SPECTROSCOPY

0\% Uranium Alloys

Silicon

(wt \%)

$\mathrm{Cu}$

$\mathrm{Fe}$

$\mathrm{Mg}$

$\underline{M n}$

0.6

1.3

4.5

.002

.013

.003

.002

$<.01$

.005

.002

.01

.008

10.5

Average

$<.002$

$\frac{.03}{.01} \quad \frac{.01}{.008}$

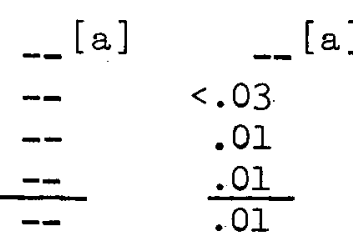

$22 \%$ Uranium Alloys

Silicon

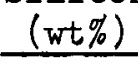

$\mathrm{Cu}$

Fe

$\underline{\mathrm{Mg}}$

0

3.0

4.5

.001

.01

.002

.003

.013

.002

Average

.01

$\frac{.0095}{.01}$

$\frac{.01}{.004}$

\section{2\% Uranium Alloys}

Silicon

\begin{tabular}{|c|c|c|c|c|c|}
\hline$(w t \%)$ & $\mathrm{Cu}$ & $\mathrm{Fe}$ & $\mathrm{Mg}$ & $\mathrm{Mn}$ & $\mathrm{Ni}$ \\
\hline 0 & .001 & .012 & .002 & $-\ldots$ & -- \\
\hline 0.6 & .003 & .03 & .01 & .002 & .01 \\
\hline 1.3 & .006 & .03 & .01 & .002 & .04 \\
\hline 3.0 & .003 & .04 & .01 & .001 & .01 \\
\hline 4.5 & .003 & .04 & .02 & .001 & .02 \\
\hline Average & .003 & .04 & .01 & .001 & .02 \\
\hline
\end{tabular}

[a] Indicates sought and not found.

\section{RADIOGRAPHIC AND METALLOGRAPHIC EXAMINATION}

\subsection{Radiographic Results}

Figures A-I through A-5 show positive prints of the radiographs taken through the center sections of the as-rolled slabs of uraniumaluminum alloys. Inspection of the radiograph prints in Figure A-I shows that the apparent grain size increases as the silicon content is increased in the alloys containing $22 \mathrm{wt} \%$ uranium. The amount of edge cracking is at a minimum when the silicon content is three percent. 


\section{○}

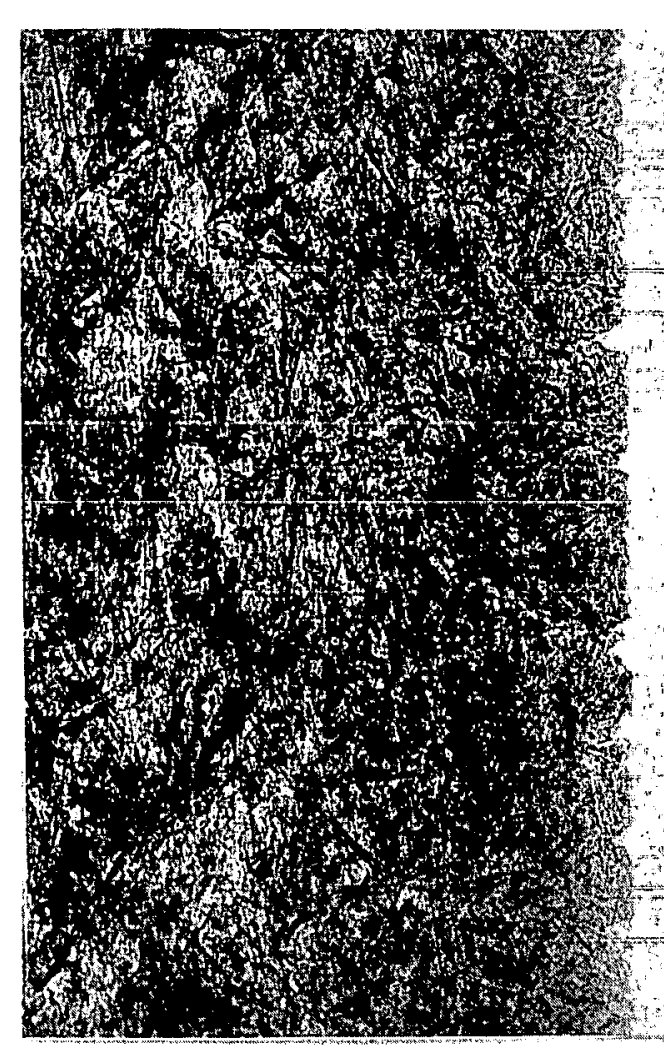

No Si (Heat I)

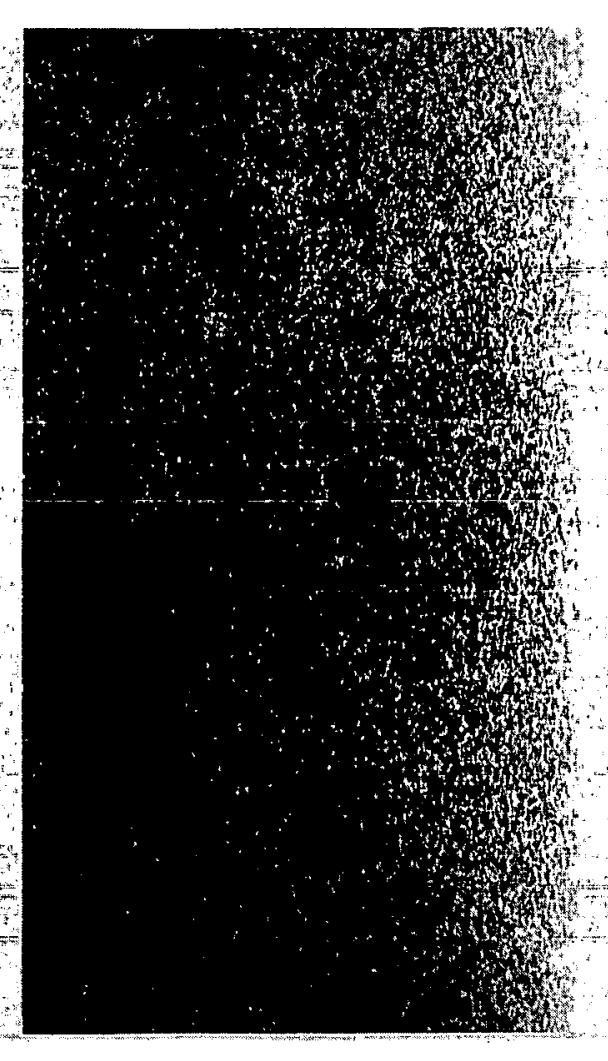

3 wt $\%$ Si (Heat 2)

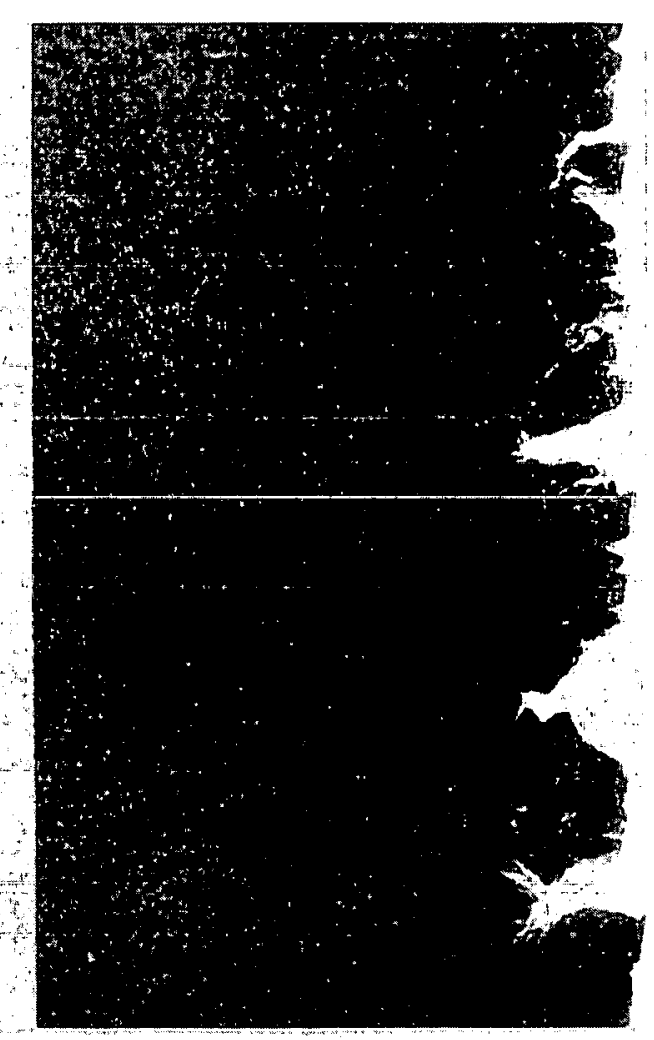

4.5 wt $\%$ Si (Heat 3 )

Figure A-I Positive prints of radiographs of 0.1 -inch thick hot-rolled slabs of aluminum alloy containing 22 wt $\%$ uranium and differing amounts of silicon. (Photo reduced $60 \%$ in size). 


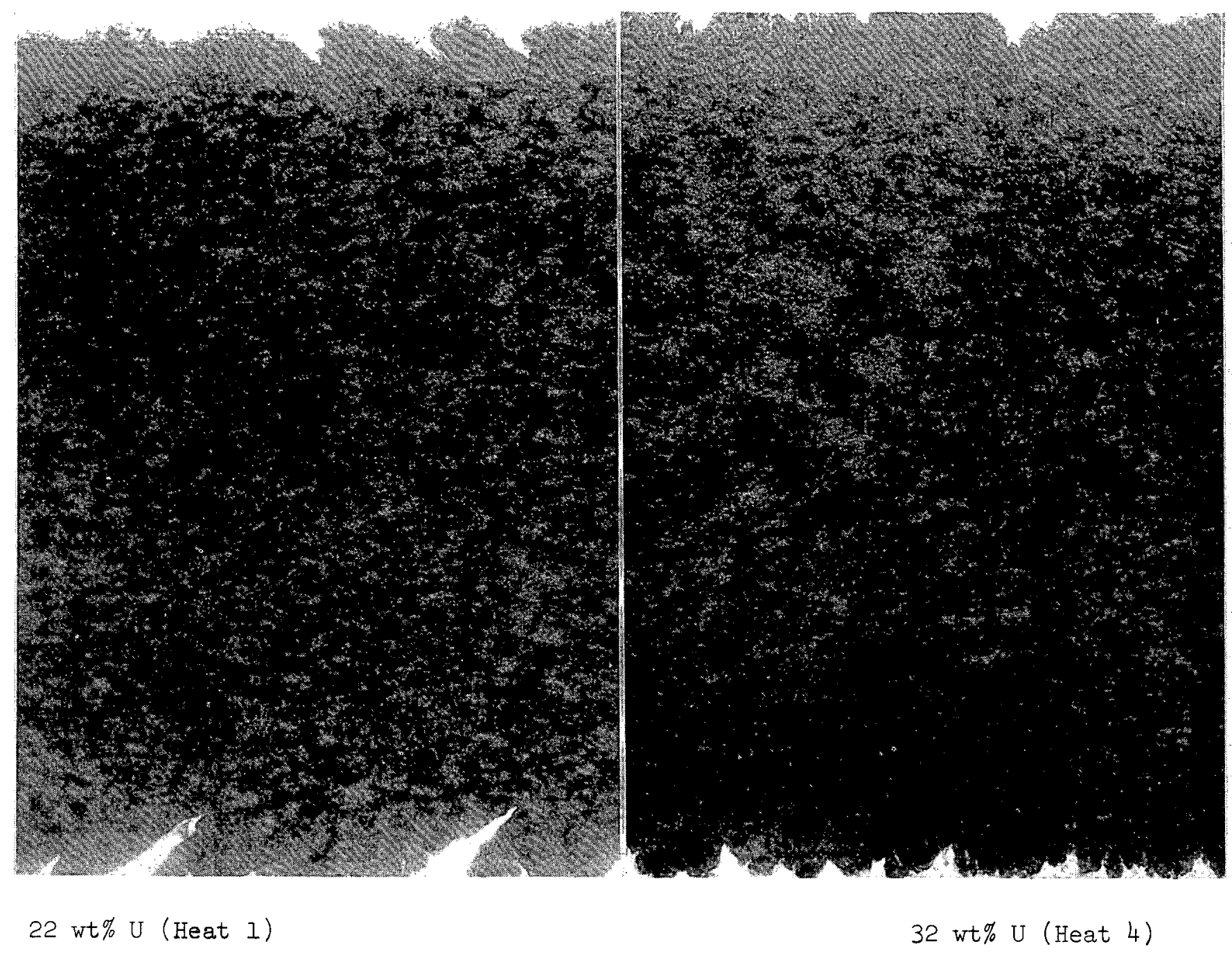

Figure A-2 Comparison of positive prints of radiographs of aluminum alloy containing 22 and 32 wt\% uranium made without silicon additions. (Photo reduced $60 \%$ in size.) 


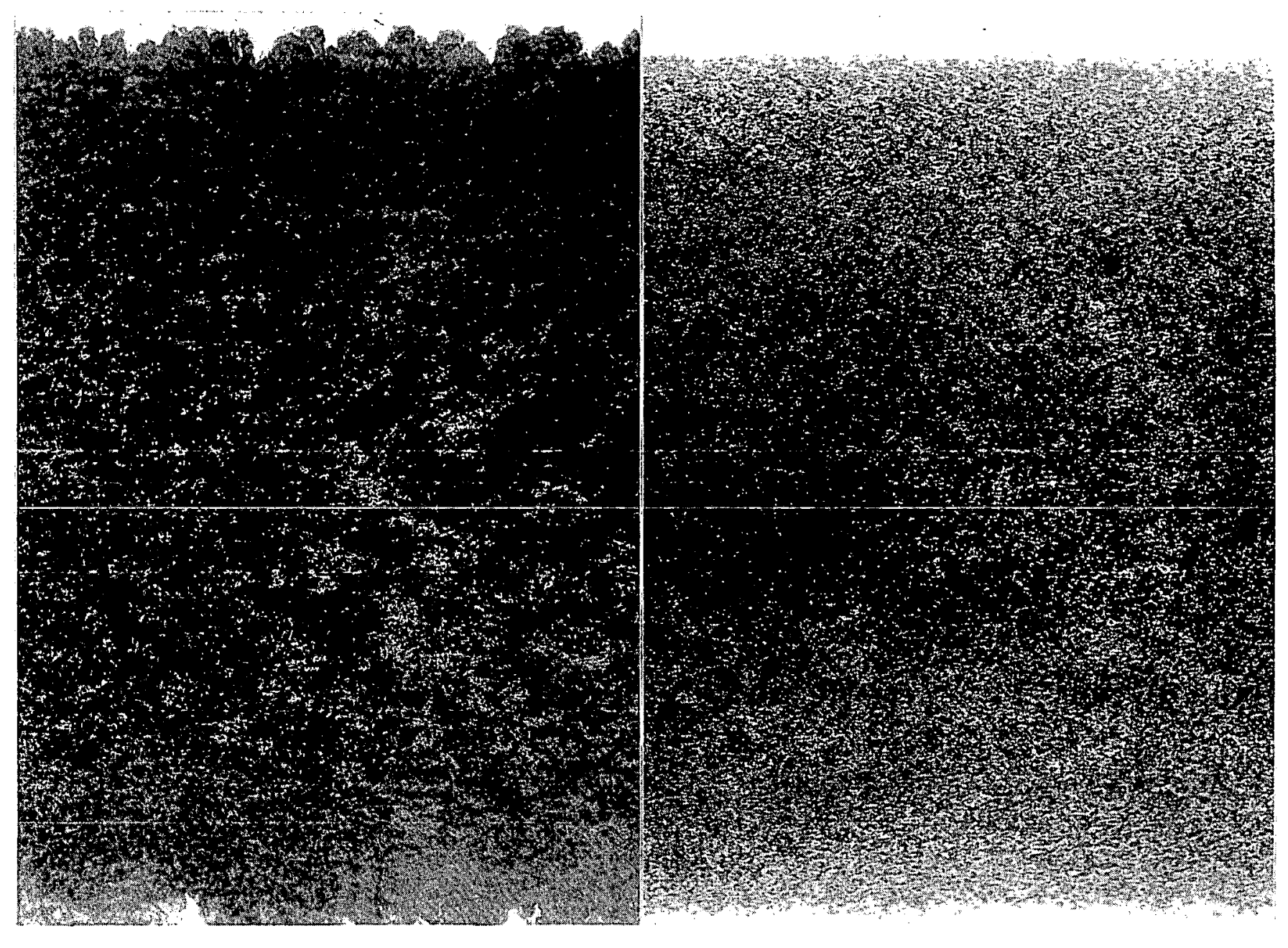

$22 w t \% U+3 w t \%$ Si (Heat 2)

$32 w t \% U+3 w t \%$ Si (Heat 8)

Figure A-3 Comparison of positive prints of radiographs of aluminum alloy containing 22 and 32 wt\% uranium and $3 \mathrm{wt} \%$ silicon. (Photo reduced $60 \%$ in size.) 

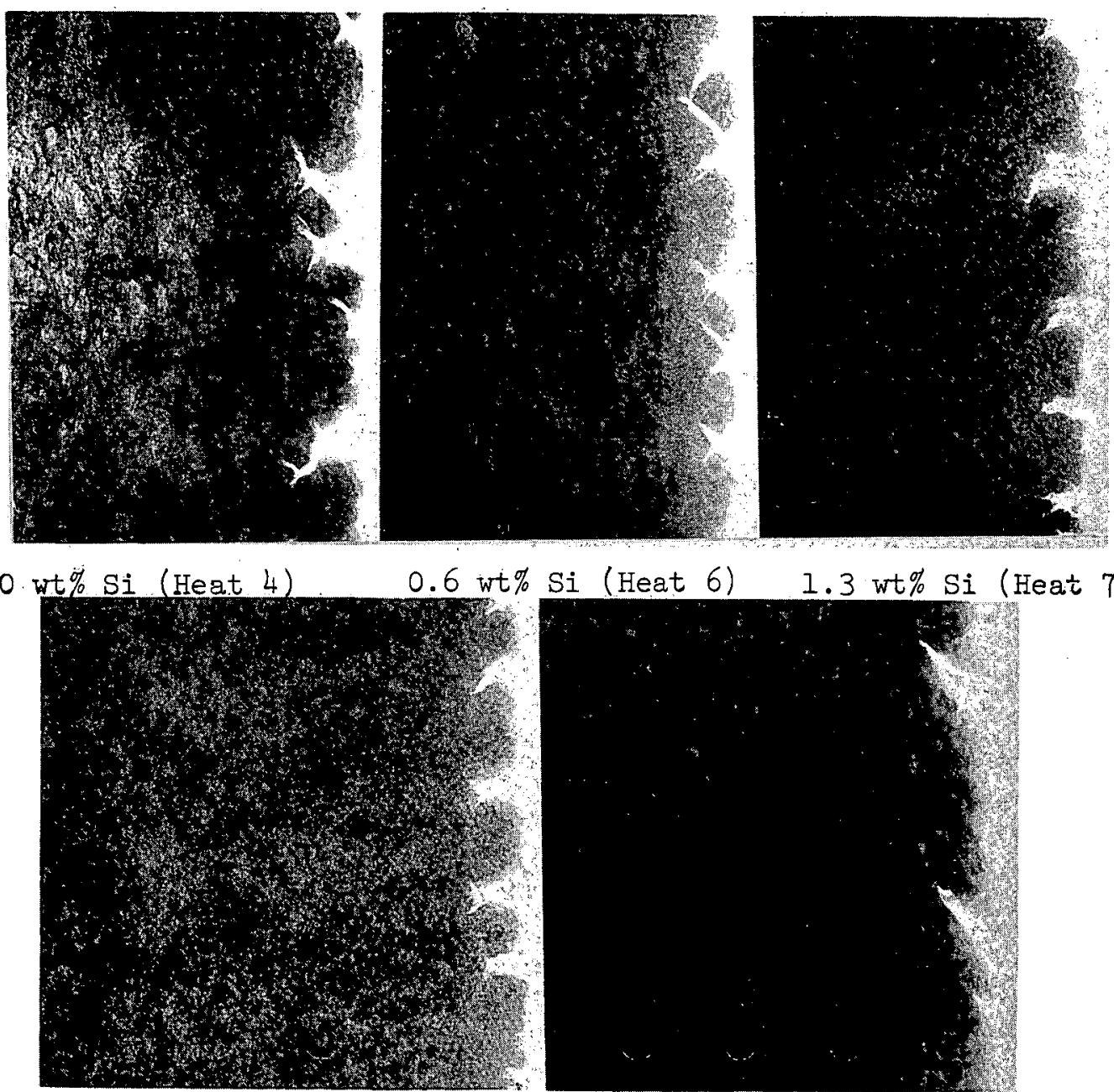

$3 \mathrm{wt} \% \mathrm{Si}$ (Heat 9c)

$4.5 \mathrm{wt} \% \mathrm{Si}$. (Heat 10)

Figure A-4 Positive prints of radiographs of center sections of aluminum alloy containing 32 wt\% uranium showing effect of silicon addition. (Photo reduced $60 \%$ in size.) 


\section{○}

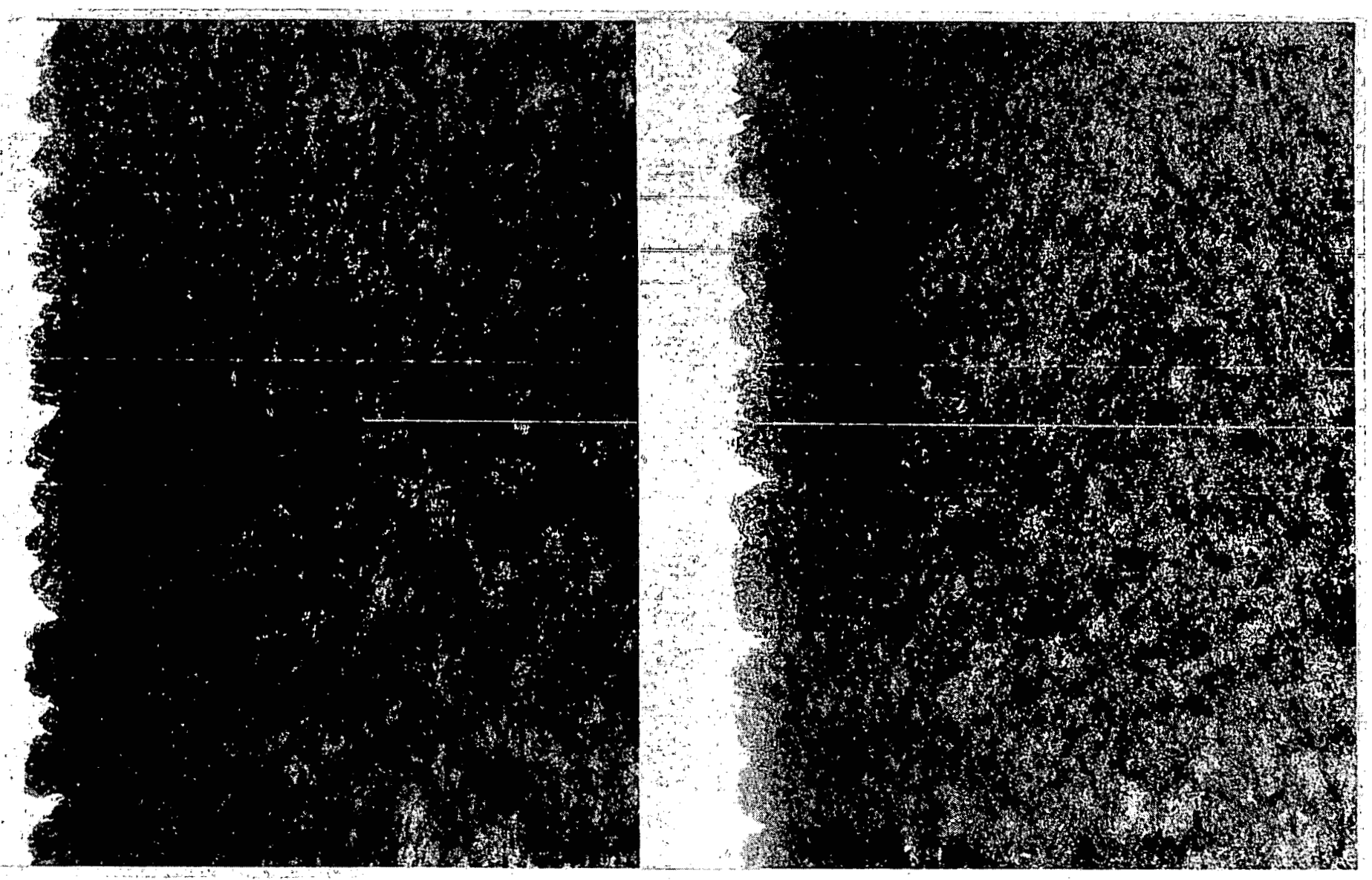

Silicon added as Si-Al hardener (Heat 8)

Silicon added as elemental silicon (Heat 9)

Figure A-5 Comparison of positive prints of radiographs of aluminum alloy containing 32 wt $\%$ uranium and 3 wt $\%$ silicon in which silicon was added by two different methods. (Photo reduced 60\% in size.) 
Figure A-2 shows the positive prints of center sections of hot rolled slabs of aluminum alloys containing 22 and $32 \mathrm{wt} \%$ uranium which do not contain silicon. Both slabs are fine grained with considerable amounts of edge cracking; the extent of cracking is greater in the alloy with the higher uranium content. The radiograph prints shown in Figure A-3 compare similar alloys in which $3 \%$ silicon addition was made. The alloy containing $22 \mathrm{wt} \%$ uranium is fairly fine grained and shows little edge cracking. The alloy containing $32 \mathrm{wt} \%$ uranium shows more edge cracking and is coarser grained.

Figure A-4 shows radiograph prints made on rolled slabs of aluminum alloys containing 32 wt\% uranium and with silicon contents ranging from 0 to $4.5 \%$. The results indicate that the silicon additions to alloys containing the higher uranium concentration have no marked effect on the amount of edge cracking produced in the slabs during hot rolling. The addition of silicon does make the radiographs of the slabs appear to be more grainy indicating that micro segregation of uranium is promoted by the presence of this element.

Figure A-5 shows radiograph prints from two heats of alloys made with the same nominal chemical composition ( $32 \mathrm{wt} \% \mathrm{U}$ and $3 \mathrm{wt} \% \mathrm{Si}$ ) which were rolled with nearly identical procedures. (Heats 8 and 9e). The silicon additions, however, were made in different manners. In one heat, the silicon was added as elemental silicon and in the other the silicon was added as a hardner. As would be expected, no differences were obtained in rolling characteristics of the slabs.

\subsection{Metallographic Results}

In order to investigate the cause of the grainy appearance of the radiographs of the rolled slabs, metallographic specimens were prepared from representative areas of the slabs. These samples were polished in the plan view so as to reveal the structure of the alloys. Figures A-6 through A-19 show these structures. The photomosaics and micrographs in these figures show that the acicular structures seen in the radiographs are actually clusters of intermetallic particles.

The structures seen in Figures A-6, A-7, and A-8, are from 22 wt\% uranium-aluminum alloys with increasing amounts of silicon. As indicated in Table II, the same rolling schedules were used in the preparation of the three slabs. The sample with the highest silicon content (Heat 3 , Figure A-8) has a small amount of micro-segregation, but the intermetallic particle size is about the same in all three samples. The apparent grain size increase on the radiographs is due to the microsegregation of the intermetallic particles. The amount of intermetallic particles is reduced by the addition of silicon.

In comparing the structures seen in Figures A-6 (22 wt\%) and A-9 (32 wt\%), the chief difference is the expected increase in the amount of intermetalic particles with the increasing uranium content.

The structures of the $32 \mathrm{wt} \%$ uranium-aluminum alloys (Figures A-9 through A-19) are not greatly changed by the silicon additions, or by 

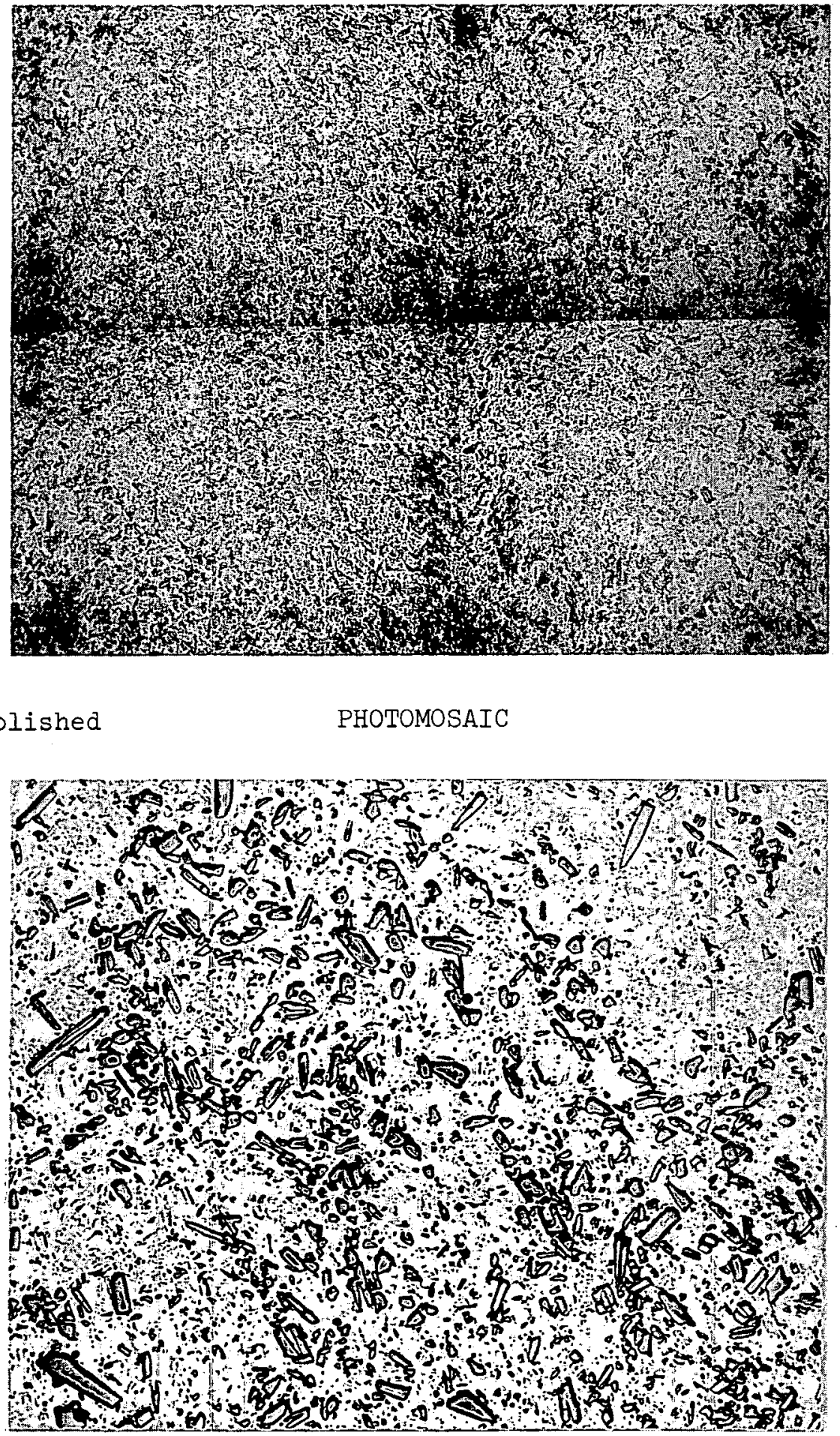

As Polished

MICROGRAPH

$100 \mathrm{x}$

Figure A-6 Structure of as-rolled slab of aluminum alloy containing 22 wt\% uranium with no silicon (Heat 1 ). 


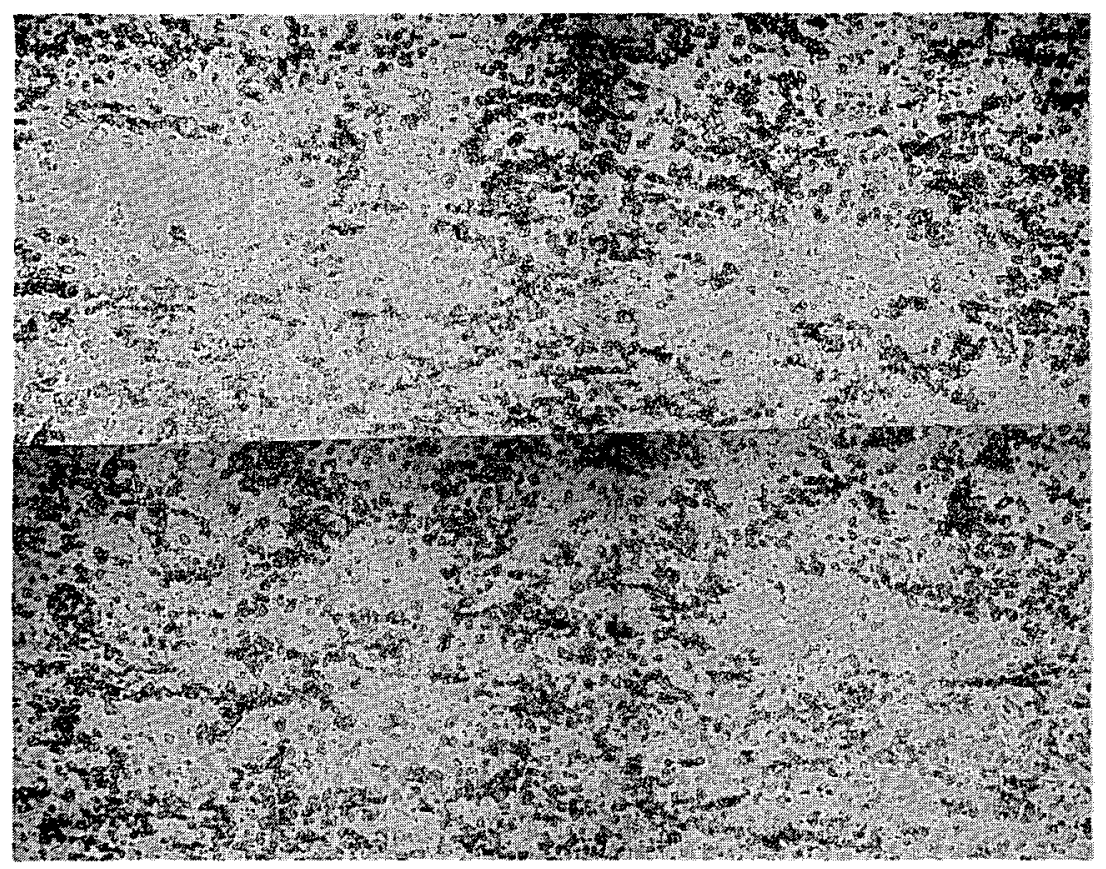

As Polished

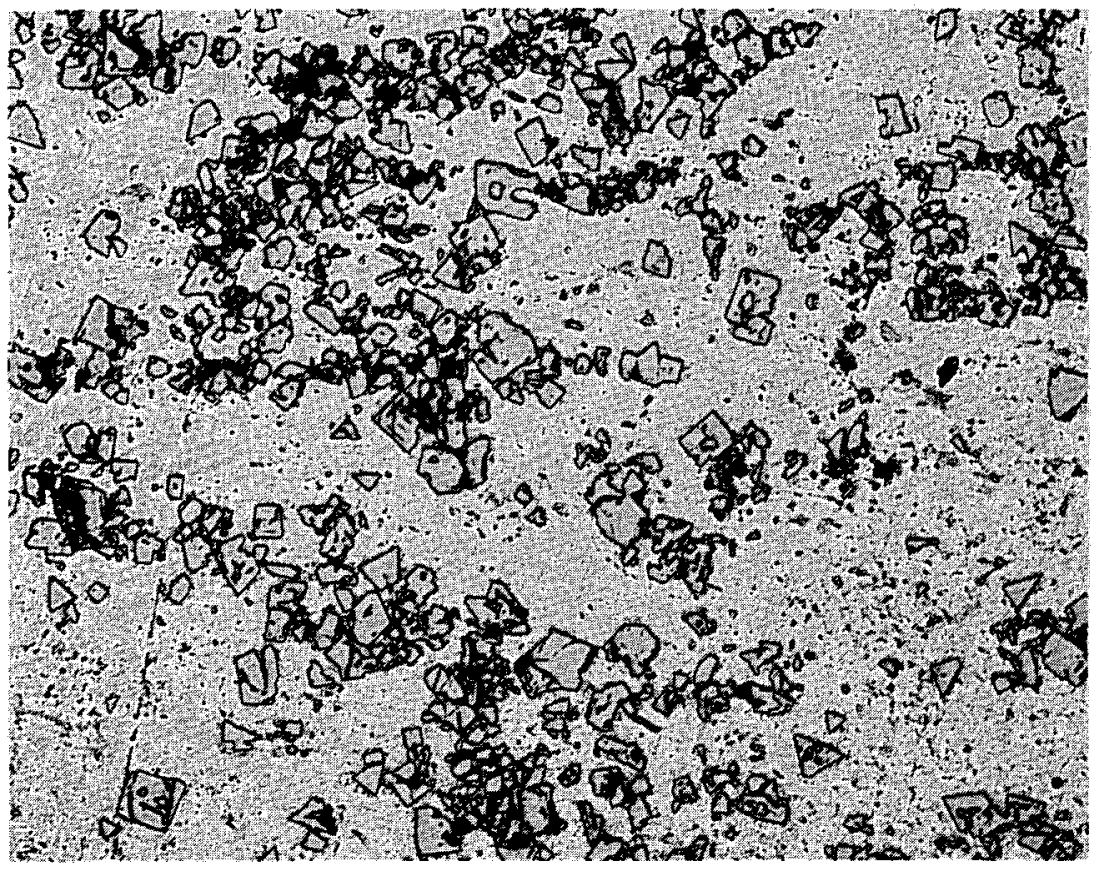

As Polished

MICROGRAPH

$100 \mathrm{X}$

Figure A-7 Structure of as-rolled slab of aluminum alloy containing 22 wt\% uranium and 3 wt\% silicon (Heat 2). 


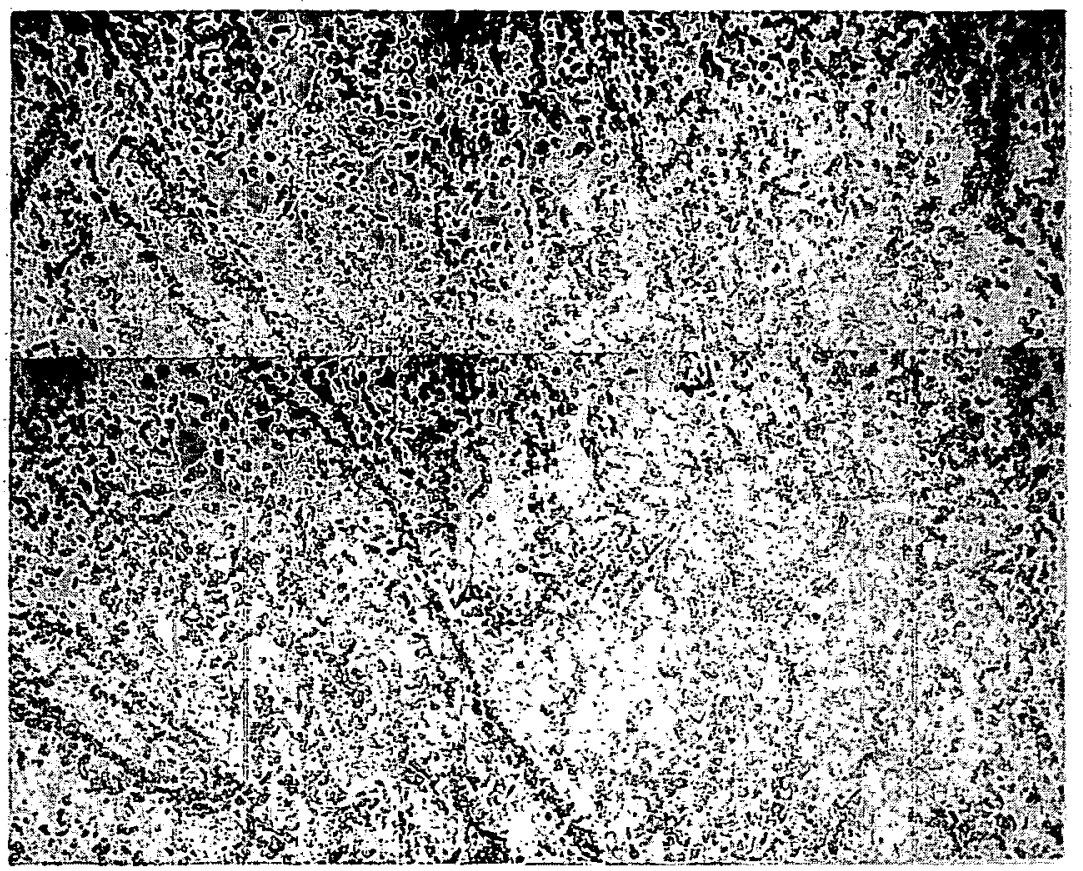

As Polished

PHOTOMOSAIC

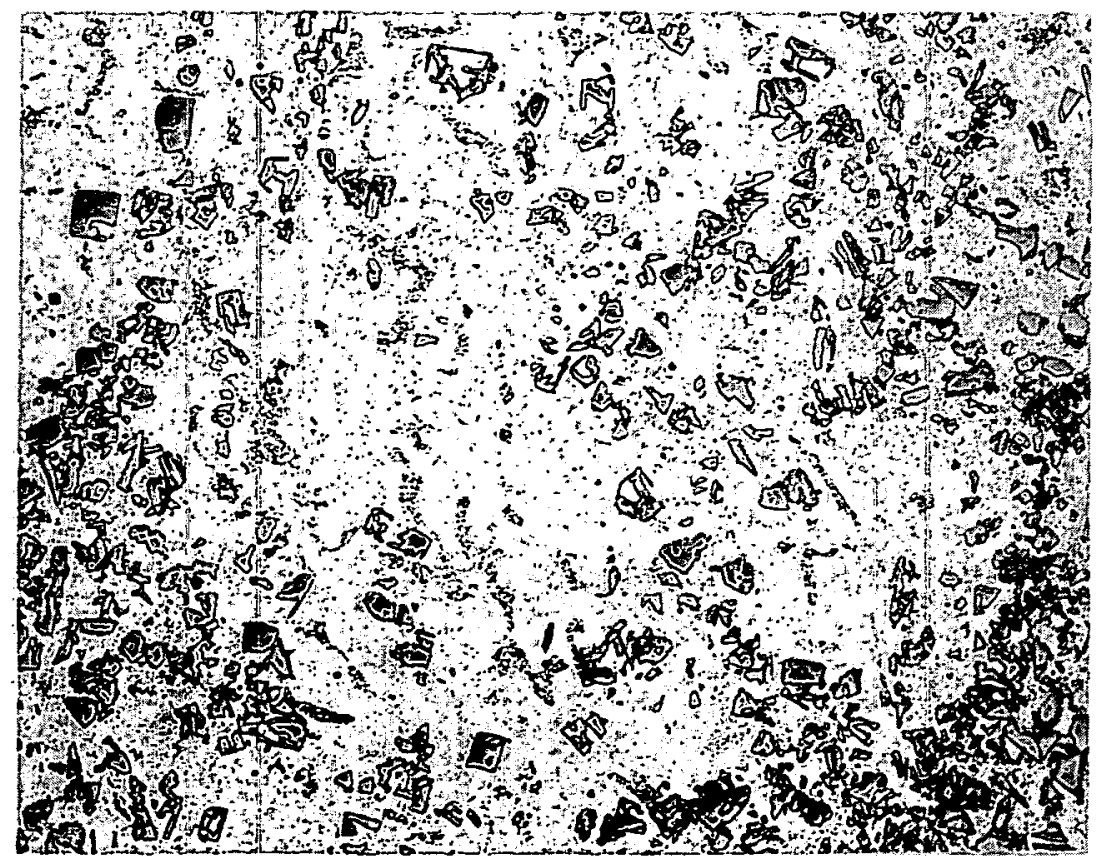

As Polished

MICROGRAPH

$100 \mathrm{X}$

Figure A-8 Structure of as-rolled slab of aluminum alloy containing 22 wt \% uranium and $4.5 \mathrm{wt} \%$ silicon (Heat 3 ). 


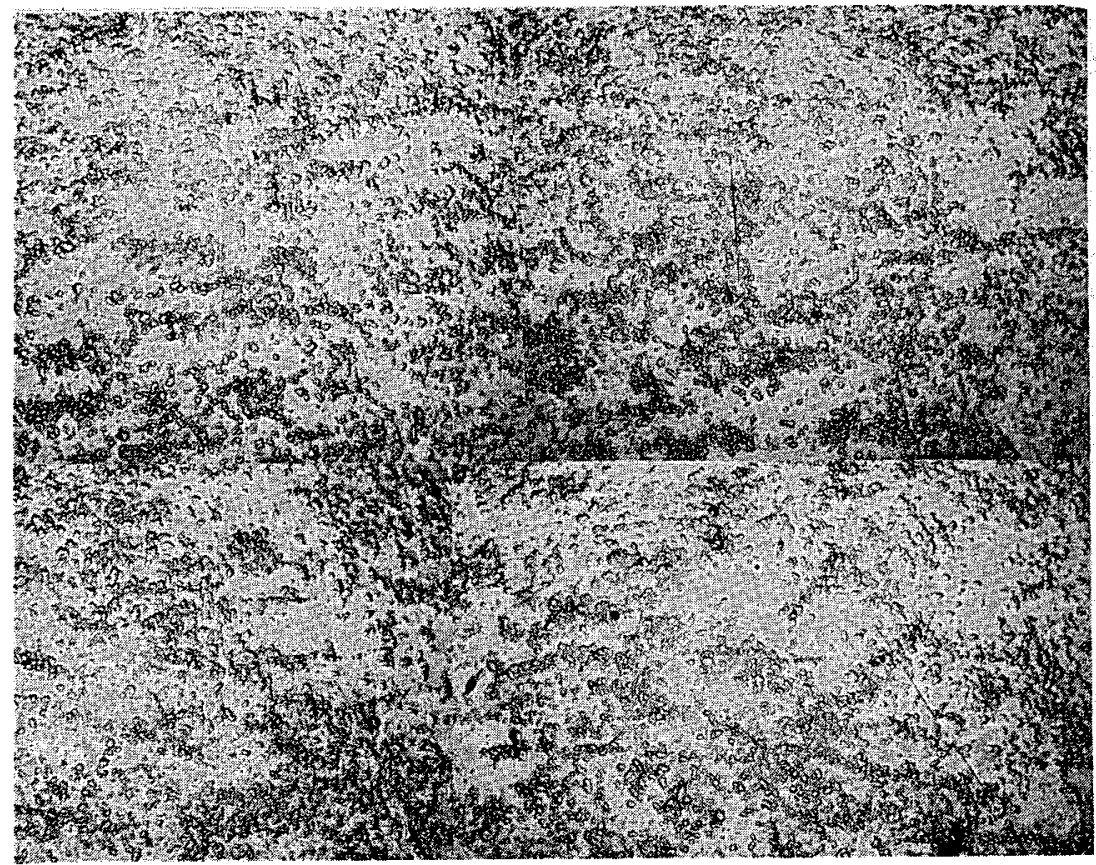

As Polished

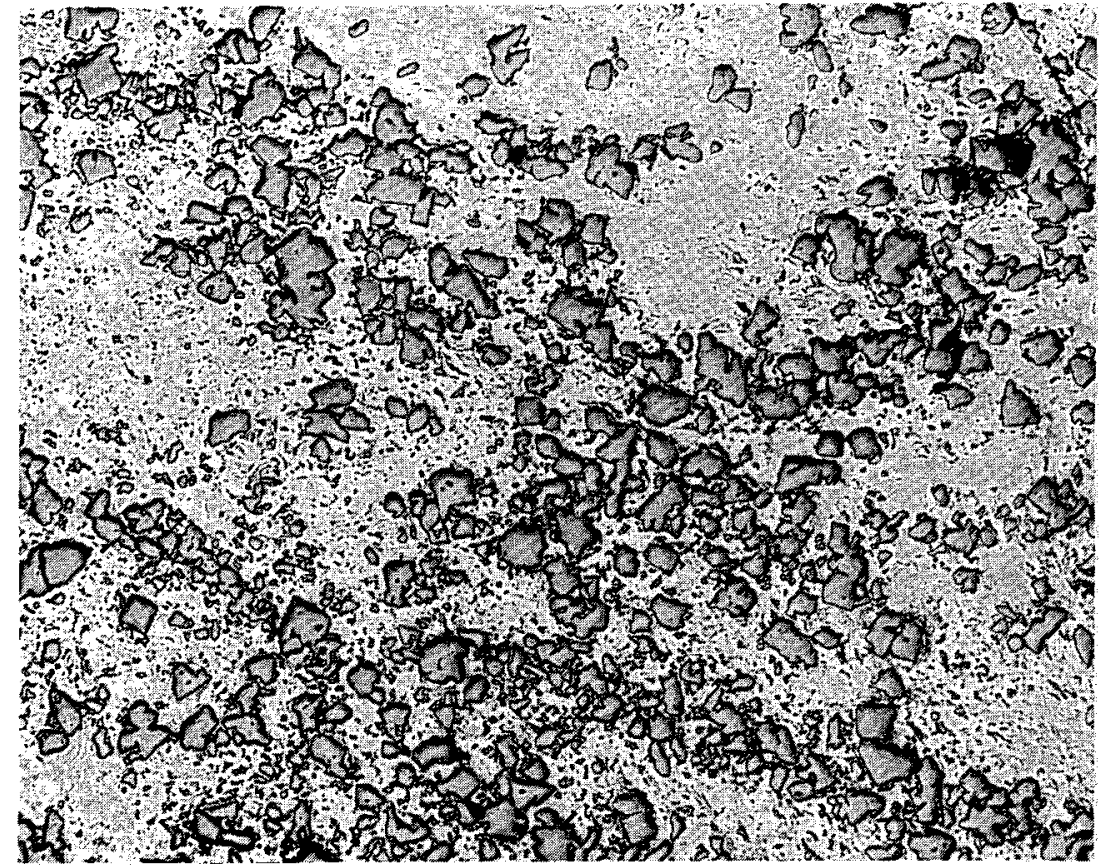

As Polished

MICROGRAPH

Figure A-9 Structure of as-rolled slab of aluminum alloy containing 32 wt\% uranium with no silicon addition (Heat 4 ). 


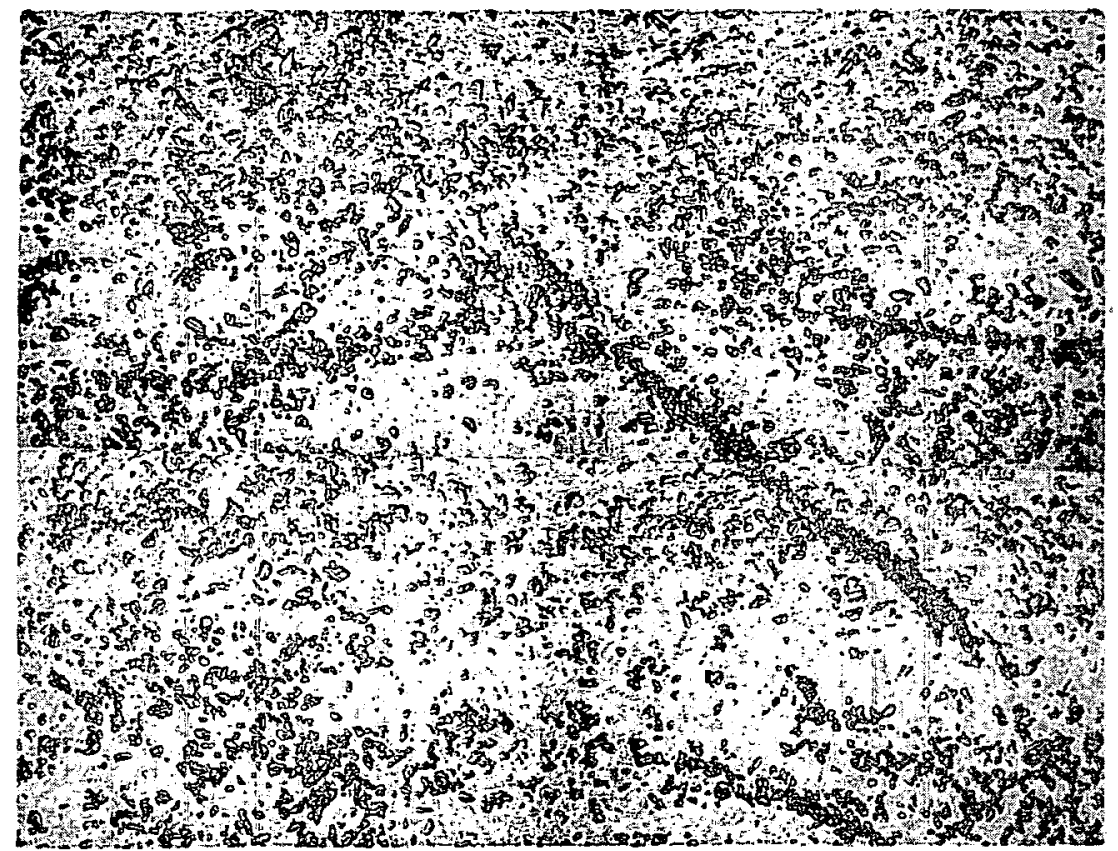

As Polished

PHOTOMOSAIC

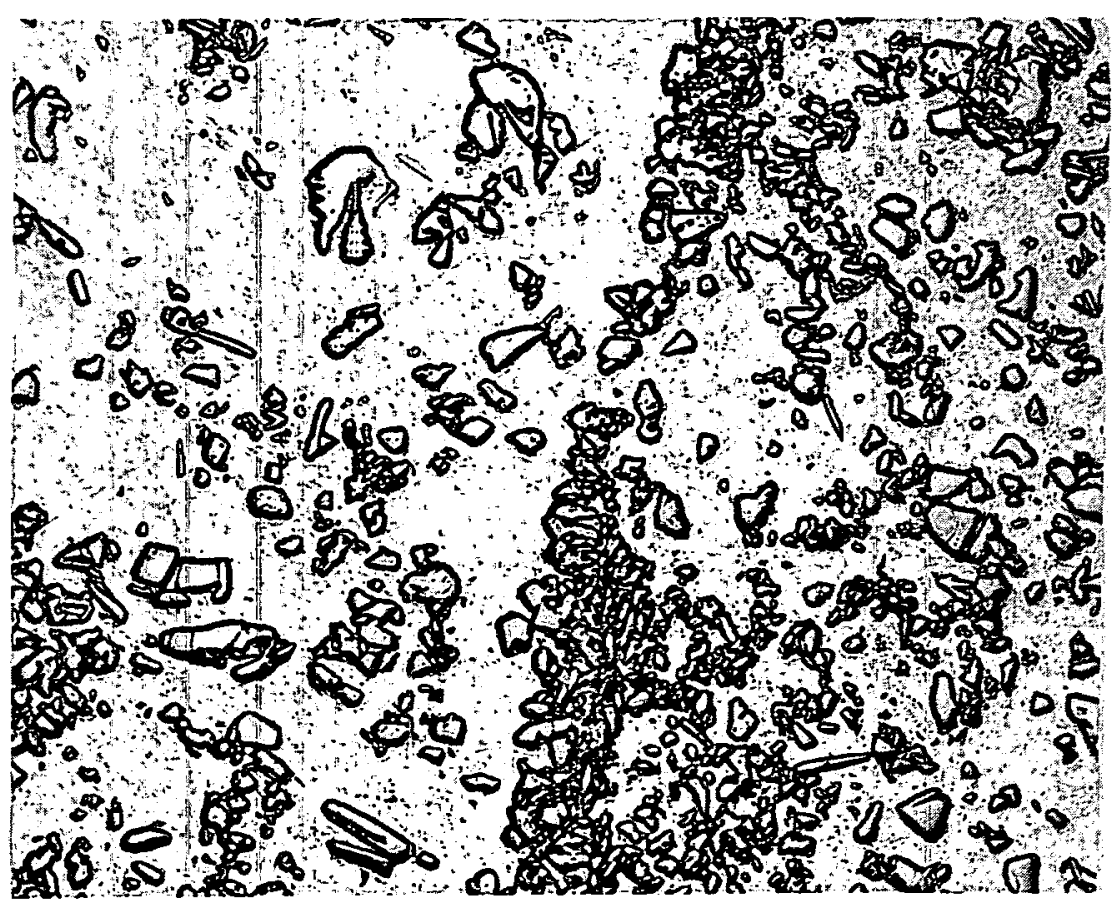

As Polished

MICROGRAPH

$100 \mathrm{X}$

Figure A-10 Structure of as-rolled slab of aluminum alloy containing 32 wt $\%$ uranium and 0.1 wt\% silicon (Heat 5 ). 


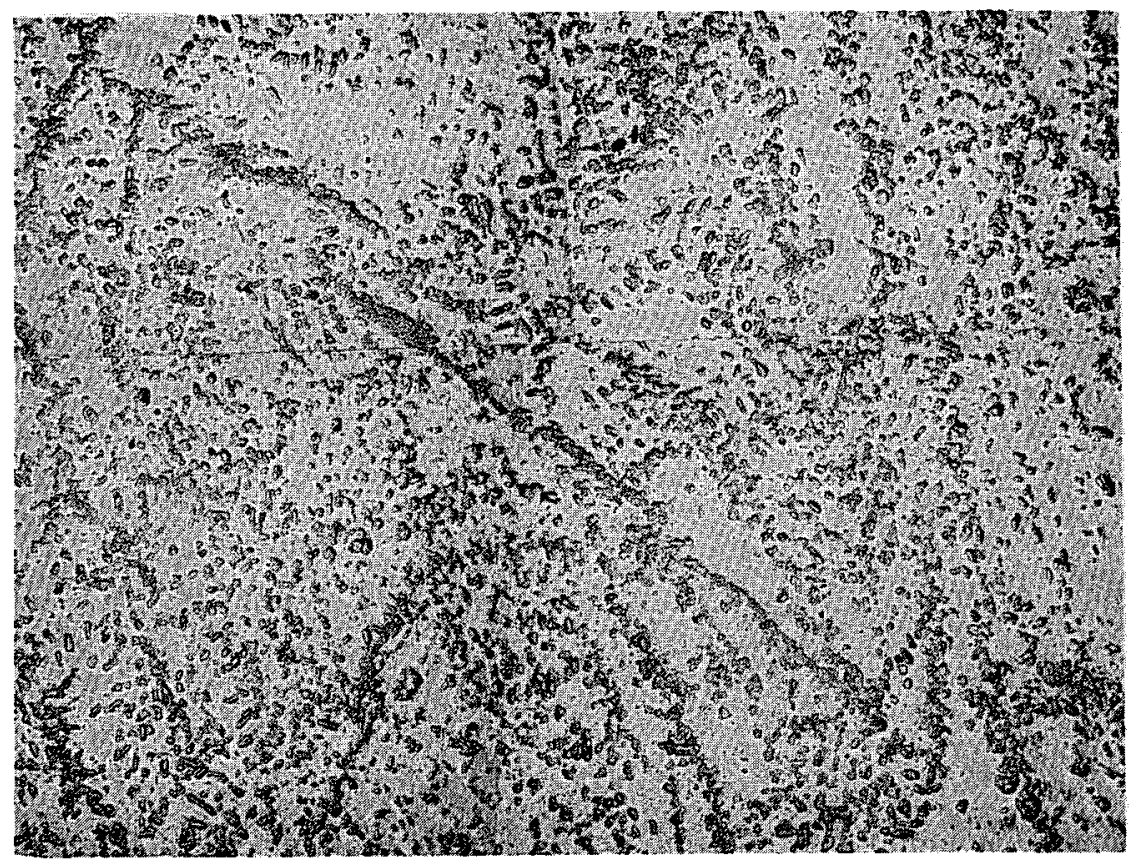

As Polished

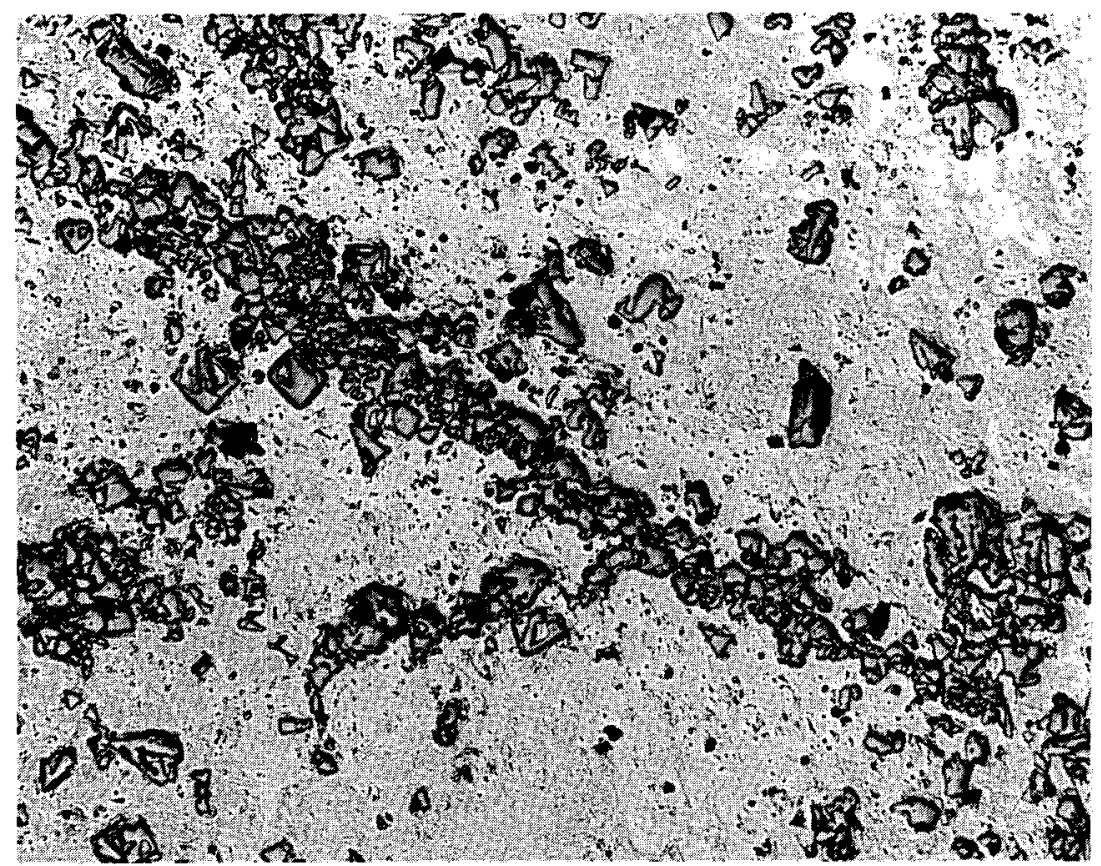

Figure A-Il Structure of as-rolled aluminum alloy containing 32 wt uranium and $0.6 \mathrm{wt} \%$ silicon (Heat 6 ). 


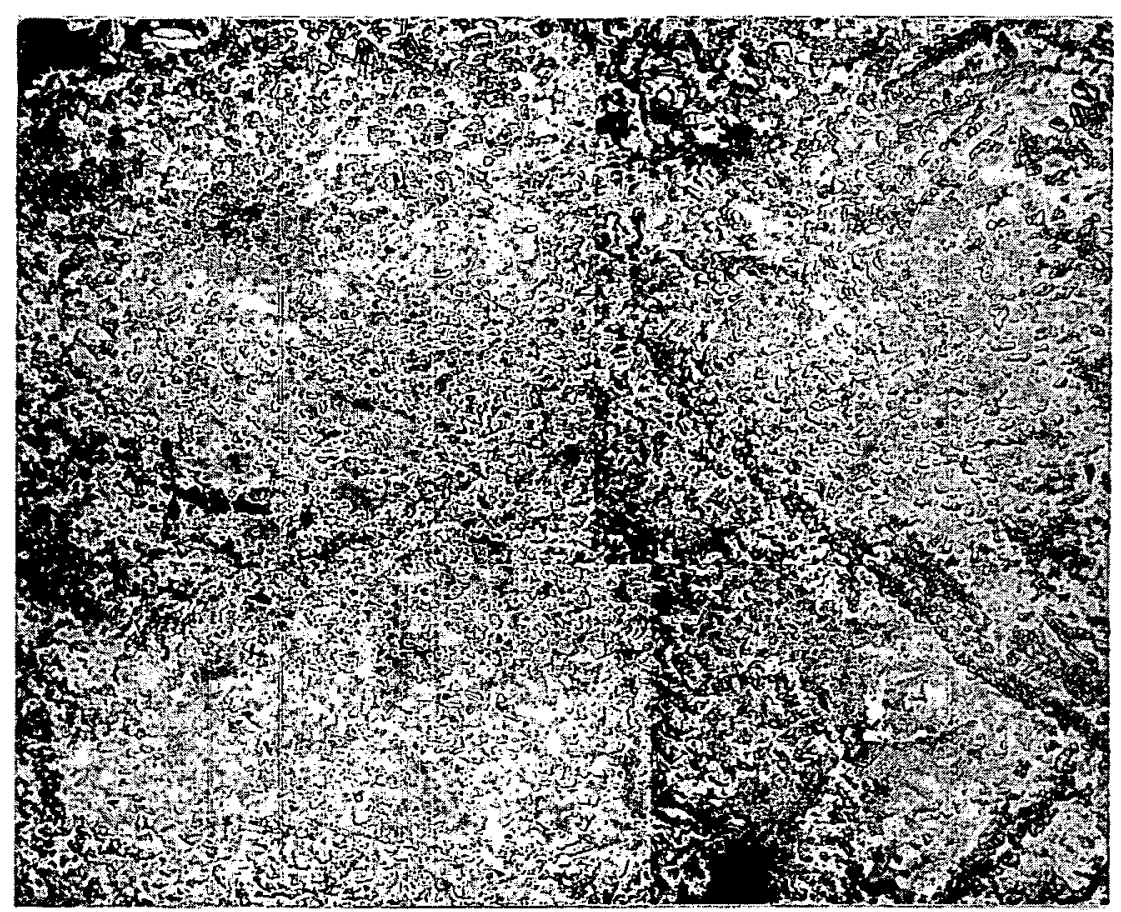

As Polished

PHOTOMOSAIC

$12 \mathrm{X}$

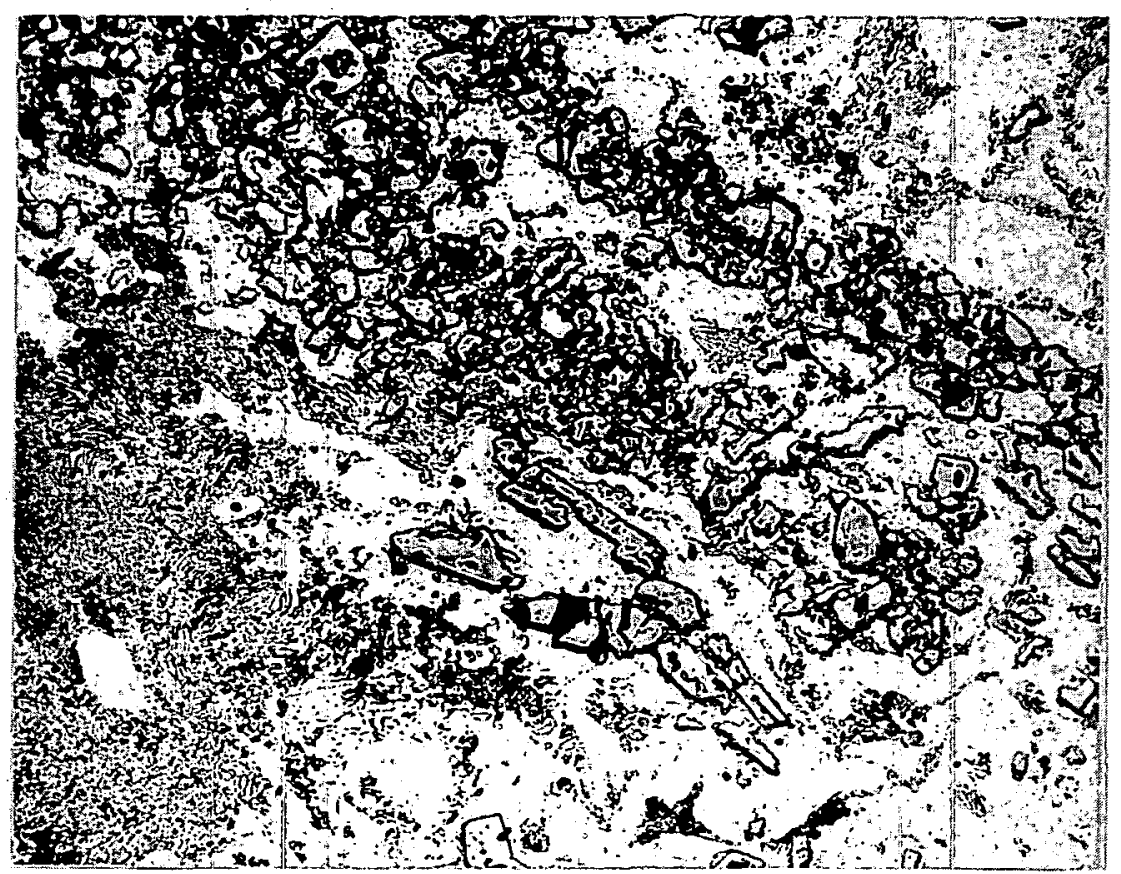

As Polished

MICROGRAPH

$100 \mathrm{X}$

Figure A-12 Structure of as-rolled aluminum alloy containing 32 wt\% uranium and $1.3 \mathrm{wt} \%$ silicon (Heat 7 ). 


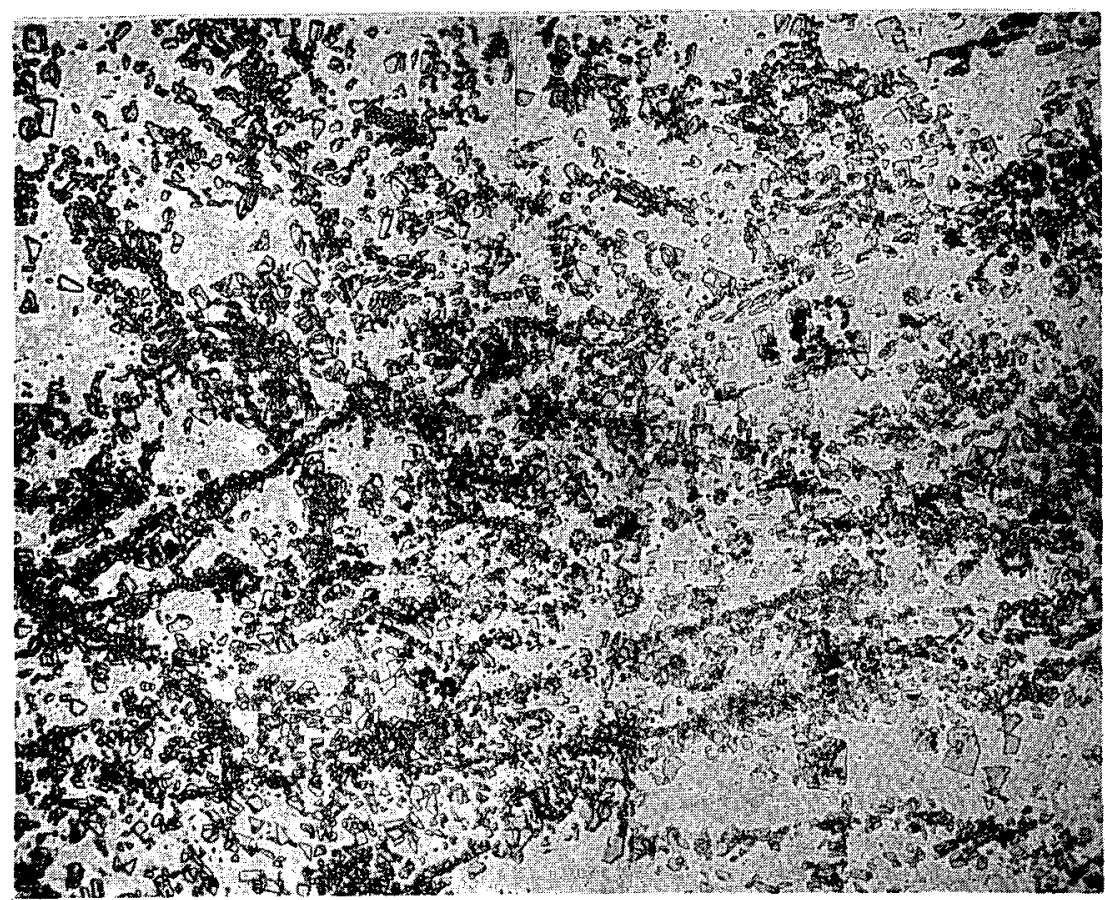

As Polished

PHOTOMOSAIC

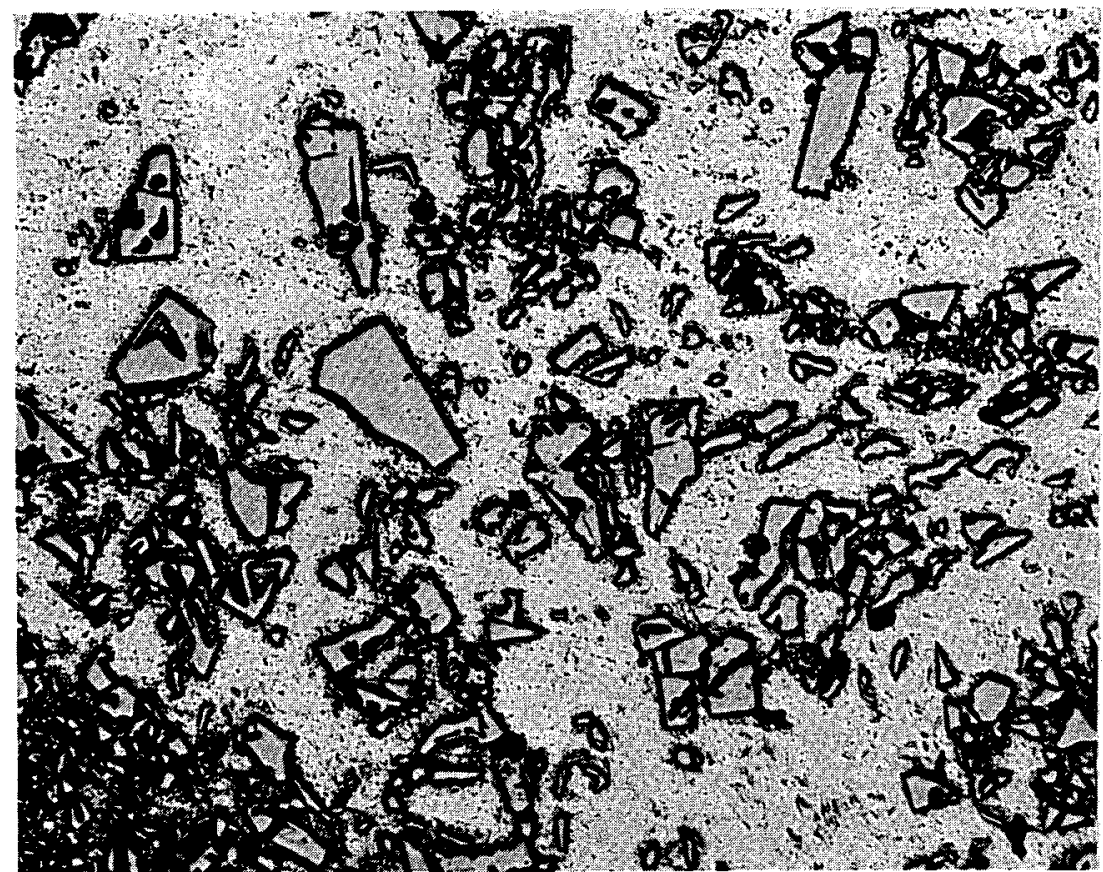

As Polished

MICROGRAPH

$100 \mathrm{X}$

Figure A-13 Structure of as-rolled aluminum alloy containing 32 wt\% uranium and $3 \mathrm{wt} \%$ silicon (Heat 8 ). 


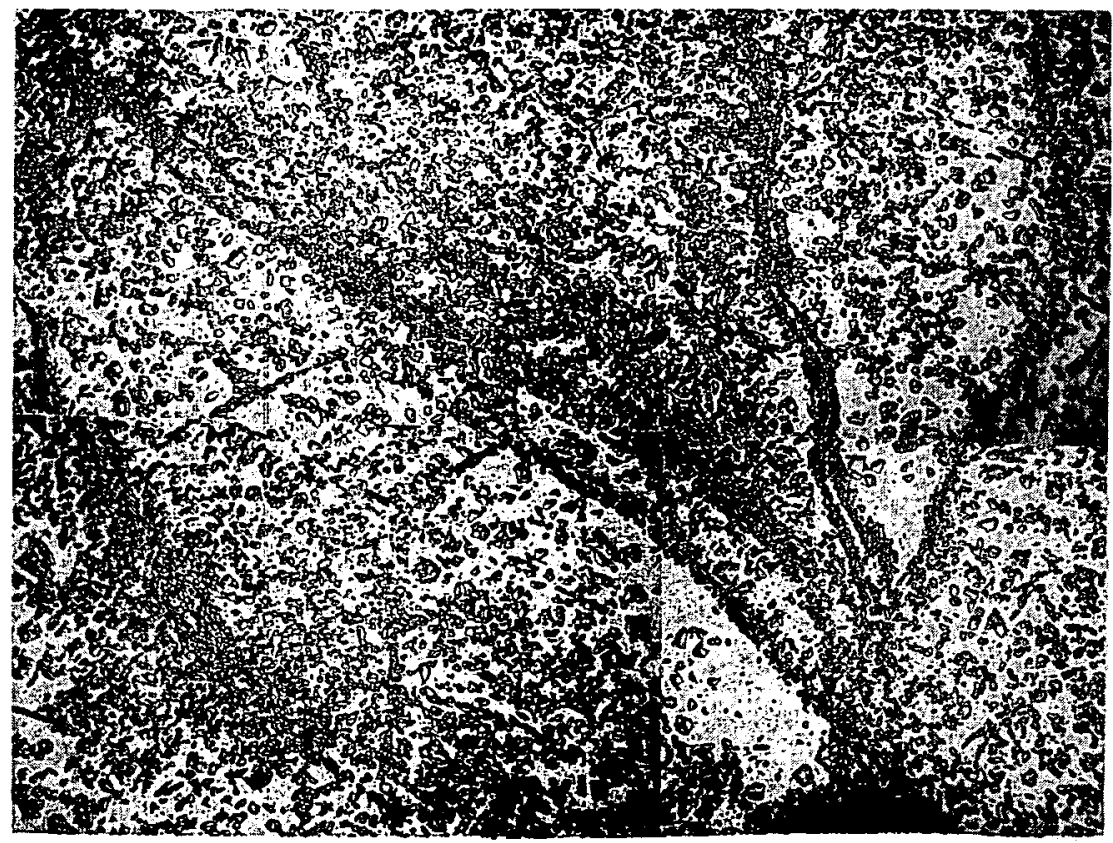

As Polished

PHOTOMOSAIC

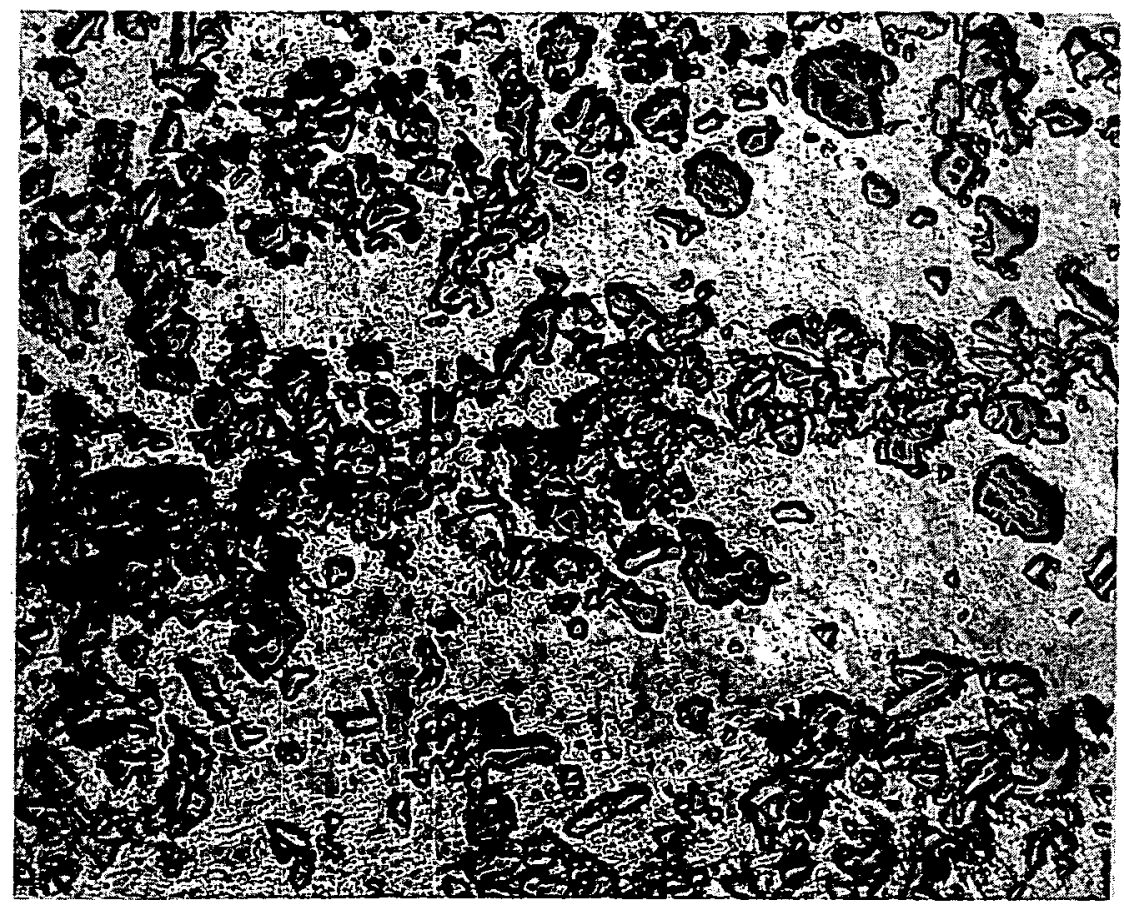

As Polished

MICROGRAPH

$100 \mathrm{X}$

Figure A-14 Structure of as-rolled aluminum alloy containing $32 \mathrm{wt} \%$ uranium and $3 \mathrm{wt} \%$ silicon (Heat $9 \mathrm{a}$ ). 


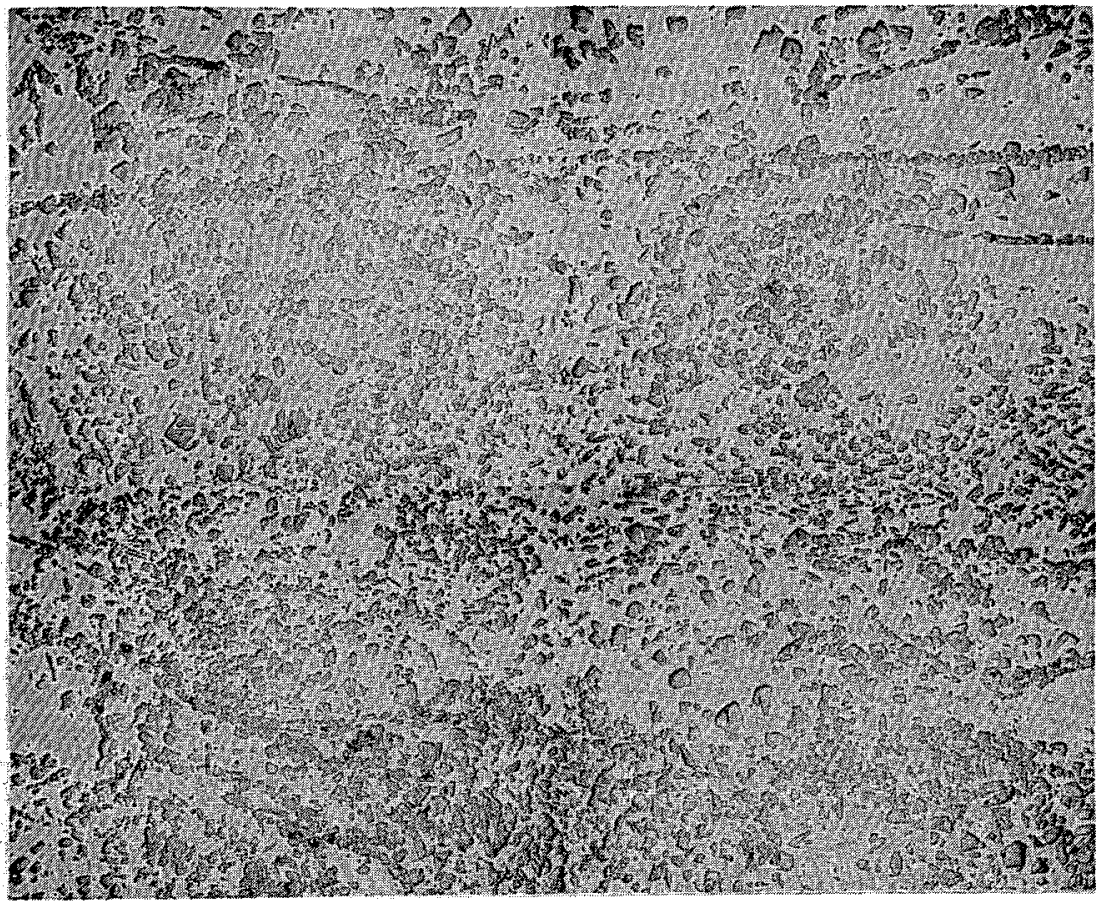

As Polished

PHOTOMOSAIC

$12 \mathrm{X}$

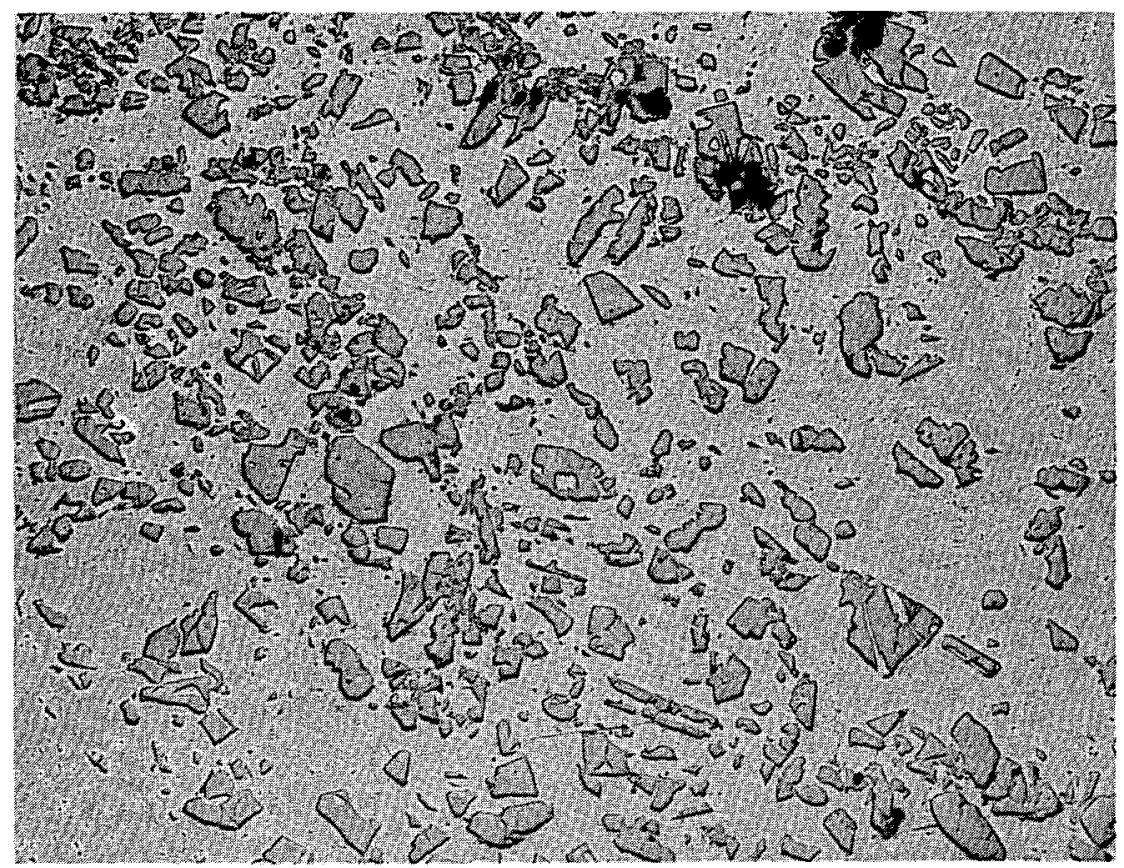

As Polished

MICROGRAPH

$100 \mathrm{X}$

Figure A-15 Structure of as-rolled aluminum alloy containing 32 wt uranium and $3 \mathrm{wt} \%$ silicon (Heat $9 \mathrm{~b}$ ). 


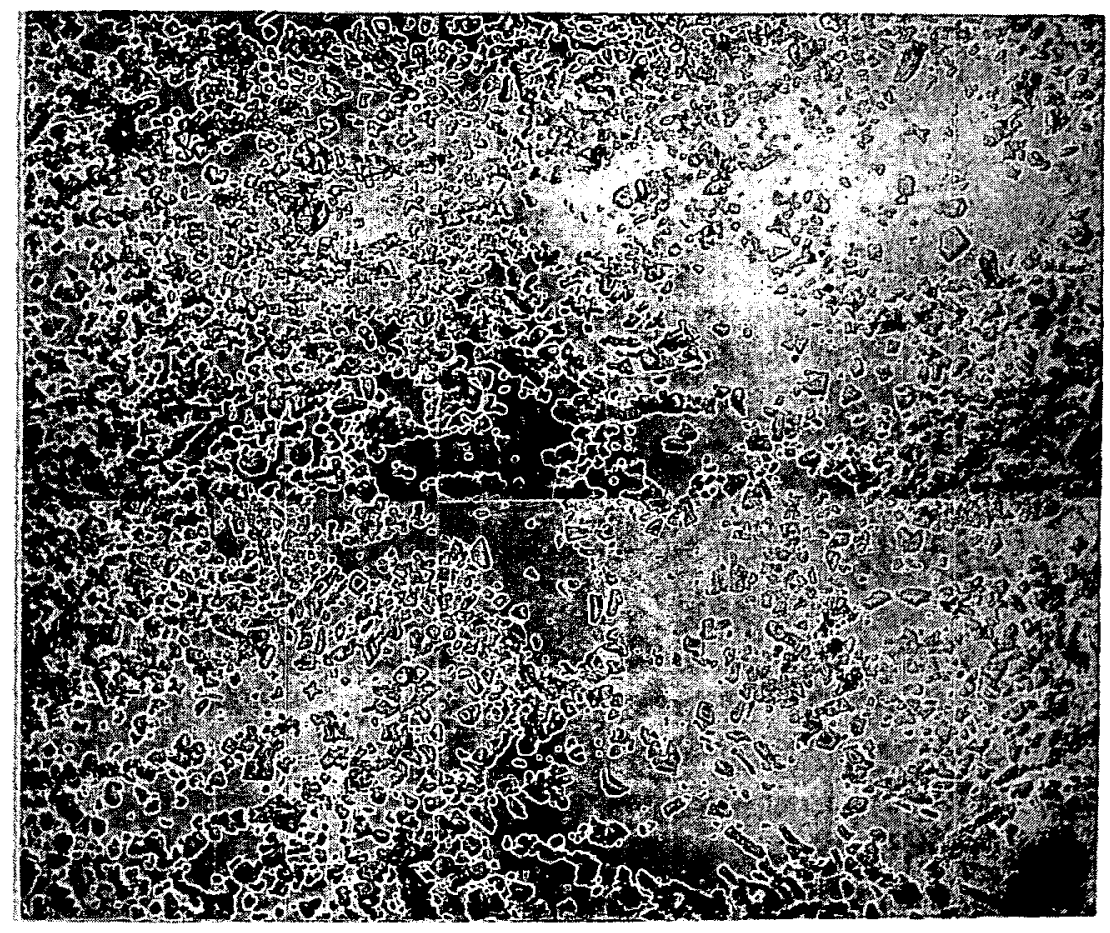

As Polished

PHOTOMOSAIC

$12 X$

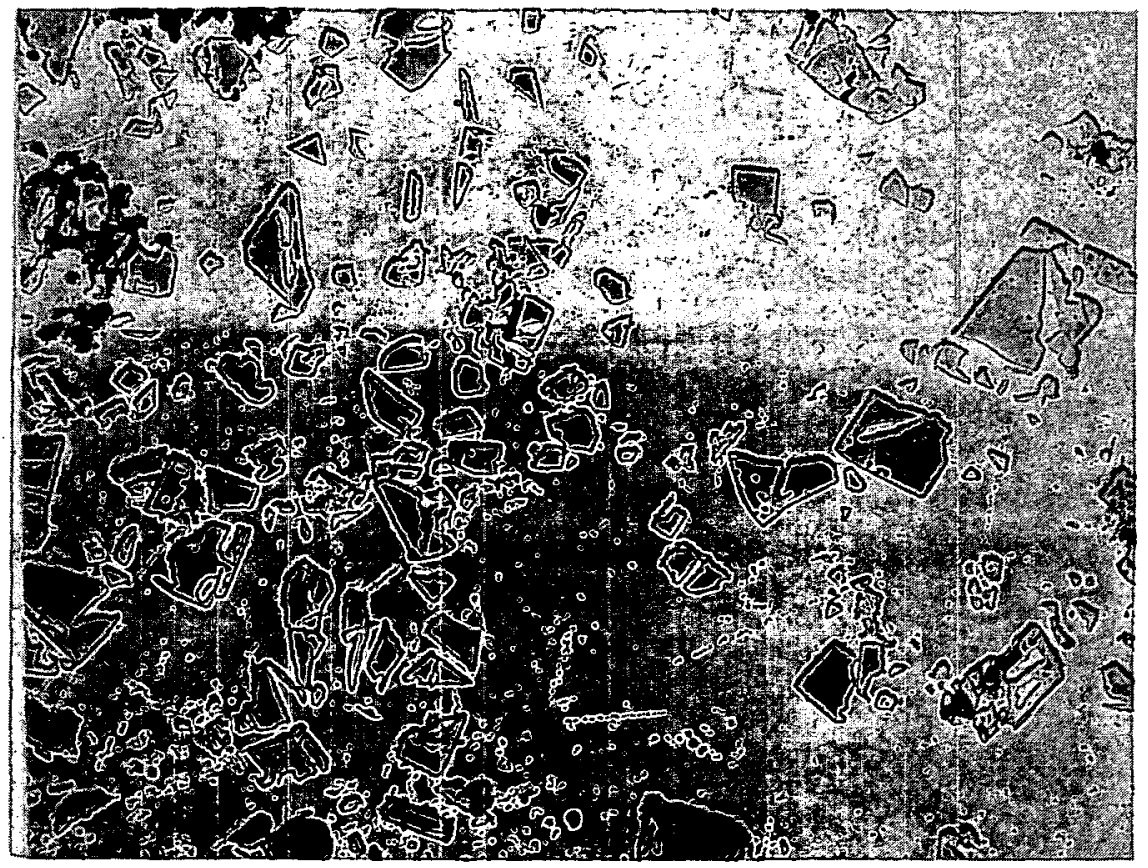

As Polished

MICROGRAPH

$100 \mathrm{x}$

Figure A-16 Structure of as-rolled aluminum alloy containing 32 wt\% uranium and $3 \mathrm{wt} \%$ silicon (Heat $9 \mathrm{c}$ ). 


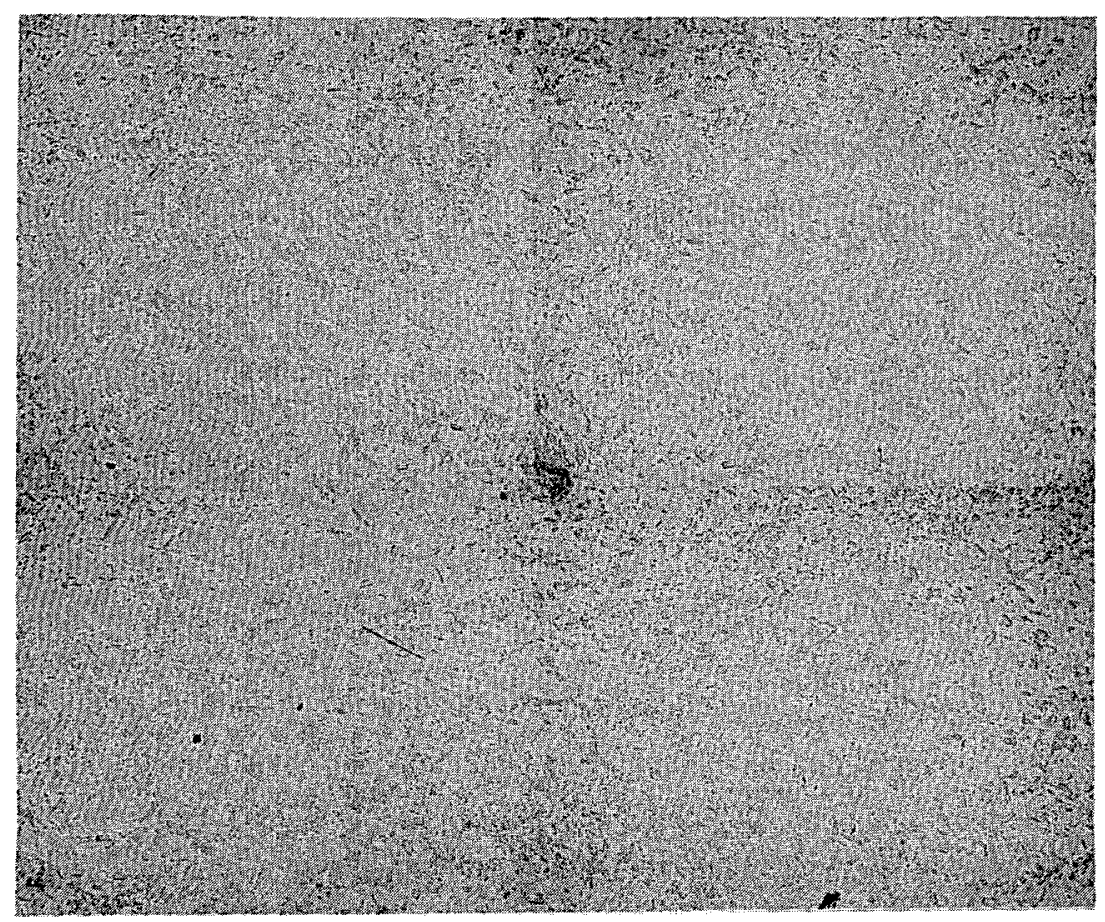

As Polished

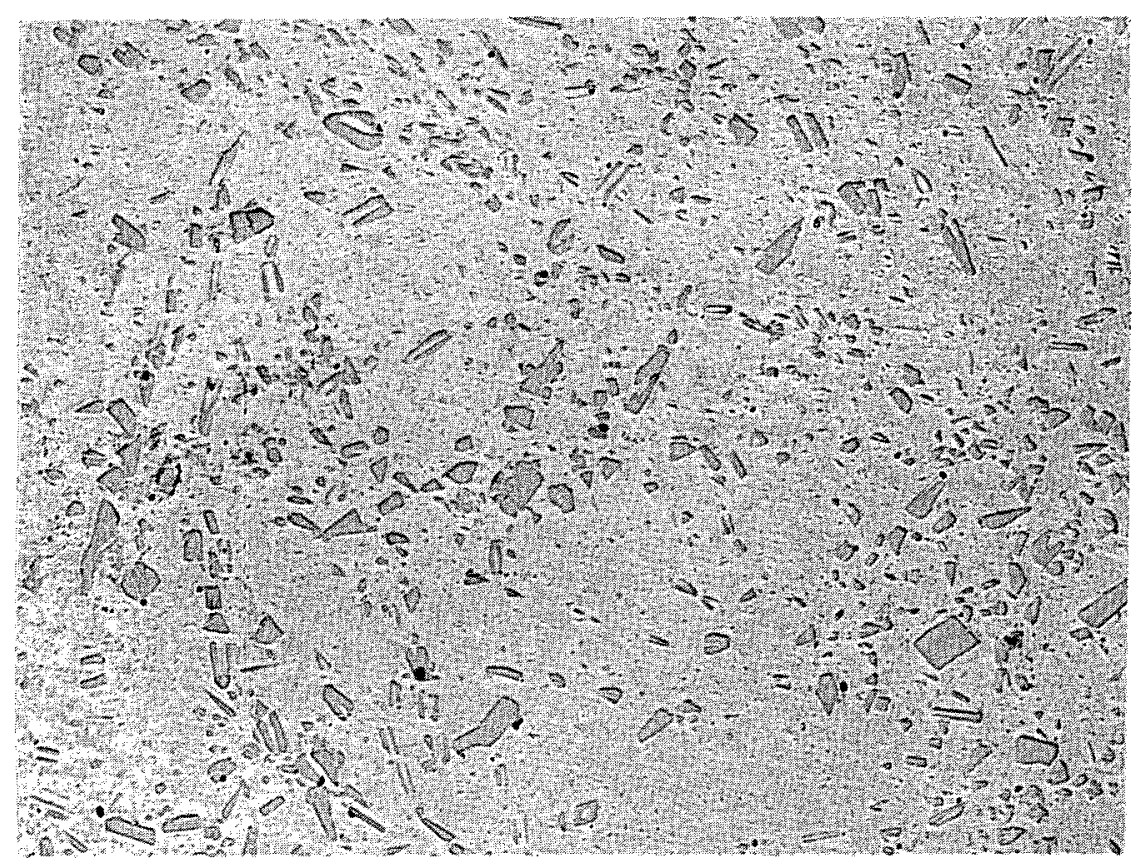

As Polished

MICROGRAPH

$100 \mathrm{X}$

Figure A-17 Structure of as-rolled aluminum alloy containing 32 wt $\%$ uranium and 3 wt\% silicon (Heat 9d). 


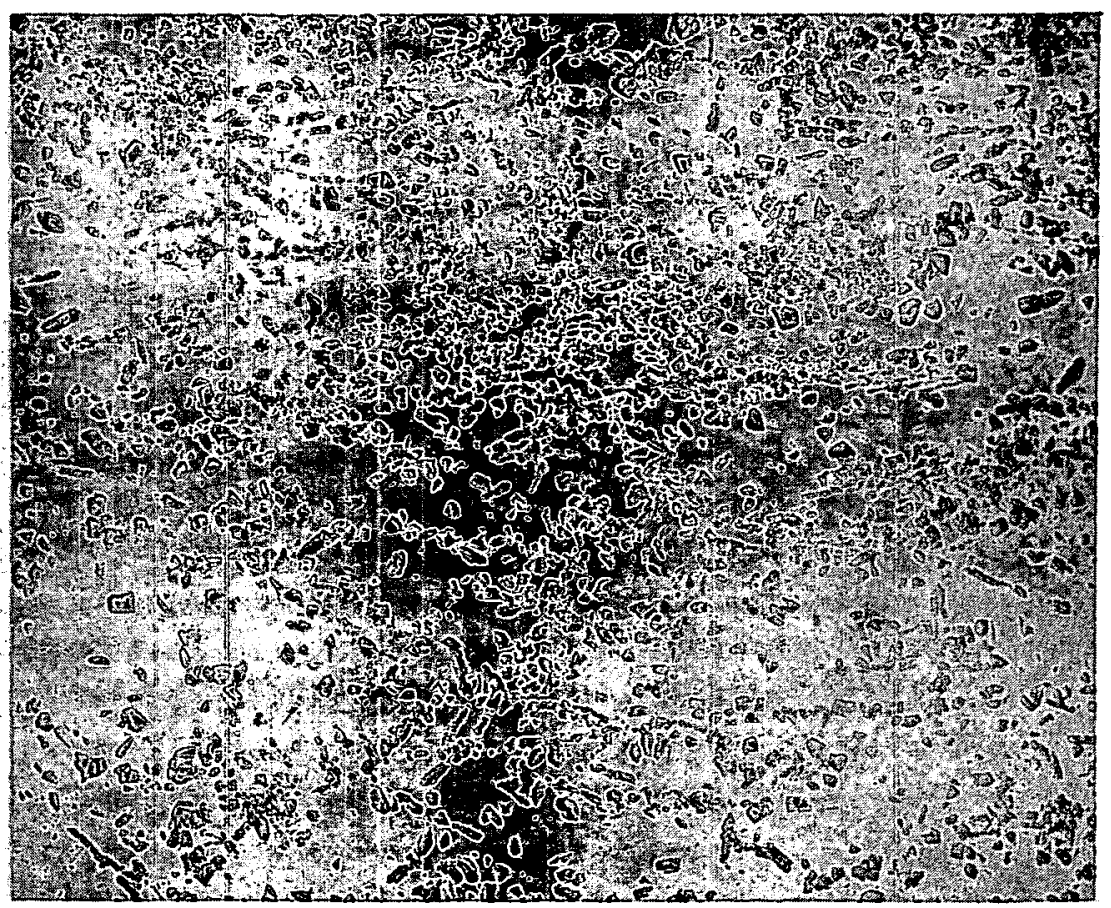

As Polished

PHOTOMOSAIC

$12 \mathrm{X}$

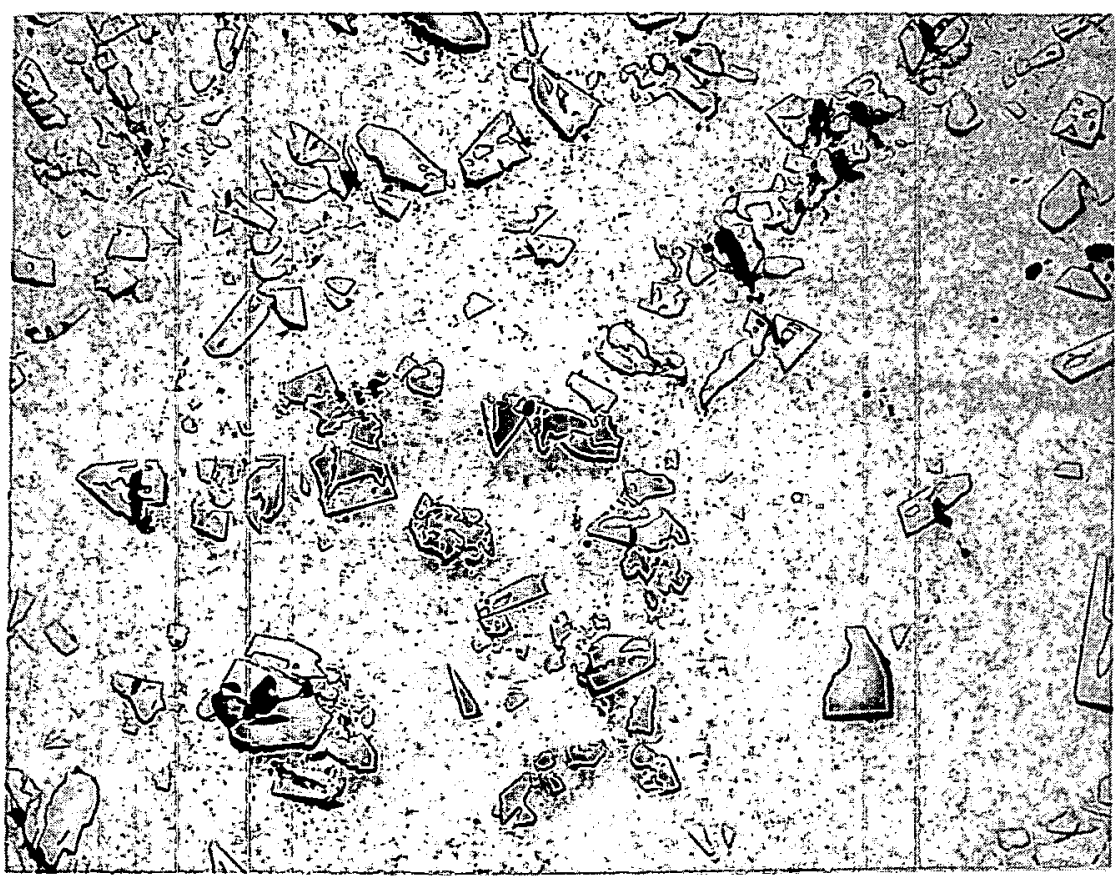

As Polished

MICROGRAPH

$100 \mathrm{X}$

Figure A-18 structure of as-rolled aluminum alloy containing 32 wt\% uranium and $3 \mathrm{wt} \%$ silicon (Heat $9 \mathrm{e}$ ). 


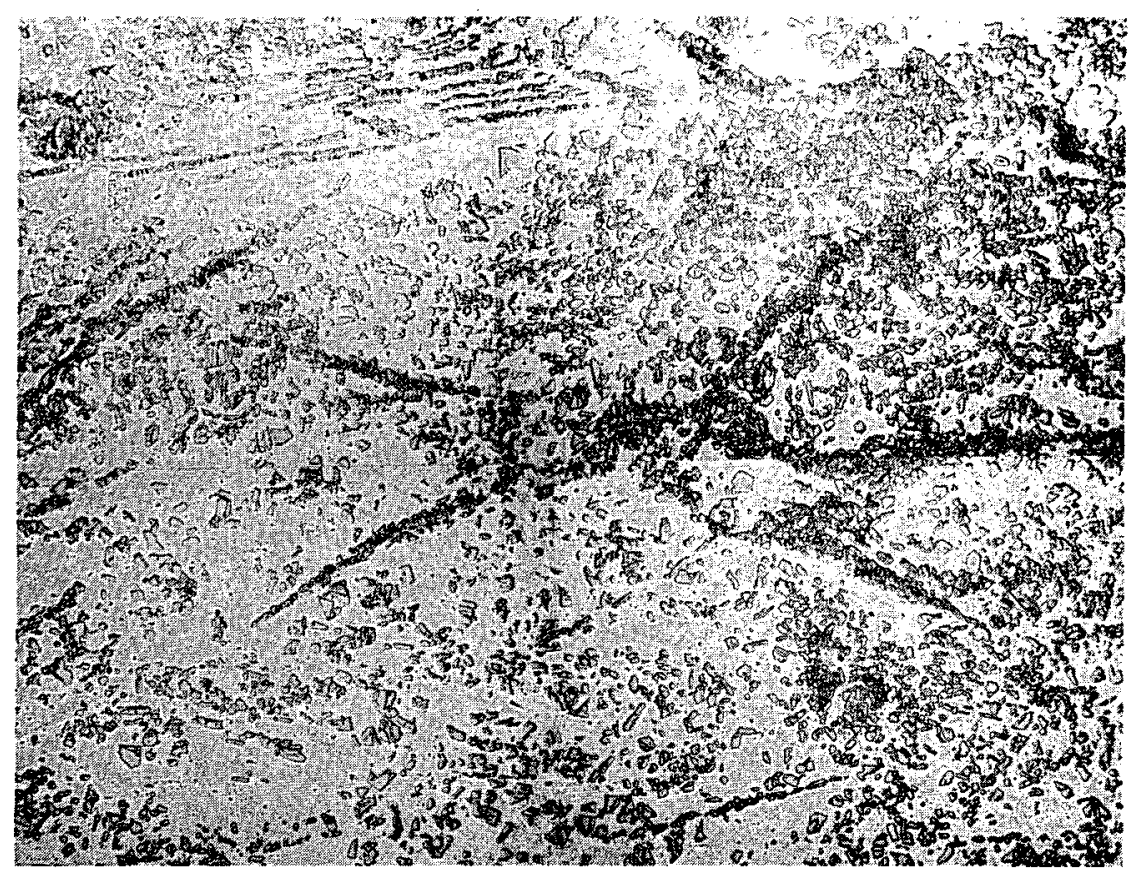

As Polished

PHOTOMOSAIC

$12 \mathrm{X}$

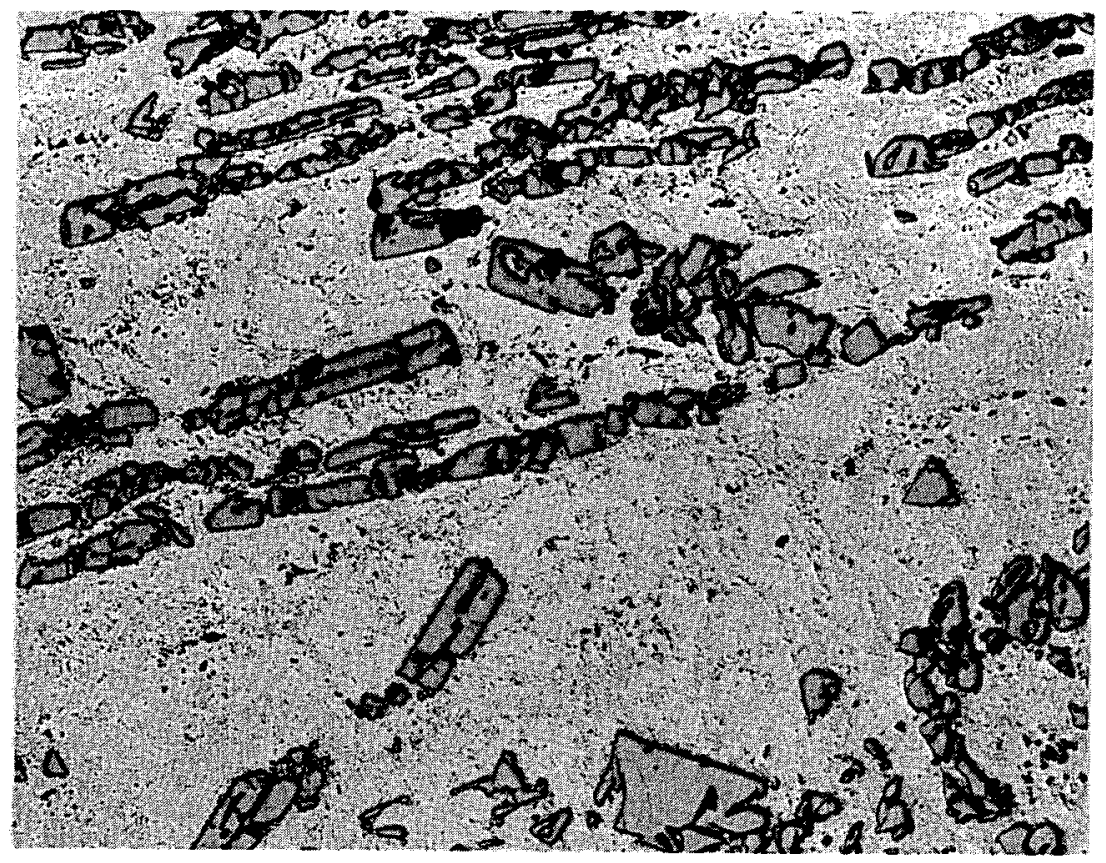

As Polished

MICROGRAPH

$100 \mathrm{X}$

Figure A-19 Structure of as-rolled aluminum alloy containing 32 wt\% uranium and 4.5 wt\% silicon (Heat 10). 
slightly different rolling schedules. As seen in the prints of the radiographs, the silicon additions do seem to promote the agglomeration of the uranium-bearing particles.: It is believed that the agglomeration of the intermetallic particles is the result of the original dendritic structure in the castings being broken up during the hot rolling operation.

A more uniform structure could probably be obtained by at least four methods: (1) the use of a casting procedure which would promote a more rapid cooling rate; (2) a long time, elevated temperature heat treatment of the casting prior to rolling; (3) more cross-rolling of the slab; and (4) a more severe hot working operation such as extrusion of the forging prior to rolling. However, it was not the purpose of the present work to optimize the production processes for uranium-aluminum alloy sheet, but only to produce uranium-aluminum alloys typical of those found in the cores of aluminum clad fuel plates used in nuclear reactors.

\section{METALLURGICAL DESCRIPTION OF FUEL PARTICLES}

The X-ray diffraction analysis and electron-beam microprobe analysis of the alloys studied have been discussed in the text in Section III. As stated there, the silicon present in the alloy in an atom ratio of silicon to uranium of less than one was associated with the uraniumaluminum fuel particles. The intermetallic species, defined as $U(\mathrm{AI}, \mathrm{Si})_{3}$, was identified in all of the alloys containing the UAl 3 phase. W. C. Thurber and R. J. Beaver (1) at Oak Ridge National Laboratory showed that there is a shift in the lattice parameter of $\mathrm{UAl}_{3}$ which is proportional to the percent of silicon in the alloy for alloys containing 48 wt\% uranium. Since current work shows that the atom ratio of silicon to uranium is very significant, these lattice parameters together with the lattice parameters obtained in the current studies for alloys with 22 and 32 wt uranium have been plotted in Figure A-20 against the atom ratio. The data from the alloys with different uranium concentrations agree, showing that the addition of silicon to the $\mathrm{UAl}_{3}$ phase should be considered on the basis of the atom ratio. It should be noted that there are no data for atom ratios between 0.8 to 1.1 because the importance of the atom ratio was not known, and the selection of the alloys studied was based upon wt\% silicon in the alloy and not on the atom ratio.

As shown in Figure A-20, the systematic decrease in lattice parameter does not continue above an atom ratio of silicon to uranium of one. Aluminum alloys containing 22 wt $\%$ uranïum-3 wt $\%$ silicon, 32 wt $\%$ uranium5 wt $\%$ silicon, and 22 wt\% uranium-5 wt\% silicon with silicon-to-uranium ratios of $1.1,1.34$, and 1.9 , respectively, all contained a species with. a lattice parameter similar to the value expected for an alloy with an atom ratio of about one. In addition, however, each of these alloys contained a small amount of an unidentified species with lattice parameters between 4.06 and 4.11 which may be a $\mathrm{UAl}_{3}$ phase containing an atom ratio of silicon to uranium greater than one. This is probably related to the low lattice parameter reported by Thurber and Beaver for the alloy containing $48 \mathrm{wt} \%$ uranium-10 wt\% silicon with a silicon-to-uranium ratio of 1.8 and shown in the plot. Thus, in alloys with an atom ratio in excess of one, it is possible that small quantities of uranium-aluminum- 
silicon intermetallic may form which contain silicon in excess of one atom of silicon to uranium in the crystal lattice even though the bulk of the silicon in excess of an atom ratio of one is rejected from the $\mathrm{UAl}_{3}$ fuel particle.

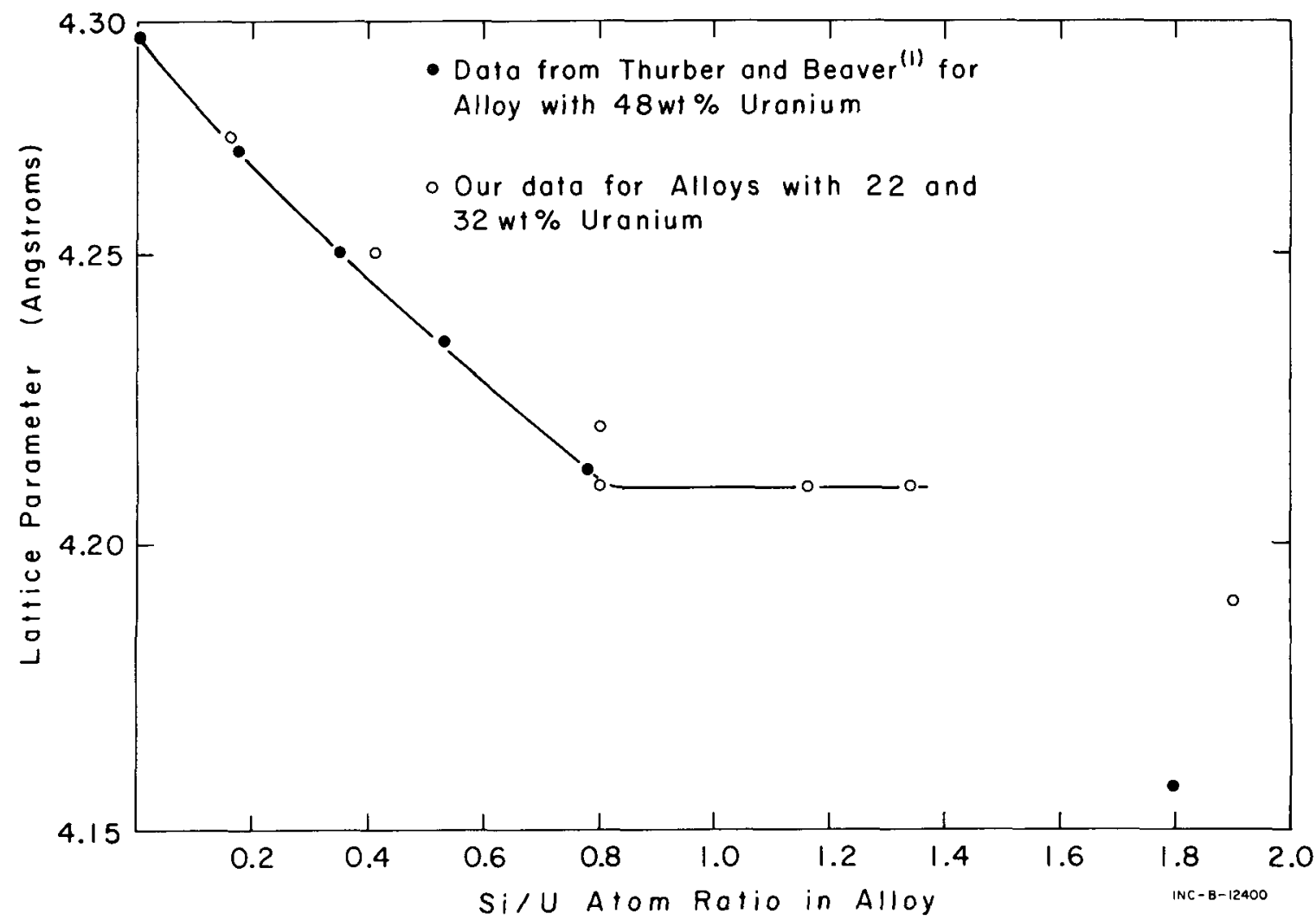

Figure A-20 Relationship of silicon-to-uranium atom ratio to lattice parameter of $\mathrm{UAl}_{3}$ phase. 
APPENDIX B

MECHANICAL PROPERTIES OF URANIUM-ALUMINUM-SILICON ALLOYS 
The data obtained for ultimate tensile strength, tensile yield strength, and percent elongation for uranium-aluminum alloys containing 22 and 32 wt\% silicon are shown in Table B-I. The effects of silicon, of the silicon-to-uranium atom ratio, and of temperature are discussed in the text. The measurements were made using one-inch gagelength tensile specimens which were prepared from the as-rolled alloy sheets, heated for one hour at $500^{\circ} \mathrm{C}$, and air cooled. From two to ten determinations were made on each alloy. 
TABLE B-I

MECHANICAL PROPERTIES OF URANIUM-ALUMINUM ALIOYS CONTAINING

22 and 32 WT\% URANIUM WITH AND WITHOUT SILICON ADDITIONS

\begin{tabular}{|c|c|c|c|c|c|c|c|c|c|c|c|c|}
\hline \multirow[b]{2}{*}{ Heat__ } & \multirow{2}{*}{$\begin{array}{c}\text { Nominal } \\
\text { Composition } \\
\text { U-Si } \\
\text { (wt } \%) \\
\end{array}$} & \multirow[b]{2}{*}{$\begin{array}{l}\text { Atom } \\
\text { Ratio } \\
\text { (Si/U) } \\
\end{array}$} & \multirow[b]{2}{*}{$\begin{array}{l}\text { Level of } \\
\text { Tensile }[a] \\
\text { Property }\end{array}$} & \multicolumn{3}{|c|}{ Room Temperature } & \multicolumn{3}{|c|}{$150^{\circ} \mathrm{C}$} & \multicolumn{3}{|c|}{$550^{\circ} \mathrm{C}$} \\
\hline & & & & 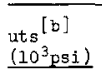 & 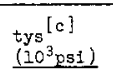 & $q_{E}^{[d]}$ & $\begin{array}{l}{ }_{\text {uts }}^{[\mathrm{b}]} \\
\left(20^{3} \mathrm{psi}\right)\end{array}$ & $\begin{array}{l}\text { tys }[\mathrm{c}] \\
\underline{\left(10^{3} \mathrm{psi}\right)} \\
\end{array}$ & $q_{E}[\mathrm{~d}]$ & 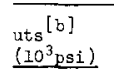 & $\begin{array}{l}\operatorname{tys}[\mathrm{c}] \\
\left(10^{3} \mathrm{psi}\right) \\
\end{array}$ & $\phi E^{[a]}$ \\
\hline 1 & $22-0$ & 0 & $\begin{array}{l}\text { High } \\
\text { Low } \\
\text { Avg }\end{array}$ & $\begin{array}{l}19.7 \\
17.6 \\
18.6\end{array}$ & $\begin{array}{r}11.1 \\
8.5 \\
9.5\end{array}$ & $\begin{array}{r}16 \\
9 \\
13\end{array}$ & $\begin{array}{l}17.9 \\
17.8 \\
17.9\end{array}$ & $\begin{array}{l}12.1 \\
10.9 \\
11.5\end{array}$ & $\begin{array}{r}15 \\
9 \\
12\end{array}$ & $\begin{array}{l}3.0 \\
2.6 \\
2.8\end{array}$ & $\begin{array}{l}2.8 \\
2.2 \\
2.5\end{array}$ & $\begin{array}{l}28 \\
19 \\
24\end{array}$ \\
\hline 2 & $22-3$ & 1.2 & $\begin{array}{l}\text { High } \\
\text { Iov } \\
\text { Avg }\end{array}$ & $\begin{array}{l}16.7 \\
34.3 \\
14.9\end{array}$ & $\begin{array}{l}5.1 \\
4.5 \\
4.9\end{array}$ & $\begin{array}{l}17 \\
11 \\
14\end{array}$ & $\begin{array}{l}14.1 \\
13.9 \\
14.0\end{array}$ & $\begin{array}{l}9.6 \\
8.1 \\
8.8\end{array}$ & $\begin{array}{r}10 \\
6 \\
8\end{array}$ & $\begin{array}{l}2.3 \\
2.1 \\
2.2\end{array}$ & $\begin{array}{l}2.2 \\
1.9 \\
2.0\end{array}$ & $\begin{array}{l}22 \\
19 \\
21\end{array}$ \\
\hline 3 & $22-4.5$ & 1.8 & $\begin{array}{l}\text { High } \\
\text { Low } \\
\text { Avg }\end{array}$ & $\begin{array}{l}17.0 \\
16.3 \\
16.7\end{array}$ & $\begin{array}{l}5.5 \\
4.2 \\
5.0\end{array}$ & $\begin{array}{l}20 \\
13 \\
15\end{array}$ & $\begin{array}{l}14.5 \\
33.5 \\
14.0\end{array}$ & $\begin{array}{l}6.4 \\
5.6 \\
6.0\end{array}$ & $\begin{array}{l}27 \\
20 \\
23\end{array}$ & $\begin{array}{l}3.1 \\
3.1 \\
3.1\end{array}$ & $\begin{array}{l}2.6 \\
2.4 \\
2.5\end{array}$ & $\begin{array}{l}44 \\
50 \\
48\end{array}$ \\
\hline 4 & $32-0$ & 0 & $\begin{array}{l}\text { High } \\
\text { Low } \\
\text { Avg }\end{array}$ & $\begin{array}{l}24.0 \\
19.3 \\
22.3\end{array}$ & $\begin{array}{l}13.9 \\
12.3 \\
13.0\end{array}$ & $\begin{array}{r}20 \\
3 \\
8\end{array}$ & $\begin{array}{l}21.2 \\
18.3 \\
19.7\end{array}$ & $\begin{array}{l}17.7 \\
13.2 \\
15.4\end{array}$ & $\begin{array}{l}2 \\
2 \\
2\end{array}$ & $\begin{array}{l}5.5 \\
2.8 \\
3.8\end{array}$ & $\begin{array}{l}3.5 \\
2.3 \\
2.8\end{array}$ & $\begin{array}{l}45 \\
34 \\
41\end{array}$ \\
\hline 5 & $32-0.1$ & 0.03 & $\begin{array}{l}\text { High } \\
\text { Low } \\
\text { Avg }\end{array}$ & $\begin{array}{l}22.1 \\
19.3 \\
20.1\end{array}$ & $\begin{array}{l}16.2 \\
13.3 \\
14.5\end{array}$ & $\begin{array}{l}5 \\
4 \\
4\end{array}$ & $\begin{array}{l}22.0 \\
21.0 \\
21.3\end{array}$ & $\begin{array}{l}17.0 \\
16.8 \\
16.9\end{array}$ & $\begin{array}{l}8 \\
6 \\
7\end{array}$ & $\begin{array}{l}5.6 \\
5.2 \\
5.4\end{array}$ & $\begin{array}{l}5.1 \\
4.8 \\
5.0\end{array}$ & $\begin{array}{l}15 \\
14 \\
15\end{array}$ \\
\hline 6 & $32-0.6$ & 0.2 & $\begin{array}{l}\text { High } \\
\text { Low } \\
\text { Avg }\end{array}$ & $\begin{array}{l}20.8 \\
19.0 \\
19.6\end{array}$ & $\begin{array}{r}1.0 .4 \\
9.7 \\
9.9\end{array}$ & $\begin{array}{l}5 \\
3 \\
4\end{array}$ & $\begin{array}{l}19.3 \\
18.0 \\
18.7\end{array}$ & $\begin{array}{l}12.6 \\
11.4 \\
11.8\end{array}$ & $\begin{array}{l}6 \\
6 \\
6\end{array}$ & $\begin{array}{l}5.5 \\
4.7 \\
5.5\end{array}$ & $\begin{array}{l}4.4 \\
3.8 \\
4.2\end{array}$ & $\begin{array}{l}25 \\
14 \\
20\end{array}$ \\
\hline 7 & $32-1.3$ & 0.4 & $\begin{array}{l}\text { High } \\
\text { Low } \\
\text { Avg }\end{array}$ & $\begin{array}{l}19.3 \\
18.3 \\
18.6\end{array}$ & $\begin{array}{l}8.4 \\
6.3 \\
7.6\end{array}$ & $\begin{array}{l}6 \\
6 \\
6\end{array}$ & $\begin{array}{l}17.8 \\
16.0 \\
17.0\end{array}$ & $\begin{array}{l}11.2 \\
10.3 \\
10.8\end{array}$ & $\begin{array}{l}8 \\
6 \\
7\end{array}$ & $\begin{array}{l}3.0 \\
2.8 \\
2.9\end{array}$ & $\begin{array}{l}2.6 \\
2.4 \\
2.5\end{array}$ & $\begin{array}{l}16 \\
16 \\
16\end{array}$ \\
\hline 8 & $32-3$ & 0.8 & $\begin{array}{l}\text { Bigh } \\
\text { Low } \\
\text { Avg }\end{array}$ & $\begin{array}{l}13.3 \\
11.6 \\
12.6\end{array}$ & $\begin{array}{l}7.0 \\
5.3 \\
6.0\end{array}$ & $\begin{array}{r}14 \\
8 \\
10\end{array}$ & $\begin{array}{l}14.0 \\
13.1 \\
13.4\end{array}$ & $\begin{array}{l}8.8 \\
7.8 \\
8.2\end{array}$ & $\begin{array}{r}12 \\
8 \\
10\end{array}$ & $\begin{array}{l}2.3 \\
2.3 \\
2.3\end{array}$ & $\begin{array}{l}2.1 \\
1.9 \\
2.0\end{array}$ & $\begin{array}{l}20 \\
17 \\
19\end{array}$ \\
\hline $9 \mathrm{a}$ & $32-3$ & 0.8 & $\begin{array}{l}\text { High } \\
\text { Low } \\
\text { Avg }\end{array}$ & $\begin{array}{l}13.8 \\
11.7 \\
12.6\end{array}$ & $\begin{array}{l}6.7 \\
5.6 \\
6.1\end{array}$ & $\begin{array}{l}7 \\
6 \\
7\end{array}$ & $\begin{array}{l}14.1 \\
12.2 \\
13.4\end{array}$ & $\begin{array}{l}8.2 \\
6.9 \\
7.5\end{array}$ & $\begin{array}{l}9 \\
7 \\
8\end{array}$ & $\begin{array}{l}3.5 \\
2.5 \\
2.9\end{array}$ & $\begin{array}{l}2.8 \\
2.3 \\
2.4\end{array}$ & $\begin{array}{l}19 \\
17 \\
18\end{array}$ \\
\hline $9 \mathrm{~b}$ & $32-3$ & 0.8 & $\begin{array}{l}\text { High } \\
\text { Low } \\
\text { Avg }\end{array}$ & $\begin{array}{r}12.6 \\
8.8 \\
11.0\end{array}$ & $\begin{array}{l}5.4 \\
4.8 \\
5.2\end{array}$ & $\begin{array}{l}9 \\
5 \\
7\end{array}$ & $\begin{array}{l}11.9 \\
10.6 \\
11.4\end{array}$ & $\begin{array}{l}6.8 \\
6.2 \\
6.3\end{array}$ & $\begin{array}{l}9 \\
6 \\
8\end{array}$ & $\begin{array}{l}2.5 \\
1.8 \\
2.2\end{array}$ & $\begin{array}{l}2.2 \\
1.5 \\
1.9\end{array}$ & $\begin{array}{l}18 \\
11 \\
15\end{array}$ \\
\hline $9 c$ & $32-3$ & 0.8 & $\begin{array}{l}\text { High } \\
\text { Low } \\
\text { AvB }\end{array}$ & $\begin{array}{l}16.3 \\
14.4 \\
15.6\end{array}$ & $\begin{array}{l}7.7 \\
7 . \frac{1}{1} \\
7.4\end{array}$ & $\begin{array}{l}8 \\
6 \\
7\end{array}$ & $\begin{array}{l}10.3 \\
10.1 \\
10.2\end{array}$ & $\begin{array}{l}5.4 \\
5.0 \\
5.2\end{array}$ & $\begin{array}{r}10 \\
9 \\
9\end{array}$ & $\begin{array}{l}4.6 \\
3.0 \\
3.7\end{array}$ & $\begin{array}{l}3.4 \\
2.6 \\
2.7\end{array}$ & $\begin{array}{l}13 \\
13 \\
13\end{array}$ \\
\hline $9 d$ & $32-3$ & 0.8 & $\begin{array}{l}\text { High } \\
\text { Low } \\
\text { Avg }\end{array}$ & $\begin{array}{l}14.3 \\
14.1 \\
14.2\end{array}$ & $\begin{array}{l}7.1 \\
6.8 \\
6.9\end{array}$ & $\begin{array}{l}6 \\
6 \\
6\end{array}$ & $\begin{array}{l}13.7 \\
12.8 \\
13.3\end{array}$ & $\begin{array}{l}7.0 \\
6.7 \\
6.9\end{array}$ & $\begin{array}{r}13 \\
8 \\
10\end{array}$ & $\begin{array}{l}3.5 \\
2.8 \\
3.2\end{array}$ & $\begin{array}{l}2.8 \\
1.5 \\
2.1\end{array}$ & $\begin{array}{l}16 \\
11 \\
15\end{array}$ \\
\hline $9 \mathrm{e}$ & $32-3$ & 0.8 & $\begin{array}{l}\text { High } \\
\text { Low } \\
\text { Avg }\end{array}$ & $\begin{array}{l}14.1 \\
13.5 \\
13.8\end{array}$ & $\begin{array}{l}6.9 \\
6.2 \\
6.5\end{array}$ & $\begin{array}{l}9 \\
9 \\
9\end{array}$ & $\begin{array}{r}10.9 \\
9.5 \\
10.3\end{array}$ & $\begin{array}{r}16.2 \\
5.0 \\
5.4\end{array}$ & $\begin{array}{r}13 \\
8 \\
11\end{array}$ & $\begin{array}{l}3.6 \\
2.8 \\
3.2\end{array}$ & $\begin{array}{l}2.7 \\
2.4 \\
2.6\end{array}$ & $\begin{array}{l}19 \\
19 \\
19\end{array}$ \\
\hline 10 & $32-4.5$ & 1.2 & $\begin{array}{l}\text { High } \\
\text { Low } \\
\text { Avg }\end{array}$ & $\begin{array}{l}14.2 \\
12.4 \\
13.4\end{array}$ & $\begin{array}{l}6.7 \\
6.3 \\
6.4\end{array}$ & $\begin{array}{l}5 \\
2 \\
4\end{array}$ & $\begin{array}{l}-- \\
---\end{array}$ & $\begin{array}{l}-- \\
---\end{array}$ & $\begin{array}{l}-- \\
---\end{array}$ & $\begin{array}{l}0.6 \\
0.6 \\
0.6\end{array}$ & $\begin{array}{l}0.5 \\
0.5 \\
0.5\end{array}$ & $\begin{array}{l}28 \\
34 \\
31\end{array}$ \\
\hline $\begin{array}{l}\text { [a] The } \\
\text { [b] The } \\
\text { [c] The } \\
\text { [d] The }\end{array}$ & $\begin{array}{l}h, \text { low, and } \\
\text { imate tensi } \\
\text { sile yield } \\
\text { cent elongs }\end{array}$ & $\begin{array}{l}\text { strengt } \\
\text { ength } \\
\text { on }(z E)\end{array}$ & $\begin{array}{l}\text { ue is presen } \\
\text { is designate } \\
\text { s) is } 0.2 \% \\
\text { s determined }\end{array}$ & $\begin{array}{l}\text { for two } \\
\text { ts. } \\
\text { et. } \\
\text { one-inch }\end{array}$ & e-length & ecimens & & each al: & & & & \\
\hline
\end{tabular}


APPENDIX C

EFFECT OF SILICON IN URANIUM-ALUMINUM FUEL ON CHEMICAL REPROCESSING 
APPENDIX C

EFFECT OF SILICON IN URANIUM-ALUMINUM FUEL ON CHEMICAL REPROCESSING

\section{DISSOLUTION RATES}

\subsection{Dissolution Data and Calculations of Instantaneous Rates}

During the dissolution of alloy specimens, aliquots of the dissolver solution were removed and analyzed for aluminum, hydrogen ion, and uranium. Figures $\mathrm{C}-1$ through $\mathrm{C}-13$ show the decrease of acidity as the dissolution progresses and the corresponding decrease in the dissolution rate of the aluminum. The square of the aluminum concentration is also plotted on these figures using the same time scale. The initial portion of this latter curve is approximately a straight line indicating that the dissolution of the aluminum obeys a parabolic rate law, $\mathrm{Al}^{2}=\mathrm{kt}$, where $\mathrm{Al}$ is the aluminum concentration in solution, $\mathrm{k}$ is the rate constant, and $t$ is the time from the start of the dissolution. The rate, $\mathrm{dAl} / \mathrm{dt}$, is equal to the slope of the curve shown in the figures divided by twice the concentration of the aluminum in solution at a particular instant during the dissolution. The calculated instantaneous rates for levels of 10 and $30 \mathrm{~g} /$ liter of aluminum in the dissolver solution are given for duplicate dissolutions in Table C-I.

Dissolution rates are reported as $\mathrm{mg}$ of aluminum dissolved per $\mathrm{cm}^{2}$-min. Similarly, the rates for the alloys could be calculated on the basis of the uranium dissolved. The data for the concentration of uranium in solution from which these calculations can be made are given in Table C-II.

\subsection{Difference in Dissolution Rate of Aluminum and Uranium}

During the dissolution of uranium alloys, aluminum appeared in the dissolver solution more rapidly than uranium. A curve showing the relative dissolution of uranium and aluminum from an alloy containing 22 wt $\%$ uranium and $5 \mathrm{wt} \%$ silicon is shown in Figure 4 of the text. Similar curves were prepared for each of the uranium-aluminum alloys, and the percent uranium dissolved was determined from the curve for the point at which 30,50 , and $80 \%$ of the aluminum was dissolved from the alloy. Table C-III presents the data obtained for the 22 wt $\%$ uranium alloys, and Table C-IV presents the data for the $32 \mathrm{wt} \%$ uranium alloys. The slower dissolution is caused by the intermetallic fuel particles, since the uranium dissolution lags considerably even in alloys which do not contain silicon. In most cases, the lag in dissolution is enhanced by the addition of silicon, and it is greatest in the alloys with the highest silicon-to-uranium atom ratio. 


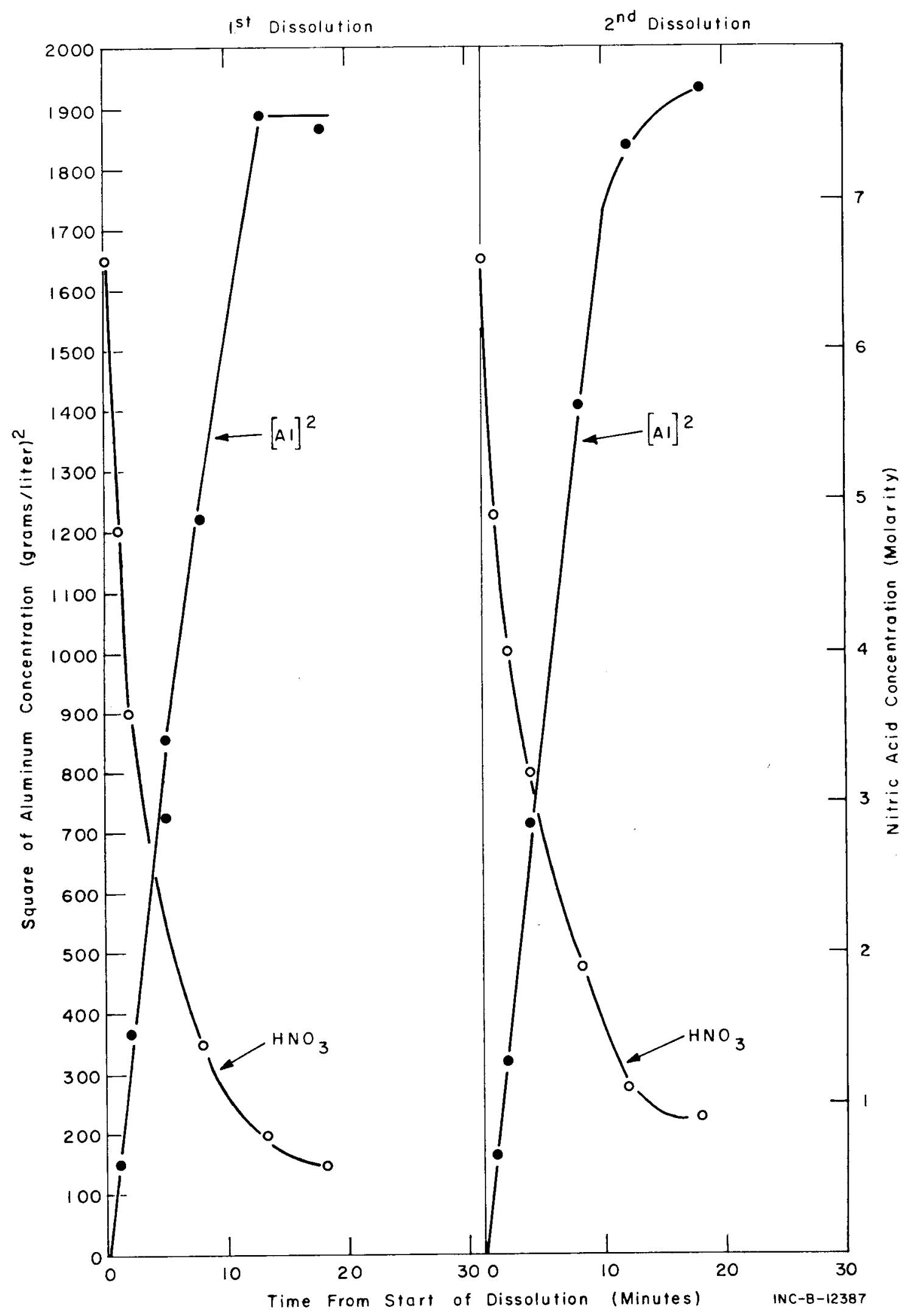

Figure C-l Aluminum and nitric acid concentration during dissolution of aluminum. 


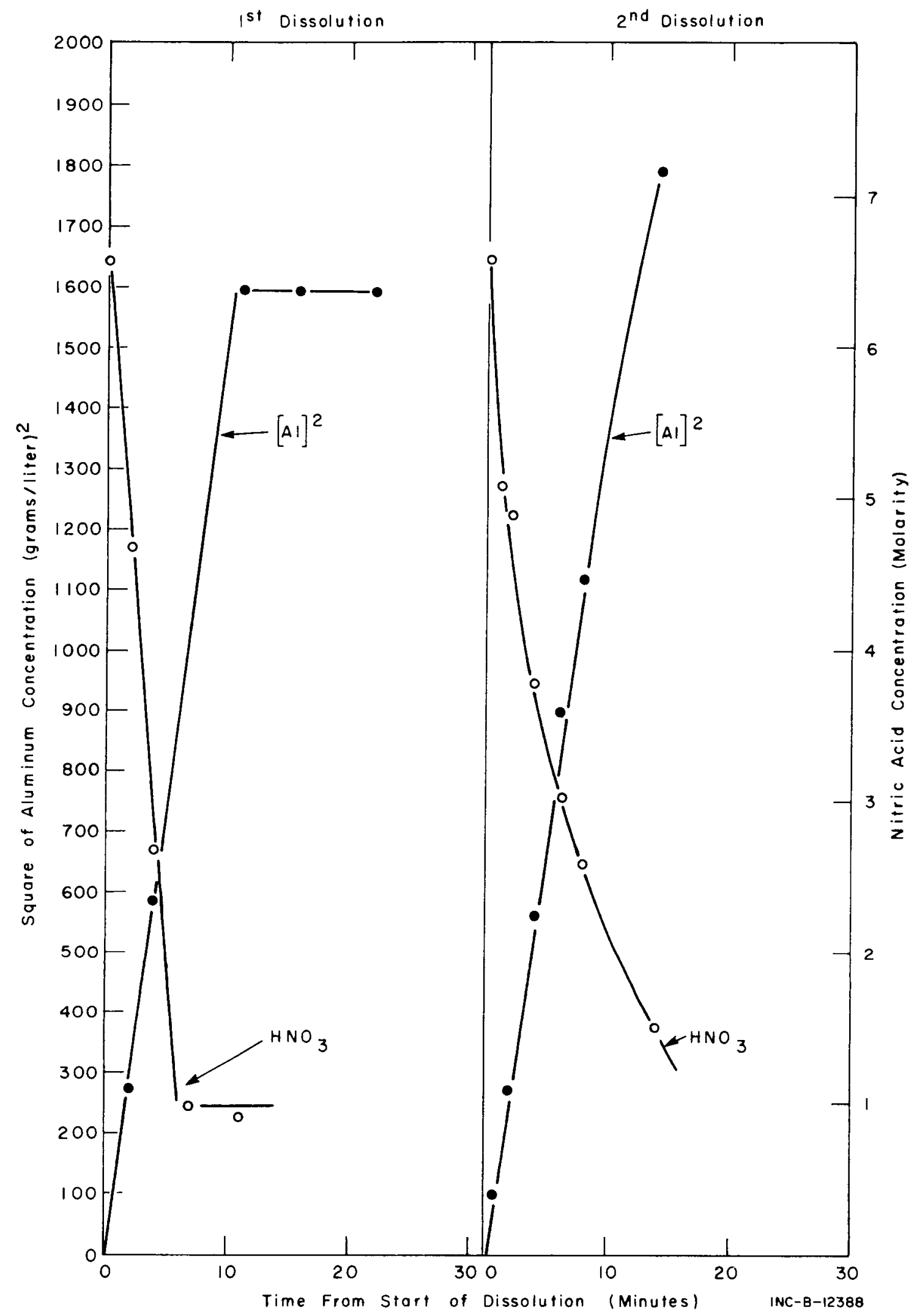

Figure C-2 Aluminum and nitric acid concentration during dissolution of aluminum alloy containing 0.6 wt $\%$ silicon. 


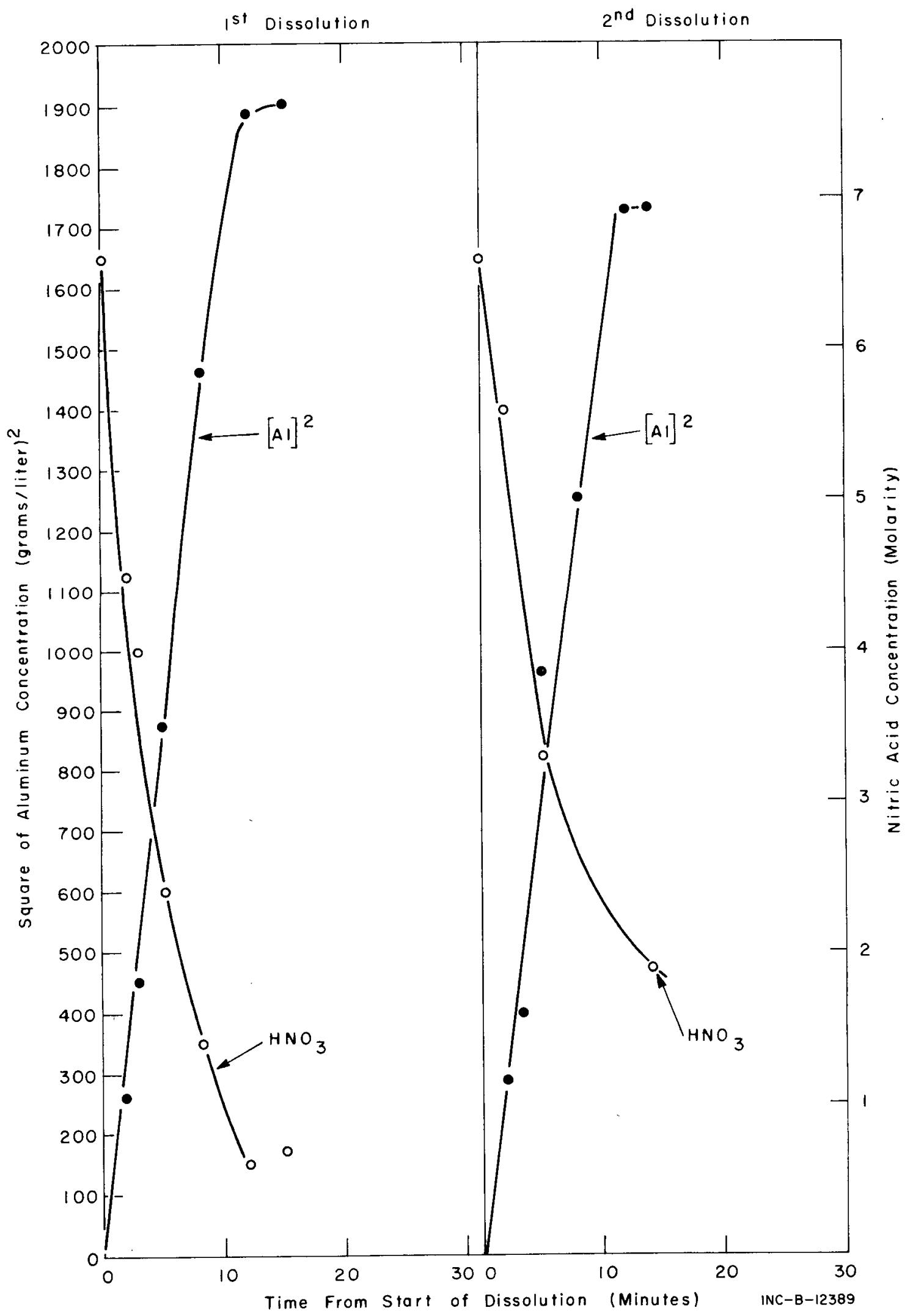

Figure C-3 Aluminum and nitric acid concentration during dissolution of aluminum alloy containing 1.3 wt $\%$ silicon. 


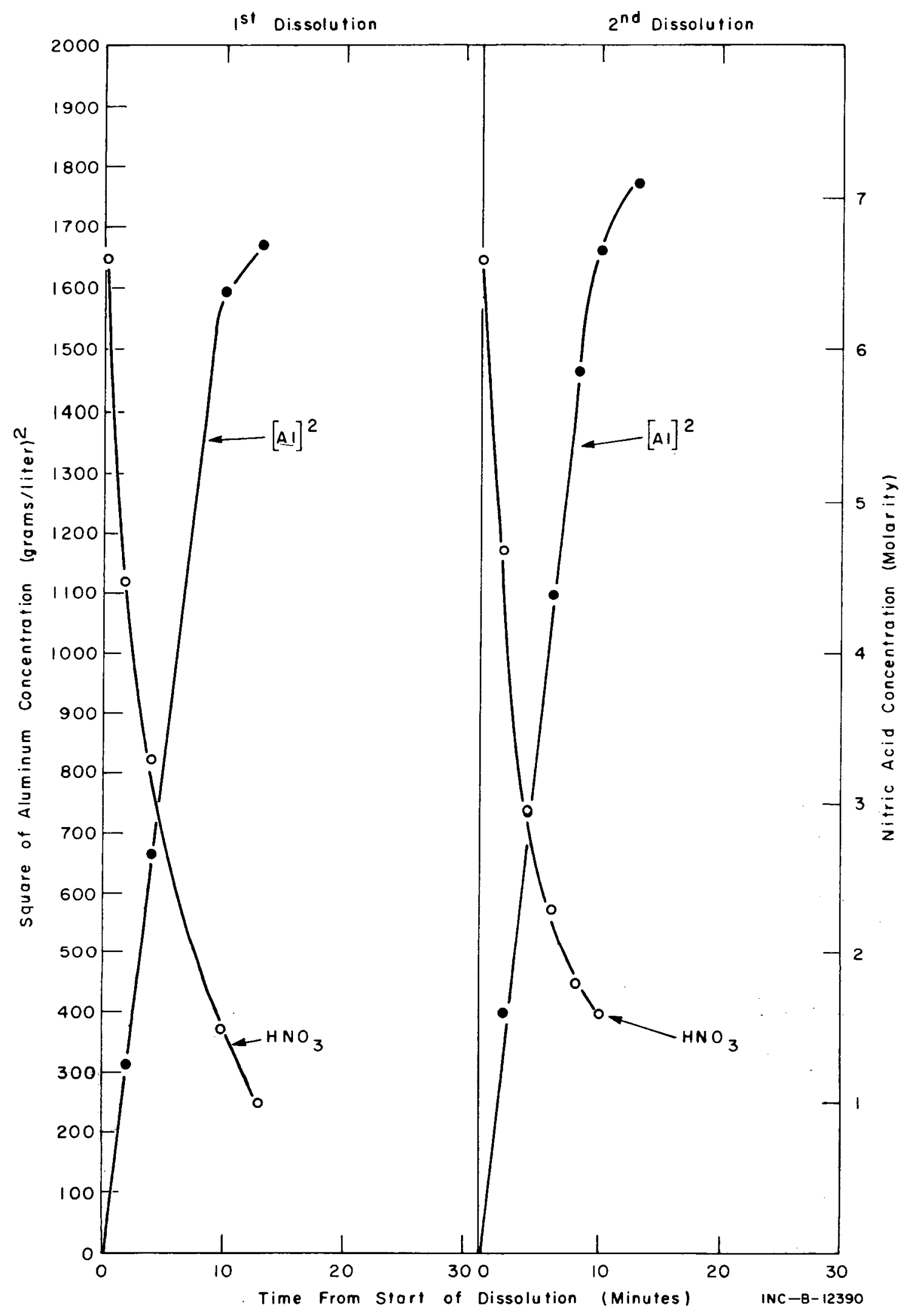

Figure C-4 Aluminum and nitric acid concentration during dissolution of aluminum alloy containing 4.5 wt $\%$ silicon. 


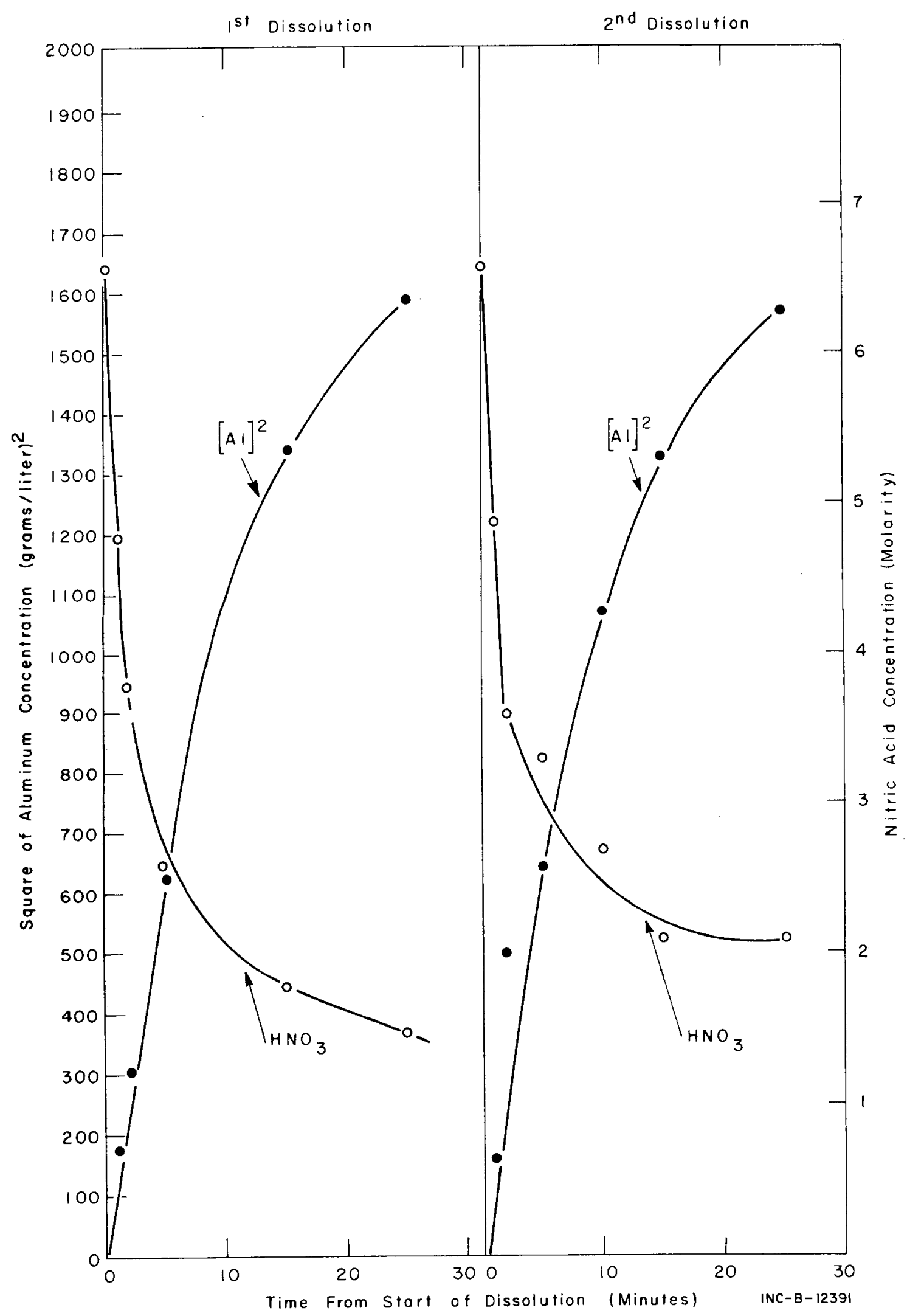

Figure $\mathrm{C}-5$ Aluminum and nitric acid concentration during dissolution of aluminum alloy containing $10.5 \mathrm{wt} \%$ silicon. 


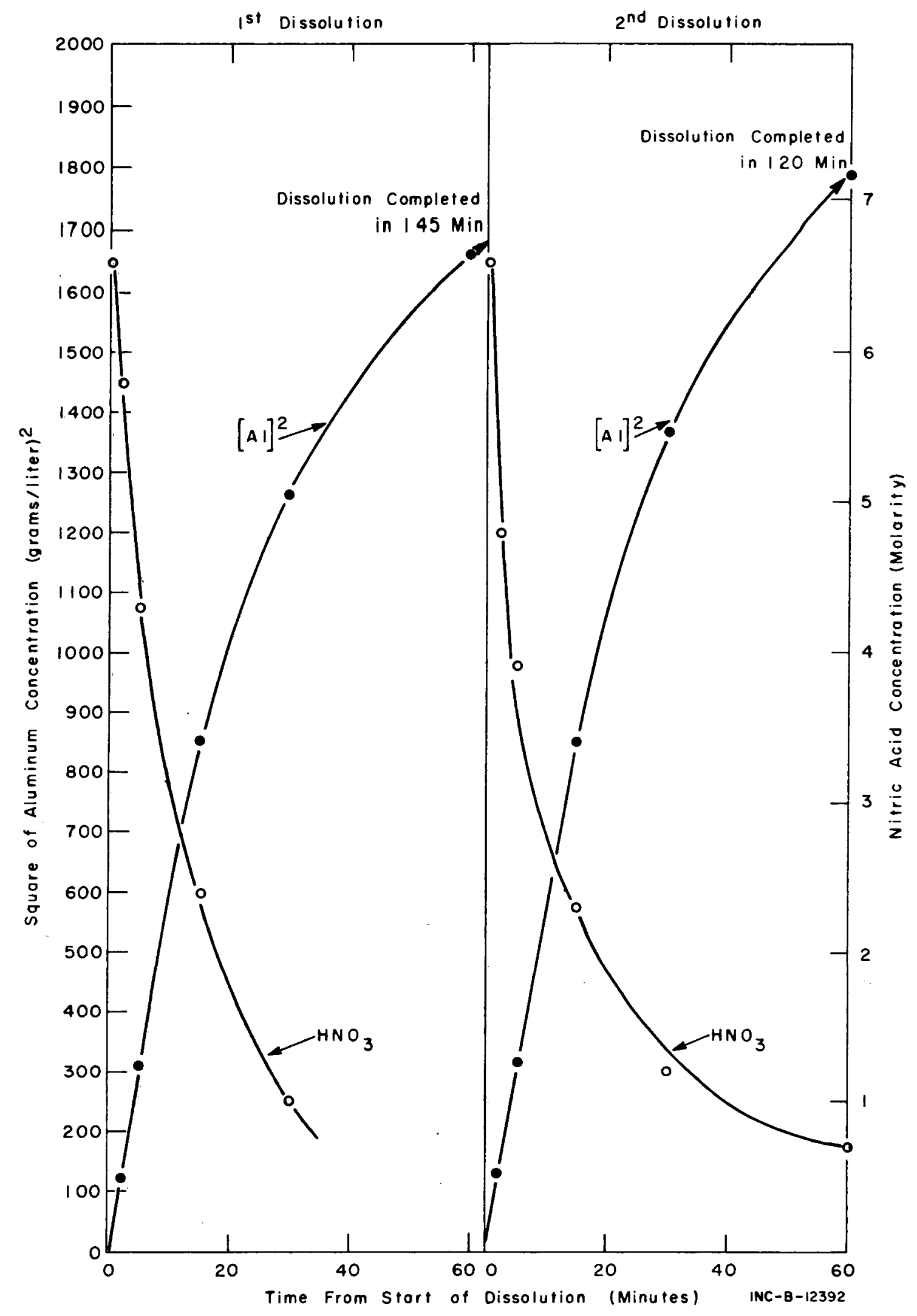

Figure C-6 Aluminum and nitric acid concentration during dissolution of aluminum alloy containing $22 \mathrm{wt} \%$ uranium and $0 \mathrm{wt} \%$ silicon. 


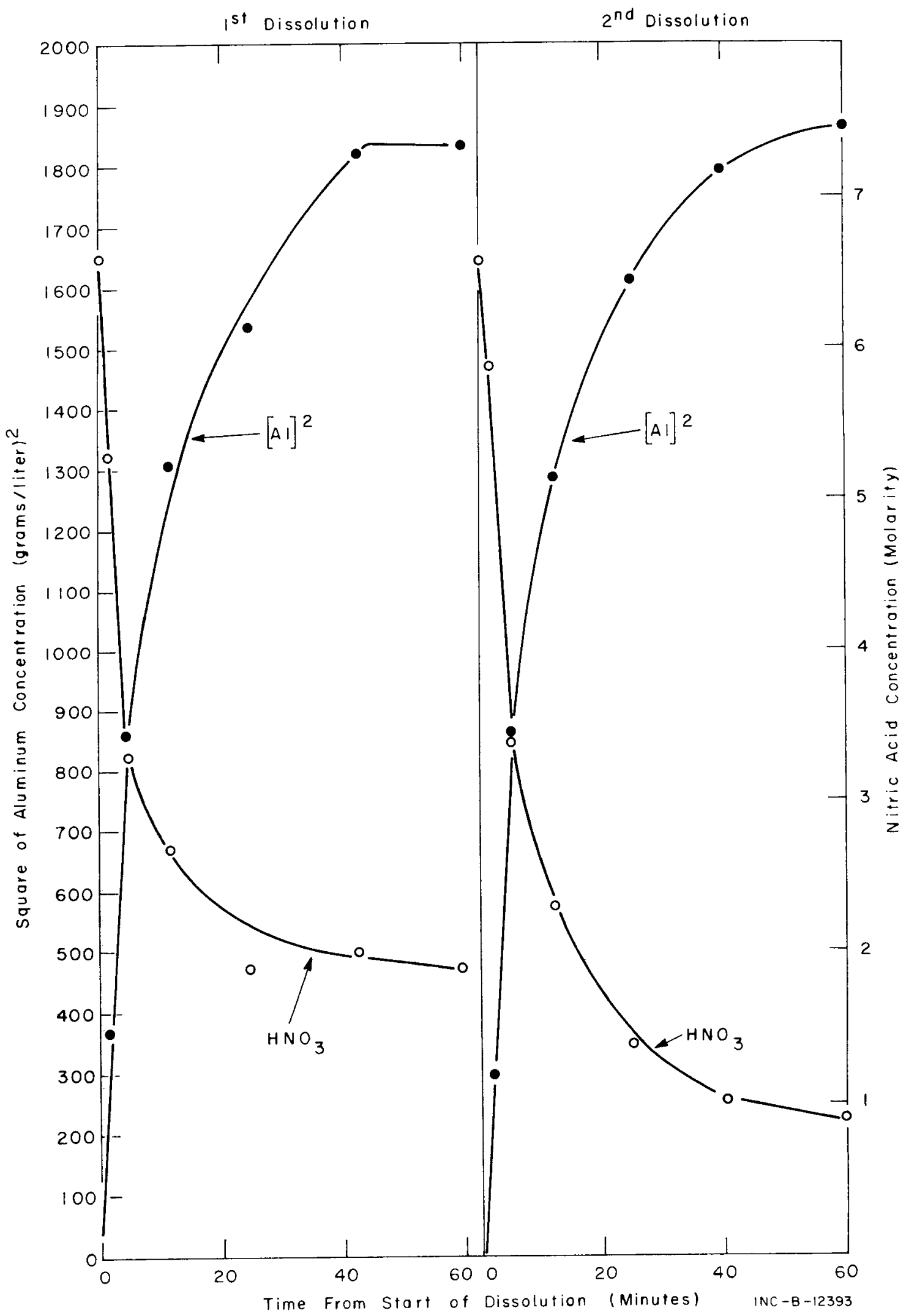

Figure C-7 Aluminum and nitric acid concentration during dissolution of aluminum alloy containing $22 \mathrm{wt} \%$ uranium and 3 wt $\%$ silicon. 


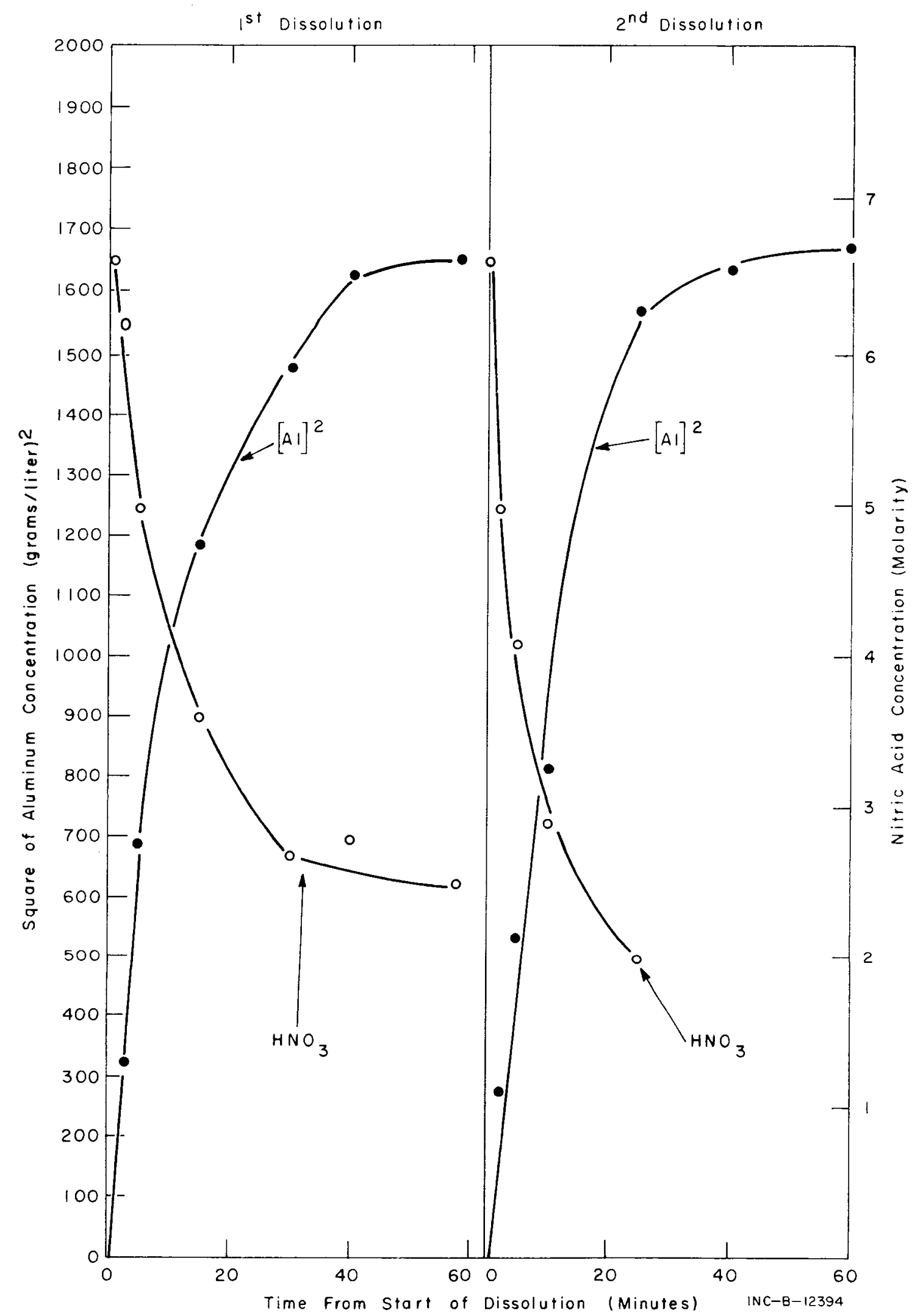

Figure C-8 Aluminum and nitric acid concentration during dissolution of aluminum alloy containing 22 wt \% uranium and 4.5 wt \% silicon. 


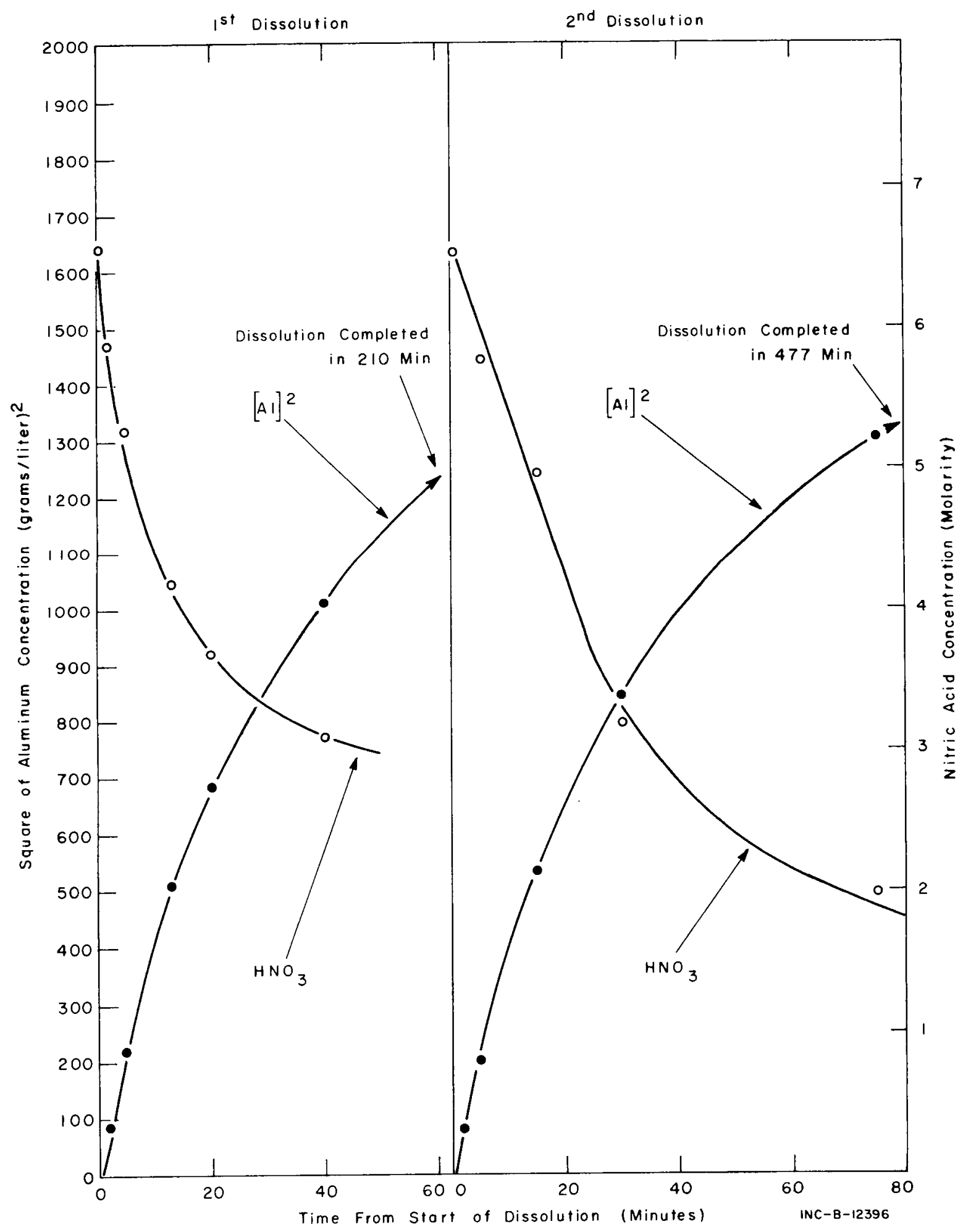

Figure C-9 Aluminum and nitric acid concentration during dissolution of aluminum alloy containing 32 wt $\%$ uranium and 0 wt $\%$ silicon. 


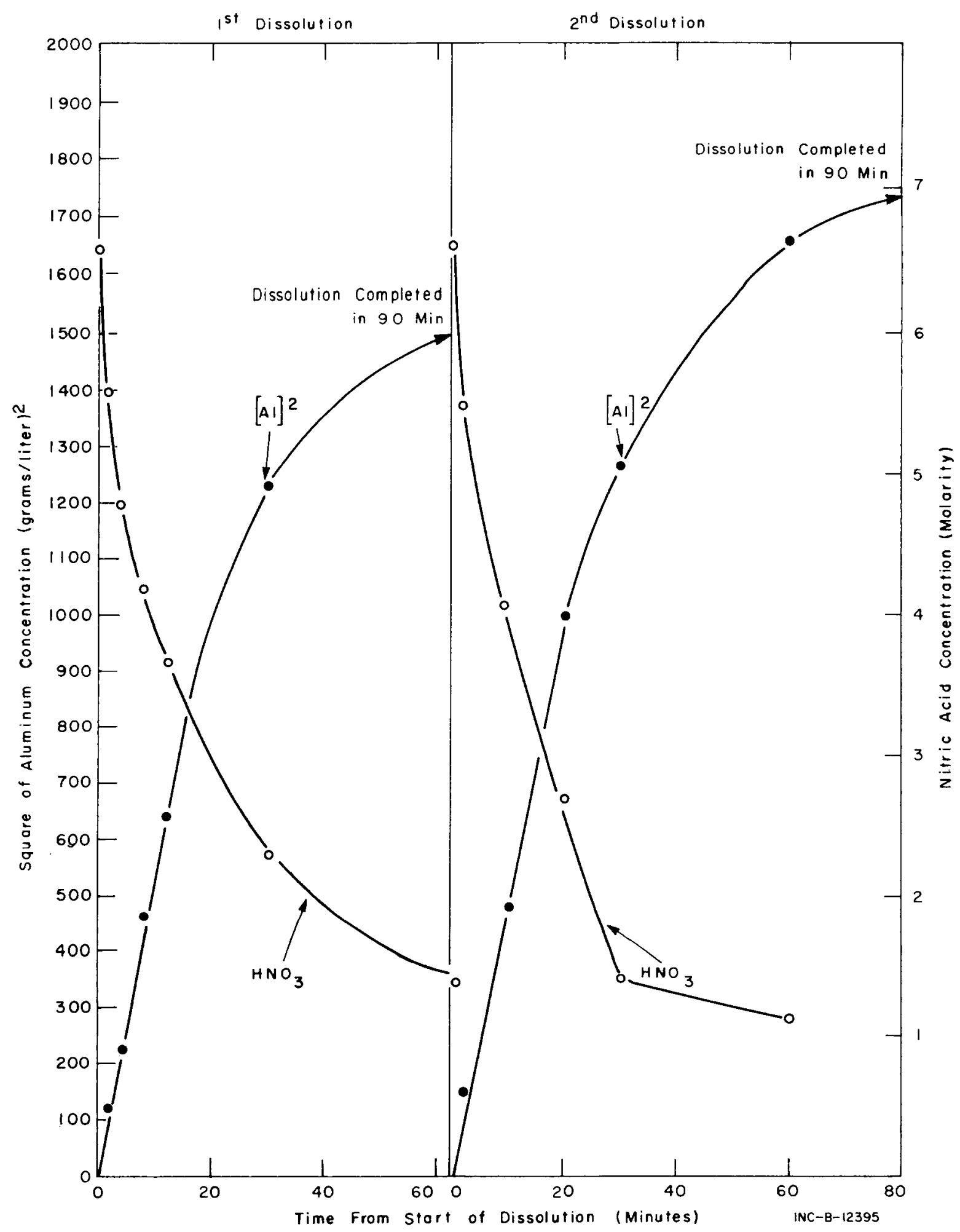

Figure C-10 Aluminum and nitric acid concentration during dissolution of aluminum alloy containing 32 wt $\%$ uranium and 0.6 wt $\%$ silicon. 


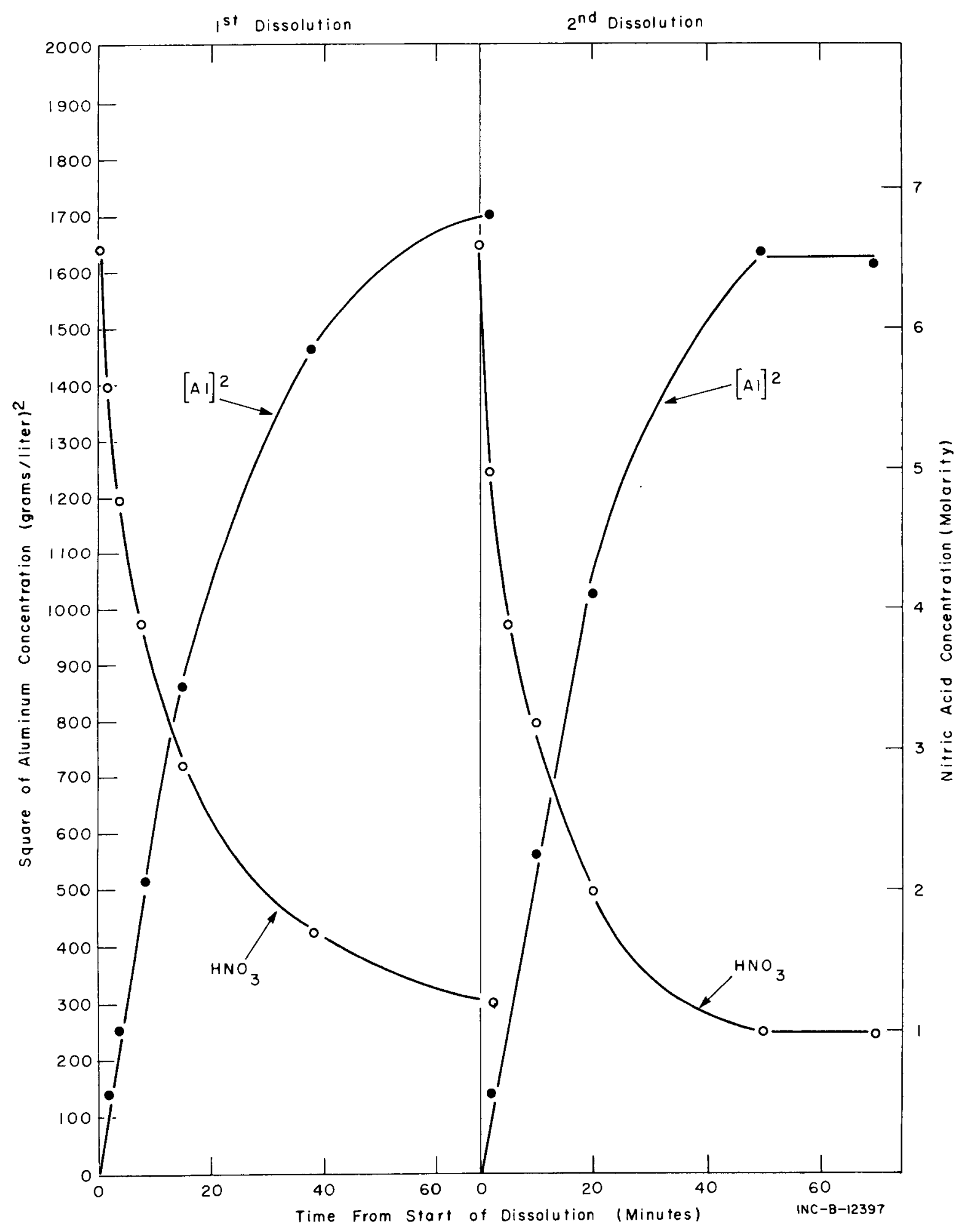

Figure C-II Aluminum and nitric acid concentration during dissolution of aluminum alloy containing $32 \mathrm{wt} \%$ uranium and $1.3 \mathrm{wt} \%$ silicon. 


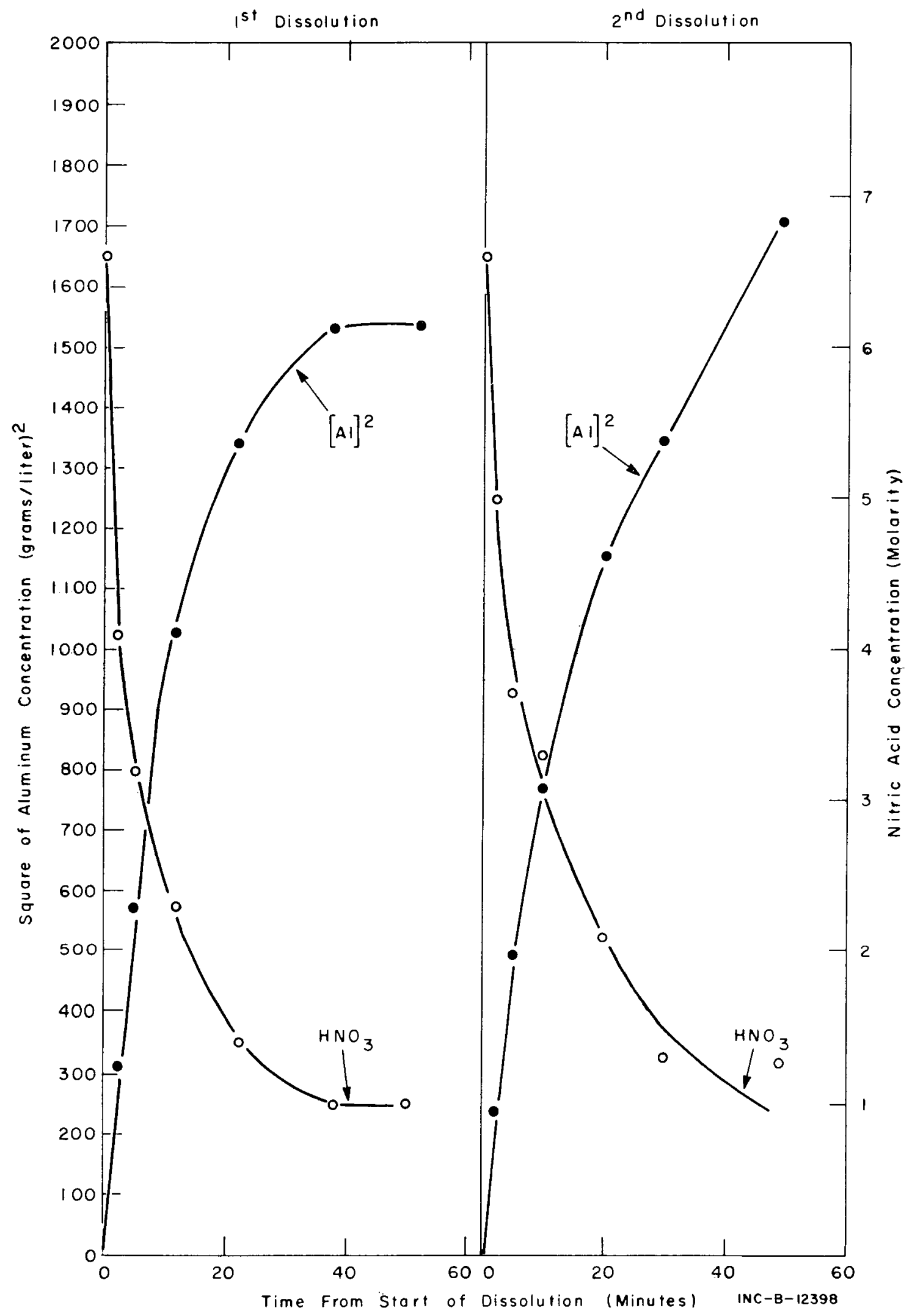

Figure C-12 Aluminum and nitric acid concentration during dissolution of aluminum alloy containing 32 wt $\%$ uranium and 3 wt $\%$ silicon. 


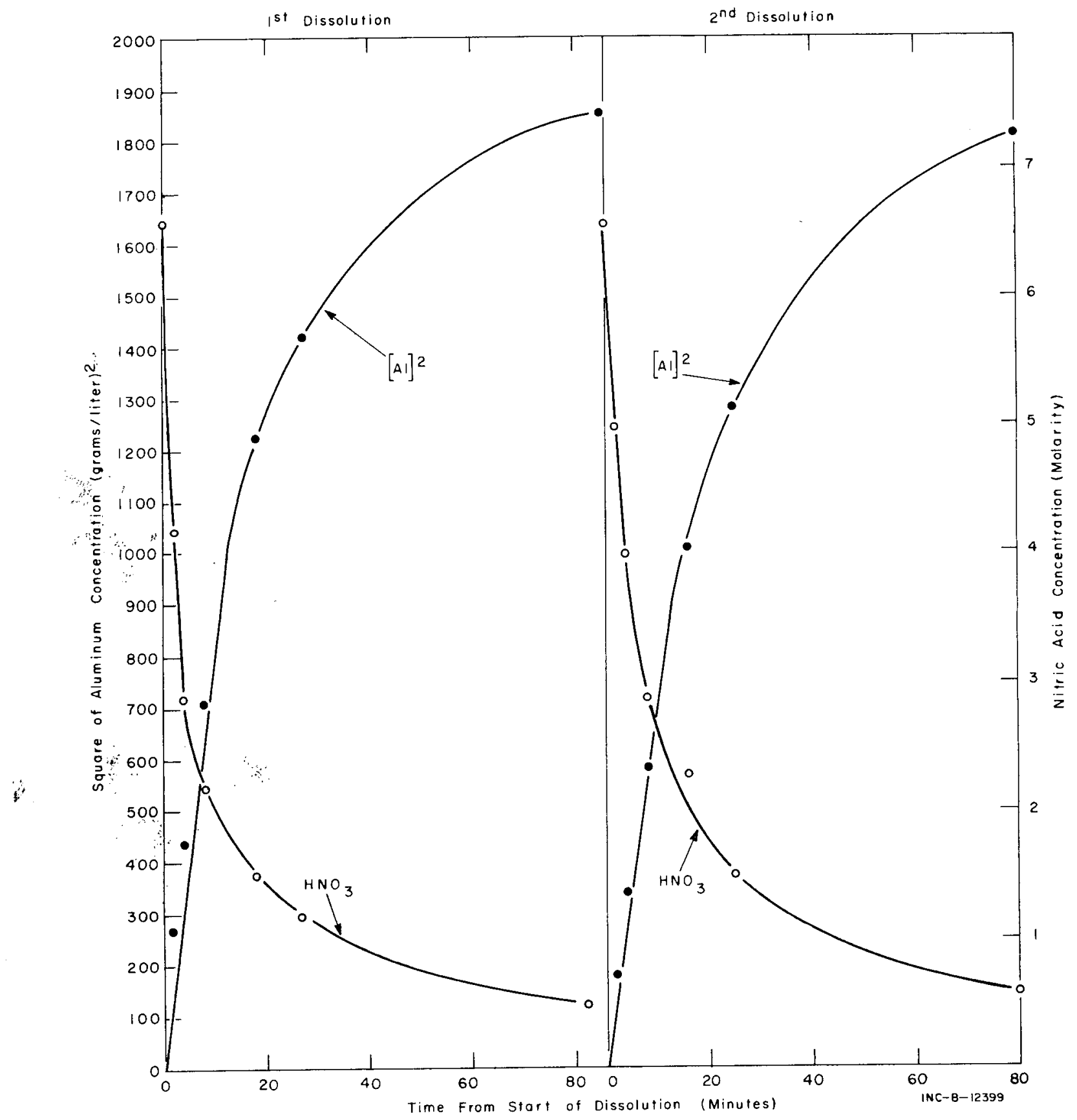

Figure C-13 Aluminum and nitric acid concentration during dissolution of aluminum alloy containing $32 \mathrm{wt} \%$ uranium and $4.5 \mathrm{wt} \%$ silicon. 
TABLE C-I

MULTIPLICATE DISSOLUTION RATE DATA FOR

ALLOY COUPONS IN BOILING $\left(103^{\circ} \mathrm{C}\right)$ NITRIC ACID

\begin{tabular}{|c|c|c|c|c|c|c|}
\hline \multirow{3}{*}{$\begin{array}{c}\text { Silicon } \\
\text { in } \\
\text { Alloy } \\
\text { (wt } \%) \\
\end{array}$} & \multicolumn{6}{|c|}{ Dissolution Rates of Aluminum (mg/ $\left./ \mathrm{cm}^{2}-\mathrm{min}\right)$} \\
\hline & \multicolumn{2}{|c|}{ O wt\% U Alloy } & \multicolumn{2}{|c|}{$22 \mathrm{wt} \%$ U Alloy } & \multicolumn{2}{|c|}{$32 \mathrm{wt} \% \mathrm{U}$ Alloy } \\
\hline & $\begin{array}{l}10 \mathrm{~g} \mathrm{Al} / 1 \\
\text { in Soln. }\end{array}$ & $\begin{array}{l}30 \mathrm{~g} \mathrm{Al} / 1 \\
\text { in Soln. }\end{array}$ & $\begin{array}{l}10 \mathrm{~g} \mathrm{Al} / \mathrm{l} \\
\text { in Soln. }\end{array}$ & $\begin{array}{c}30 \mathrm{~g} \mathrm{Al} / 1 \\
\text { in Soln. }\end{array}$ & $\begin{array}{l}10 \mathrm{Bl} / \mathrm{I} \\
\text { in Soln. }\end{array}$ & $\begin{array}{l}30 \mathrm{~g} \mathrm{Al} / 1 \\
\text { in Soln. }\end{array}$ \\
\hline \multirow[t]{2}{*}{0} & 67 & 26 & 23 & 9 & 18 & 4 \\
\hline & 67 & 26 & 23 & 9 & 17 & 4 \\
\hline \multirow[t]{2}{*}{0.6} & 56 & 22 & - & -- & 20 & 8 \\
\hline & 59 & 23 & -- & -- & 31 & 8 \\
\hline \multirow[t]{2}{*}{1.3} & 67 & 26 & -- & -- & 25 & 8 \\
\hline & 59 & 23 & - & -- & 31 & 10 . \\
\hline \multirow[t]{5}{*}{3.0} & -- & - & 66 & 26 & $46[a]$ & $\left.13^{[a}\right]$ \\
\hline & -- & - & 63 & 25 & 40 & 11 \\
\hline & & & & & 39 & 11 \\
\hline & & & & & 49 & 13 \\
\hline & & & & & 45 & 12 \\
\hline \multirow[t]{2}{*}{4.5} & 69 & 27 & $4 I$ & 16 & 62 & 15 \\
\hline & 71 & 28 & 45 & 13 & 50 & 11 \\
\hline \multirow[t]{2}{*}{10.5} & 42 & 9 & -- & -- & -- & -- \\
\hline & 33 & 7 & -- & -- & -- & -- \\
\hline
\end{tabular}

[a] Five different batches were rolled from Heat 9; one dissolution of each batch was made. 
TABLE C-II

URANIUM CONCENTRATION IN SOLUTION DURING DISSOLUTION OF ALUMINUM-URANIUM-SILICON ALLOYS

Data for Alloys With 22 wt\% Uranium (g/liter of uranium)

\begin{tabular}{|c|c|c|c|c|c|c|c|c|}
\hline \multicolumn{3}{|c|}{0 wt $\%$ Si Alloy } & \multicolumn{3}{|c|}{$3.0 \mathrm{wt} \%$ Si Alloy } & \multicolumn{3}{|c|}{4.5 wt $\%$ Si Alloy } \\
\hline$t^{[a]}$ & lst & 2nd & $t^{[a]}$ & Ist & 2nd & $t^{[a]}$ & Ist & 2nd \\
\hline$(\operatorname{Min})$ & Run & Run & (Min) & Run & Run & (Min) & Run & Run \\
\hline$\sqrt{2}$ & $\overline{2.3}$ & $\overline{2.4}$ & $\overline{2}$ & $\overline{3.5}$ & $\overline{3.1}$ & $\frac{2}{2}$ & $\overline{2.3}$ & 2.4 \\
\hline 5 & 4.1 & 4.5 & 5 & 5.6 & 6.2 & 5 & 5.0 & 4.7 \\
\hline 15 & 7.6 & 7.2 & 12 & 8.2 & 8.6 & 10 & -- & 7.0 \\
\hline 30 & 9.7 & 10.4 & 25 & 8.9 & 8.8 & 15 & 8.6 & -- \\
\hline 60 & 11.0 & 11.8 & 40 & --- & 10.3 & 25 & --- & 9.9 \\
\hline 120 & --- & 12.0 & 43 & 10.6 & -- & 30 & 10.4 & -- \\
\hline 145 & 11.5 & --- & 60 & 10.8 & 11.1 & 40 & 10.7 & 10.9 \\
\hline & & & & & & 58 & 11.1 & 11.3 \\
\hline
\end{tabular}

Data for Alloys With 32 wt\% Uranium (g/liter of uranium)

\begin{tabular}{|c|c|c|c|c|c|c|c|c|c|c|c|c|c|c|}
\hline \multicolumn{3}{|c|}{0 wt $\%$ Si Alloy } & \multicolumn{3}{|c|}{0.6 wt $\%$ Si Alloy } & \multicolumn{3}{|c|}{$1.3 \mathrm{wt} \%$ Si Alloy } & \multicolumn{3}{|c|}{$3.0 \mathrm{wt} \% \mathrm{Si}$ Alloy } & \multicolumn{3}{|c|}{$4.5 \mathrm{wt} \% \mathrm{Si}$ Alloy } \\
\hline$t^{[a]}$ & lst & 2nd & $t^{[a]}$ & lst & 2nd & $t^{[a]}$ & lst & 2nd & $t^{[a]}$ & Ist & 2nd & $t^{[a]}$ & lst & $2 n d$ \\
\hline$(\operatorname{Min})$ & Run & Run & $(\underline{M i n})$ & Run & Run & (Min) & Run & Run & $(\underline{M i n})$ & Run & Run & $(\underline{M i n})$ & Run & Run \\
\hline 2 & $\overline{1.8}$ & $\overline{2.7}$ & 2 & $\overline{3.9}$ & $\overline{4.2}$ & 2 & $\overline{4.9}$ & $\overline{5.1}$ & 2 & 6.0 & $\overline{5.6}$ & 2 & $\overline{5.6}$ & $\overline{4.7}$ \\
\hline 5 & 4.7 & 4.9 & 4 & 5.9 & --- & 4 & 6.9 & --- & 4 & 6.6 & 7.4 & 5 & 8.1 & 8.2 \\
\hline 13 & 9.0 & -- & 8 & 9.3 & --- & 5 & -- & 8.0 & 8 & 9.9 & 9.5 & 10 & -- & 11.9 \\
\hline 15 & -- & 9.5 & 10 & --- & 10.1 & 8 & 9.8 & -- & 16 & --- & 16.0 & 12 & 13.4 & -- \\
\hline 20 & 10.8 & -- & 12 & 10.7 & -- & 10 & -- & 11.2 & 18 & 16.7 & --- & 20 & -- & 15.8 \\
\hline 30 & --- & 12.8 & 20 & --- & 14.9 & 15 & 13.1 & --- & 25 & --- & 18.0 & 22 & 16.5 & --- \\
\hline 40 & 14.4 & --- & 30 & 16.5 & 17.8 & 20 & --- & 14.9 & 27 & 17.9 & --- & 30 & -- & 17.3 \\
\hline 75 & -- & 16.0 & 60 & --- & 19.5 & 38 & 17.2 & -- & 80 & -- & 21.3 & 38 & 17.9 & --- \\
\hline 142 & --- & 17.8 & 90 & 18.9 & 20.3 & 50 & --- & 19.4 & 85 & 20.3 & --- & 50 & 17.9 & 19.1 \\
\hline 210 & 19.5 & -- & & & & 70 & 19.0 & 19.3 & & & & & & \\
\hline 477 & --- & 19.6 & & & & & & & & & & & & \\
\hline
\end{tabular}




\section{TABLE C-III}

RELATIVE PERCENT OF ALUMINUM AND URANIUM DISSOLVED

DURING DISSOLUTION OF 22 WT\% URANIUM ALIOY ${ }^{[a]}$

\begin{tabular}{|c|c|c|c|}
\hline $\begin{array}{l}\text { Silicon } \\
\text { in Alloy } \\
\text { (wt } \%)\end{array}$ & $\begin{array}{c}\text { Aluminum } \\
\text { Dissolution } \\
30 \text { wt } \% \text { Complete } \\
\text { (\% U Dissolved) }\end{array}$ & $\begin{array}{c}\text { Aluminum } \\
\text { Dissolution } \\
50 \text { wt } \% \text { Complete } \\
(\% \text { U Dissolved })\end{array}$ & $\begin{array}{c}\text { Aluminum } \\
\text { Dissolution } \\
80 \text { wt } \% \text { Complete } \\
(\% \text { U Dissolved) }\end{array}$ \\
\hline 0 & 25 & 45 & 75 \\
\hline 3.0 & 17 & 34 & 70 \\
\hline 4.5 & 17 & 39 & 72 \\
\hline
\end{tabular}

[a] Data are the averages of duplicate runs.

TABLE C-TV

RETATIVE PERCENT OF ALUMINUM AND URANIUM DISSOLVED DURING DISSOLUTION OF 32 WT\% URANIUM ALLOY[a]

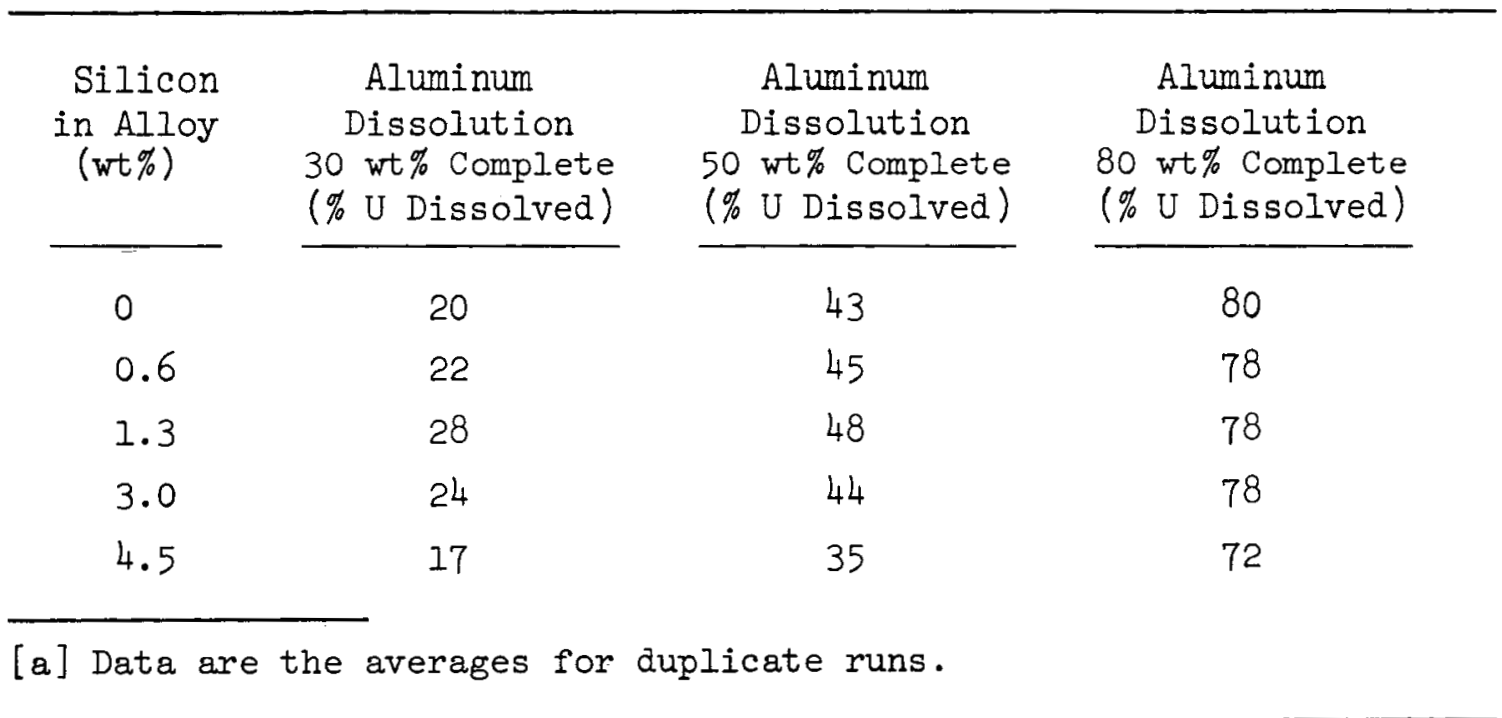




\subsection{Behavior of Dissolved Silicon During Dissolution}

During one dissolution of each alloy, samples of the dissolver solutions were filtered through a $0.3 \mu$ membrane filter and analyzed for silicon within one to three hours after completion of the dissolution. The samples were analyzed by emission spectroscopy, and therefore, the analysis is the sum of the dissolved silicon and the particulate silicon after filtration. The solutions from the uranium alloys were exceedingly difficult to filter and, in most cases, ten-fold dilutions were made with water to improve the filterability and decrease the loss of liquid by evaporation. The silicon contents of the filtrates are arranged according to the approximate time from the start of the dissolution in Tables $\mathrm{C}-\mathrm{V}$ and $\mathrm{C}-\mathrm{VI}$ for the alloys containing no uranium and for the alloys containing $32 \mathrm{wt} \%$ uranium, respectively.

\section{TABLE C-V}

SILICON CONCENTRATION IN SOLUTION DURING DISSOLUTION OF ALUMTNUM ALLOYS CONTAINING NO URANIUM ( $\mu \mathrm{g} \mathrm{Si} / \mathrm{ml}$ )

\begin{tabular}{cccccccccccc}
\hline $\begin{array}{c}\text { Silicon } \\
\text { in Alloy } \\
\text { (wt\%) }\end{array}$ & $\begin{array}{c}\text { Approximate } \\
\text { min }\end{array}$ & $\begin{array}{c}\text { mine } \\
\text { min }\end{array}$ & $\begin{array}{c}\text { min } \\
\text { min }\end{array}$ & $\begin{array}{l}12 \\
\text { min }\end{array}$ & $\begin{array}{l}16 \\
\text { min }\end{array}$ & $\begin{array}{l}20 \\
\text { min }\end{array}$ & $\begin{array}{r}30-55 \\
\text { min }\end{array}$ & $\begin{array}{r}60-80 \\
\text { min }\end{array}$ & $\begin{array}{c}>85 \\
\text { min }\end{array}$ \\
\hline 0.6 & 16 & 18 & 30 & 27 & 70 & 23 & -- & -- & -- \\
1.3 & 18 & 11 & 12 & 15 & 20 & -- & -- & -- & -- \\
4.5 & 18 & 11 & 48 & 8 & -- & -- & -- & -- & -- \\
10.5 & 12 & 12 & -- & 14 & -- & -- & 35 & 31 & -- \\
\hline
\end{tabular}

\section{TABLE C-VI}

SILICON CONCENTRATION IN SOLUTION DURING DISSOLUTION OF ALUMINUM ALLOYS CONTAINING 32\% URANIUM ( $\mu \mathrm{g} \mathrm{Si} / \mathrm{ml}$ )

\begin{tabular}{lrrrrrrrrrr}
\hline $\begin{array}{l}\text { Silicon } \\
\text { in Alloy } \\
\text { (wt\%) }\end{array}$ & $\begin{array}{c}\text { Approximate } \\
\text { in }\end{array}$ & $\begin{array}{r}4 \\
\text { min }\end{array}$ & $\begin{array}{c}8 \\
\text { min }\end{array}$ & $\begin{array}{l}12 \\
\text { min }\end{array}$ & $\begin{array}{l}\text { From } \\
\text { min }\end{array}$ & $\begin{array}{l}\text { Start of } \\
\text { min }\end{array}$ & $\begin{array}{r}30-55 \\
\text { min }\end{array}$ & $\begin{array}{r}60-80 \\
\text { min }\end{array}$ & $\begin{array}{r}>85 \\
\text { min }\end{array}$ \\
\hline 0 & 8 & 33 & 8 & -- & 15 & -- & 17 & -- & 19 \\
0.6 & 30 & 55 & 120 & 110 & -- & -- & 170 & -- & 150 \\
1.3 & 160 & 230 & 210 & -- & 400 & -- & 600 & 550 & -- \\
3 & 480 & 480 & 650 & -- & 24 & -- & 12 & 11 & -- \\
4.5 & 310 & 460 & -- & 930 & -- & 510 & 32 & 20 & -- \\
\hline
\end{tabular}


The data show that the silicon associated with the uranium alloys is dissolved, while the silicon in the non-uranium alloys is not dissolved. In alloys containing uranium, the amount of dissolved silicon increased with increasing silicon content up to 1.3 wt silicon in the alloy. Above $1.3 \mathrm{wt} \%$ silicon, the dissolved silicon increased during the initial portion of the dissolution then suddenly decreased indicating that the silicon dissolved during the later portion of the dissolution was removed by the filtration. In the case of separate dissolutions of five coupons having the same composition (Table C-VII), the decrease occurred between 8 and 20 minutes after the start of the dissolution.

TABLE C-VII

SILICON CONCENTRATION IN SOLUTION DURING DISSOLUTION OF ALUMINUM ALLOY CONTAINING 32\% URANIUM AND 3\% SILICON ( $\mathrm{Hg} \mathrm{Si} / \mathrm{mI}$ )

\begin{tabular}{|c|c|c|c|c|c|c|c|c|}
\hline \multirow{2}{*}{$\begin{array}{l}\text { Silicon } \\
\text { in Alloy } \\
\text { (wt } \% \text { ) }\end{array}$} & \multicolumn{8}{|c|}{ Approximate Time From Start of Dissolution } \\
\hline & $\begin{array}{c}2 \\
\text { min. }\end{array}$ & $\begin{array}{c}4 \\
\min .\end{array}$ & $\begin{array}{c}8 \\
\text { min. } \\
\end{array}$ & $\begin{array}{r}16 \\
\text { min. }\end{array}$ & $\begin{array}{r}20 \\
\text { min. } \\
\end{array}$ & $\begin{array}{r}30-55 \\
\text { min. }\end{array}$ & $\begin{array}{r}60-80 \\
\text { min. }\end{array}$ & $\begin{array}{l}>85 \\
\text { min. }\end{array}$ \\
\hline 3 & 480 & 480 & 650 & 24 & -- & 12 & 11 & -- \\
\hline 3 & 440 & 380 & 660 & 35 & -- & 13 & 10 & -- \\
\hline 3 & 440 & -- & 530 & 350 & -- & 27 & 9 & 25 \\
\hline 3 & 680 & -- & -- & 49 & - & 12 & 12 & - \\
\hline 3 & 340 & 470 & -- & 200 & 37 & 10 & 49 & -- \\
\hline
\end{tabular}

\section{EXTRACTION STUDIES}

\subsection{Emulsion Stabilization in Dissolver Product Solutions}

The dissolver product solutions from the dissolution rate studies were stored at room temperature in glass bottles for one to two months until the extraction studies were made. The emulsion characteristics of these solutions determined with a dispersion-coalescence tester $(7)$ are shown in Table C-VIII. Coalescence times of less than 180 seconds are considered adequate for plant operation, and none of these solutions would cause undesirable emulsions. In scoping experiments, solutions which formed undesirable stable emulsions during the dissolution did not form stable emulsions when the dissolution was entirely complete. In order to produce solutions which would reproducibly form highly stable emulsions for the extraction studies, the dissolutions were stopped before they were complete, by immersing the reaction vessel in an ice bath. 
TABLE C-VIII

COALESCENCE TIME FOR DISSOLVER SOLUTIONS

STORED ONE TO TWO MONTHS AT ROOM TEMPERATURE

Silicon in Alloy (wt\%)

$\frac{\text { Coalescence Time (seconds) }}{32 \text { wt\% U Alloy }}$

0

$$
90
$$

140

0.6

150

125

1.3

125

120

3.0

$145[a]$

140

4.5

$140[\mathrm{a}]$

130

10.5

[a]

A very slight web containing fine silicon particles persisted.

\subsection{Acidity of Dissolver Solution and Surfactancy}

A number of different dissolver solutions were produced from the alloy containing $32 \mathrm{wt} \%$ uranium and $3 \mathrm{wt} \%$ silicon. The dissolutions were terminated when the alloy was about $80 \%$ dissolved, and aluminum concentrations were between 1.1 and $1.5 \mathrm{M}$. However, solutions with a wide range of acidity were produced by variations in original acid concentration, surface area, and other factors. The solution concentrations and the coalescence behavior are presented in Table C-IX for solutions with final acidities from $0.15 \mathrm{M}$ acid deficient to $2.6 \mathrm{M}$ acid. An acidity of $2.6 \mathrm{M}$ is sufficient to prevent stabilization of the emulsion, but this acidity is too high for efficient solvent extraction of uranium according to existing flowsheets. Solutions with acidities from $0.15 \mathrm{M}$ acid deficient to $1.4 \mathrm{M}$ acid stabilized emulsions, and those in the range of $0.24 \mathrm{M}$ to $0.7 \mathrm{M}$ acid produced the most stable emulsion. A range of 0.2 to $0.8 \mathrm{M}$ hydrogen ion was used for extraction studies to minimize the effect of acidity.

\subsection{Nature of Silicon Species Causing Stable Emulsion}

Dissolver solutions for extraction studies, produced by incomplete dissolution of six alloy specimens, were separated into three fractions according to the size of the suspended particles, and each fraction was tested for coalescence behavior and analyzed for total silicon by emission spectroscopy. The entire separation, examination, and analysis of supernate was completed within six hours after discontinuing the dissolution in order to minimize changes in the nature of the dissolver silicon. The results of this study are shown in Table C-X.

The centrifugation did not remove the dissolved silicon or the emulsion stabilizer from the supernate showing that the emulsion 
TABLE C-IX

EFFECT OF ACIDITY ON EMULSION STABILIZATION

\begin{tabular}{|c|c|c|c|}
\hline $\begin{array}{l}\mathrm{H}^{+} \\
(\underline{\mathrm{M}})\end{array}$ & $\begin{array}{l}\mathrm{AI} \\
(\mathrm{M})\end{array}$ & $\begin{array}{c}U \\
(g / 1)\end{array}$ & $\frac{\mathrm{Si}}{(\mu \mathrm{g} / \mathrm{ml})}$ \\
\hline$-0.15^{[b]}$ & 1.4 & 15.5 & 525 \\
\hline 0.24 & 1.4 & -- & -- \\
\hline 0.4 & 1.2 & -- & -- \\
\hline 0.7 & 1.1 & 4.2 & 1550 \\
\hline 1.4 & 1.5 & -- & -- \\
\hline 2.6 & 1.3 & -- & -- \\
\hline
\end{tabular}

Coalescence Time and Behavior in Extraction

Stable Web

Stable Emulsion

Stable Emulsion

Stable Emulsion

Stable Web

$160 \mathrm{sec}$

[a] Solutions produced by incomplete dissolutions of alloy with 32 wt uranium-3\% silicon-65\% aluminum.

$[\mathrm{b}]$

$0.15 \mathrm{M}$ acid deficient.

TABLE C-X

EFFECT OF CENTRIFUGATION ON EMULSION STABILIZATION AND SILICON CONTENT IN SOLUTIONS OF DISSOLVED ALLOY

\begin{tabular}{|c|c|c|c|}
\hline $\begin{array}{c}\text { Alloy } \\
\text { Composition } \\
\text { Uranium-Silicon } \\
\text { (wt } \%)\end{array}$ & $\begin{array}{l}\text { Maximum } \\
\text { Particle } \\
\text { Diameter } \\
(\mathrm{m} \mu) \\
\end{array}$ & $\begin{array}{c}\text { Total } \\
\text { Silicon } \\
\text { Determined } \\
(\mu \mathrm{g} / \mathrm{ml}) \\
\end{array}$ & $\begin{array}{l}\text { Coalescence Time } \\
\text { and Behavior in } \\
\text { Extraction } \\
\end{array}$ \\
\hline $32-0$ & $\begin{array}{r}2000 \\
250 \\
35\end{array}$ & $\begin{array}{l}10 \\
-- \\
--\end{array}$ & $\begin{array}{l}95 \mathrm{Sec} \\
90 \mathrm{Sec} \\
85 \mathrm{Sec}\end{array}$ \\
\hline $0-4.5$ & $\begin{array}{r}2000 \\
250 \\
35\end{array}$ & $\begin{array}{l}50 \\
14 \\
11\end{array}$ & $\begin{array}{r}110 \mathrm{Sec} \\
80 \mathrm{Sec} \\
125 \mathrm{Sec}\end{array}$ \\
\hline $32-0.6$ & $\begin{array}{r}2000 \\
250 \\
35\end{array}$ & $\begin{array}{l}275 \\
290 \\
240\end{array}$ & $\begin{array}{l}\text { Light Web } \\
\text { Stable Web } \\
\text { Stable Web }\end{array}$ \\
\hline $22-3$ & $\begin{array}{r}2000 \\
250 \\
35\end{array}$ & $\begin{array}{l}1100 \\
1200 \\
1350\end{array}$ & $\begin{array}{l}\text { Light Web } \\
\text { Stable Web } \\
\text { Stable Web }\end{array}$ \\
\hline $32-3$ & $\begin{array}{r}2000 \\
250 \\
35\end{array}$ & $\begin{array}{l}1550 \\
1550 \\
1850\end{array}$ & $\begin{array}{l}\text { Stable Emulsion } \\
\text { Stable Emulsion } \\
\text { Stable Emulsion }\end{array}$ \\
\hline $32-4 \cdot 5$ & $\begin{array}{r}2000 \\
250 \\
35\end{array}$ & $\begin{array}{l}2050 \\
1700 \\
2150\end{array}$ & $\begin{array}{l}\text { Stable Web } \\
\text { Stable Emulsion } \\
\text { Stable Emulsion }\end{array}$ \\
\hline
\end{tabular}


stabilizer was $<35 \mathrm{~m} \mu$ in size. Turbidity measurements further indicated that the concentration of particles <35 mu was very small. The data for supernates with maximum particle size of approximately $250 \mathrm{~m} \mu$ were selected for comparison in the text because most of the solids were removed from these solutions, according to turbidity measurements. The emulsions tended to be more stable after the removal of the solids between $2000 \mathrm{~m} \mu$ and $250 \mathrm{~m} \mu$ in size. Four hours of high speed centrifugation were required to remove particles down to $35 \mathrm{~m} \mu$, and the solution temperature increased to $60-70^{\circ} \mathrm{C}$. This may be responsible for the increase in total silicon content.

When silicon is first dissolved in the acid solution, it is present as the mono-silicic acid. The content of mono- and di-silicic acid was determined immediately after measuring the coalescence characteristics for a number of solutions selected to represent different levels of emulsion stabilization. The silicon was determined by a silicomolybdate procedure using controlled color-development time so that all of the mono- and most of the di-silicic acid were determined while essentially none of the polysilicic acid was determined. The data given in Table C-XI show that these species are not responsible for emulsion stabilization.

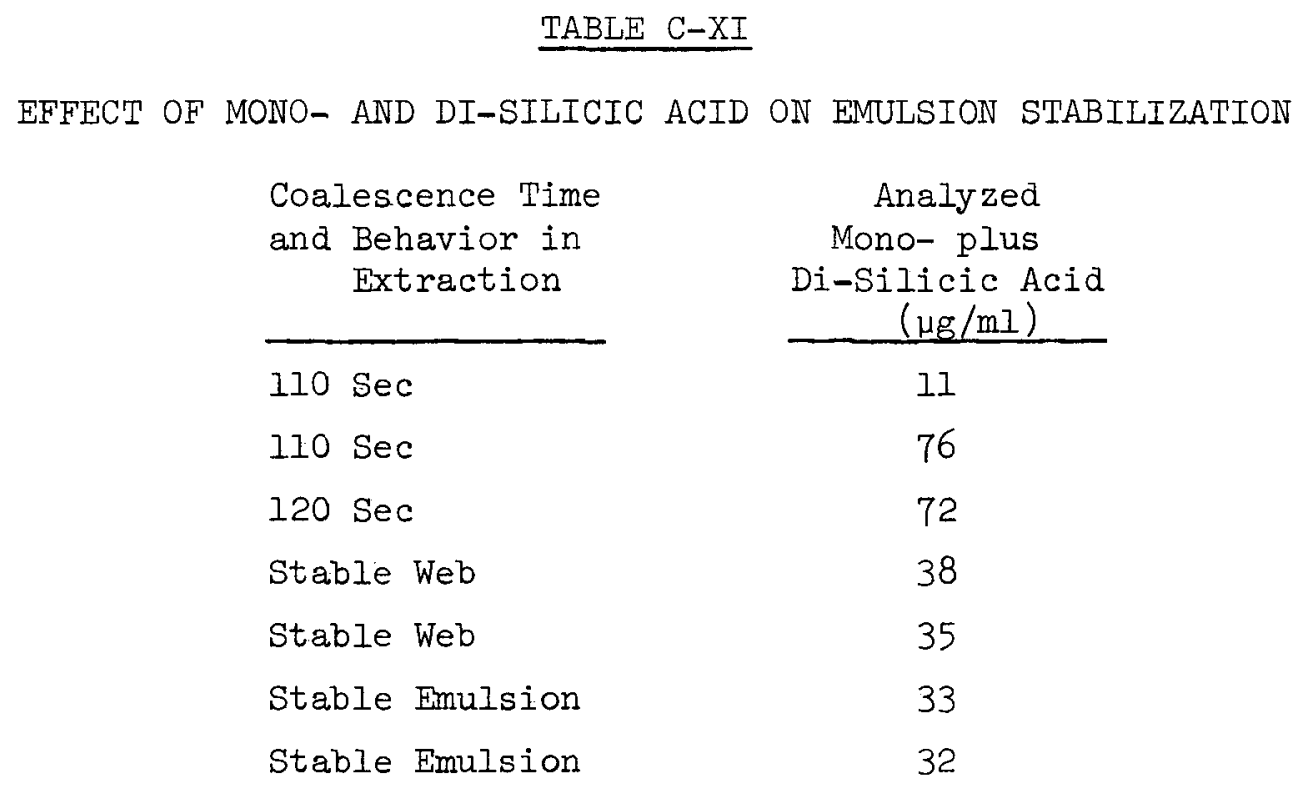

\section{RESIDUES}

\subsection{Separation of Solids According to Particle Size}

The dissolver solutions produced by partial dissolution of the alloys were separated into fractions by removing particles of different size using centrifugation. The estimated particle size used in this report assumes a particle density of $2 \mathrm{~g} / \mathrm{cm}^{3}$ as a median value for the mixture of particles suspended in the solutions; the density of elemental 
silicon is $2.4 \mathrm{~g} / \mathrm{cm}^{3}$, the density of $\mathrm{UAl}_{3}$ is $6.8 \mathrm{~g} / \mathrm{cm}^{3}$, and the density of crystalline silicon dioxide is $2.2 \mathrm{~g} / \mathrm{cm}^{3}$. The density of the hydrated silica which tends to coat the particles will be somewhat lower. Depending upon the actual density of the particles, the separation performed to remove particles down to $2000 \mathrm{~m} \mu$ in size may remove particles down to $800 \mathrm{m \mu}$; separations performed to remove particles down to $250 \mathrm{m \mu}$ may remove particles down to $95 \mathrm{m \mu}$; separations performed to remove particles down to $35 \mathrm{~m} \mu$ may include particles down to $18 \mathrm{~m} \mu$.

The separations were made by slurrying the dissolver solution, allowing it to settle 1 minute to remove large pieces of undissolved alloy, and removing three portions for centrifugation. Particles greater than $2000 \mathrm{~m} \mu$ were removed by centrifugation for 20 minutes at 100 times the force of gravity in a clinical centrifuge. Particles greater than $250 \mathrm{~m} \mu$ were removed by centrifugation for 13 minutes at 10,000 times the force of gravity in a high speed centrifuge. Particles greater than $35 \mathrm{~m} \mu$ were removed by centrifugation for four hours at 30,000 times the force of gravity in a high speed centrifuge. All separations were made immediately after termination of the dissolution. Solutions, which were cooled to room temperature to minimize additional dissolution of the solids, had densities from 1.20 to $1.22 \mathrm{~g} / \mathrm{cm}^{3}$.

\subsection{Examination of Suspended Solids by Light Scattering Photometery}

The purpose of the light scattering measurements was to determine relative quantities and size of suspended solids in the dissolver solutions after separations by centrifugation and to aid in determining the nature of the silicon stabilizing the emulsions. Light scattering measurements were made with a Brice-Phoenix Universal Light Scattering Photometer, Model 2000, using a semi-octagonal dissymmetry cell. A wave length of $546 \mathrm{~m} \mu$ was used as incident light to avoid absorption and fluorescence of the aluminum nitrate-uranium nitrate-nitric acid solutions. The turbidities of the solutions were determined from the ratio of the light scattered from the solution at $90^{\circ}$ to the transmitted light measured with a working standard and neutral filters. Considerably more light was scattered forward than backward from the solutions. The ratio of the scattering intensities at $45^{\circ}$ and $135^{\circ}$ was determined as the dissymmetry of the light scattering. The values obtained for turbidity and dissymmetry are given in Table C-XII for solutions from dissolutions which were $80 \%$ complete and were separated according to particle size by centrifugation.

Extremely high dissymmetries, which were obtained on all solutions, were probably caused primarily by the non-homogeneity of the particles suspended in the solutions. Dust and other contaminants can cause dissymmetry of light scattering, but neither improvement in technique nor dilution of the solutions with clarified diluent decreased the extremely high dissymmetries indicating that they were due to the suspended particles themselves.

According to turbidity data, alloys with silicon-to-uranium ratios $>1$ have the largest amount of suspended particles in the range of $250 \mathrm{m \mu}$ to $2000 \mathrm{~m} \mu$ in size. These solutions have siightly lower dissymmetries 


\section{TABLE C-XII}

LIGHT SCATTERING DATA FOR SUSPENDED SOLIDS

\begin{tabular}{|c|c|c|}
\hline $\begin{array}{c}\text { Alloy } \\
\text { Composition } \\
\text { Uranium-Silicon } \\
(w t \%) \\
\end{array}$ & $\begin{array}{l}\text { Atom } \\
\text { Ratio } \\
\text { (Si/U) } \\
\end{array}$ & $\begin{array}{l}\text { Maximum } \\
\text { Particle } \\
\text { Diameter } \\
(\mathrm{m} \mu) \\
\end{array}$ \\
\hline $32-0$ & No Si & $\begin{array}{r}2000 \\
250 \\
35\end{array}$ \\
\hline $32-0.6$ & 0.2 & $\begin{array}{r}2000 \\
250 \\
35\end{array}$ \\
\hline $32-3$ & 0.8 & $\begin{array}{r}2000 \\
250 \\
35\end{array}$ \\
\hline $22-3$ & 1.2 & $\begin{array}{r}2000 \\
250 \\
35\end{array}$ \\
\hline $32-4.5$ & $1: 2$ & $\begin{array}{r}2000 \\
250 \\
35\end{array}$ \\
\hline $0-4.5$ & No U & $\begin{array}{r}2000 \\
250 \\
35\end{array}$ \\
\hline
\end{tabular}

\begin{tabular}{l}
$\begin{array}{c}\text { Turbidity } \\
\text { of Suspension } \\
\left(\mathrm{cm}^{-1}\right)\end{array}$ \\
\hline 0.0053 \\
0.0012 \\
0.0012 \\
0.021 \\
0.0033 \\
0.0012 \\
0.034 \\
0.0034 \\
0.0016 \\
5.9 \\
0.021 \\
0.0031 \\
5.8 \\
0.033 \\
0.0026 \\
0.54 \\
0.0083 \\
0.0005
\end{tabular}

Dissymmetry of Suspension $\left(135^{\circ} / 45^{\circ}\right)$

$$
\begin{aligned}
& 3.7 \\
& 3.7 \\
& 3.6 \\
& 5.3 \\
& 3.9 \\
& 3.8 \\
& 4.3 \\
& 2.8 \\
& 1.4 \\
& 1.7 \\
& 2.6 \\
& 2.6 \\
& 1.8 \\
& 3.1 \\
& 2.1 \\
& 2.4 \\
& 2.4 \\
& 3.5
\end{aligned}
$$


because the particles measured are mostly elemental silicon and are more homogeneous. X-ray diffraction of the precipitates confirmed that the particles of this size range were primarily elemental silicon. The quantity of this silicon is small since, as shown in Table $C-X$, the total silicon analysis did not change when centrifugation removed these solids from the solution.

X-ray diffraction of the particles centrifuged from solution showed the particles between 35 and $250 \mathrm{~m} \mu$ were largely uranium intermetallic particles. The turbidity of the solution with maximum particle size of $250 \mathrm{~m} \mu$ decreased to background in two weeks showing that the undissolved alloy particles slowly dissolved at room temperature.

In order to determine the molecular weight and, thereby, the particle size of the suspended particles, the turbidity must be measured at several concentrations of suspended particles in the same matrix. Synthetic solutions used as diluent were prepared with the same concentration of aluminum, uranium, and acid, and the same density and refractive index as the dissolver solutions. The weight-average diameters calculated from these turbidity measurements ranged from 18 to $35 \mathrm{~m} \mu$ for particles suspended in solutions which were centrifuged to remove particles greater than $35 \mathrm{~m} \mu$. These diameters were calculated using the density and refractive index for elemental silicon. This method of particle size determination is not accurate for these suspended particles because the high dissymmetry values and $X$-ray diffraction analyses of particles indicate that the particles are not homogeneous and are not entirely silicon.

The technique of light scattering has had very little process application. Although considerable care must be taken to exclude dust and other extraneous matter from the solutions and diluents, the use of this technique for examination of suspended particles in mixed salt solutions does appear feasible. In the current work, the technique was limited because several kinds of particles were present. In addition, the refractive indexes of some solids are difficult to obtain but are required for the calculation of the molecular weight. In this work, the turbidity data showed that the emulsion stabilization was not due to the main bulk of suspended solids and that the quantity of suspended solids with less than $2000 \mathrm{m \mu}$ diameter was small. Turbidity measurements were used to show that the small undissolved alloy particles would dissolve in two weeks at room temperature. Dissymmetry measurements showed that the particles were mixtures having a range of refractive indexes and different particle diameters. 